\title{
Hippocampal plasticity and corticosterone : from dendrites to behavior
}

Citation for published version (APA):

Martínez-Claros, M. (2013). Hippocampal plasticity and corticosterone : from dendrites to behavior.

[Doctoral Thesis, Maastricht University]. Maastricht University. https://doi.org/10.26481/dis.20130516mm

Document status and date:

Published: 01/01/2013

DOI:

10.26481/dis.20130516mm

Document Version:

Publisher's PDF, also known as Version of record

\section{Please check the document version of this publication:}

- A submitted manuscript is the version of the article upon submission and before peer-review. There can be important differences between the submitted version and the official published version of record.

People interested in the research are advised to contact the author for the final version of the publication, or visit the DOI to the publisher's website.

- The final author version and the galley proof are versions of the publication after peer review.

- The final published version features the final layout of the paper including the volume, issue and page numbers.

Link to publication

\footnotetext{
General rights rights.

- You may freely distribute the URL identifying the publication in the public portal. please follow below link for the End User Agreement:

www.umlib.nl/taverne-license

Take down policy

If you believe that this document breaches copyright please contact us at:

repository@maastrichtuniversity.nl

providing details and we will investigate your claim.
}

Copyright and moral rights for the publications made accessible in the public portal are retained by the authors and/or other copyright owners and it is a condition of accessing publications that users recognise and abide by the legal requirements associated with these

- Users may download and print one copy of any publication from the public portal for the purpose of private study or research.

- You may not further distribute the material or use it for any profit-making activity or commercial gain

If the publication is distributed under the terms of Article $25 \mathrm{fa}$ of the Dutch Copyright Act, indicated by the "Taverne" license above, 
Hippocampal plasticity and corticosterone:

From dendrites to behavior

Marisela Martínez-Claros 



\title{
Hippocampal plasticity and corticosterone: From dendrites to behavior
}

\author{
DISSERTATION \\ To obtain the degree of Doctor at \\ Maastricht University, \\ on the authority of the Rector Magnificus, \\ Prof. dr. L.L.G. Soete \\ in accordance with the decision of the Board of Deans, \\ to be defended in public \\ on Thursday $16^{\text {th }}$ of May 2013 at $16: 00$
}

by

Marisela Martínez-Claros

Born the $6^{\text {th }}$ of March of 1978 in Mexico City 


\section{Promotor:}

Prof. Dr. H.W.M. Steinbusch

\section{Co-promotors:}

Dr. J.L. Pawluski

Dr. J. Prickaerts

\section{Assessment Committee:}

Prof. Dr. Y. Temel (Chairman)

Dr. T. Charlier (Ohio University)

Prof. Dr. D. A. Hopkins

Prof. Dr. T. Kozicz (Radboud University Nijmegen)

Dr. T. Strekalova 
A mis padres,

To my husband, 



\section{Contents}

List of abbreviations

Page 8

Chapter 1. General Introduction

Page 9

Chapter 2. Effect of water maze training and

Page 29

swimming on neurogenesis and

synaptogenesis in the hippocampus

Chapter 3. Adrenalectomy and corticosterone replacement differentially alter CA3

Page 51 dendritic morphology and new cell survival in the adult rat hippocampus

Chapter 4. Adrenalectomy, regardless of

Page 75 corticosterone replacement, affects memory and hippocampal morphology

Chapter 5. When are new hippocampal neurons Page 97 born, in the adult brain, integrated into the network that process spatial information?

Chapter 6. Summary and general conclusions

Page 129

Co-authors and affiliations

Page 135

Curriculum Vitae

Page 137

List of Publications

Page 138

Acknowledgments

Page 141 


\section{List of abbreviations}

\begin{tabular}{|c|c|}
\hline ADX & Adrenalectomy \\
\hline Arc & Activity related cytoskeleton associated protein \\
\hline AVP & Arginine vasopressin \\
\hline BrdU & Bromodeoxiuridine \\
\hline $\mathrm{CA}$ & Cornu ammonis \\
\hline $\mathrm{CC}$ & Cage control \\
\hline Cort/CORT & Corticosterone \\
\hline $\mathrm{CRH}$ & Corticotropin releasing hormone \\
\hline DCX & Doublecortin \\
\hline DG & Dentate gyrus \\
\hline EC & Entorhinal cortex \\
\hline GABA & gamma-aminobutyric acid \\
\hline GCL & Granular cell layer \\
\hline GR & Glucocorticoid receptor \\
\hline HPA & Hypothalamic pituitary adrenal \\
\hline IEG & Immediate early gene \\
\hline LTP & Long term potentiation \\
\hline MR & Mineralocorticoid receptor \\
\hline MWM & Morris water maze \\
\hline NeuN & Neuronal nuclear antigen \\
\hline PBI & Post BrdU injection \\
\hline SE & Spatial exploration \\
\hline SGZ & Subgranular zone \\
\hline SL & Stratum Iucidum \\
\hline SO & Stratum oriens \\
\hline SP & Stratum pyramidale \\
\hline
\end{tabular}




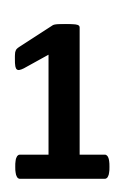

\section{General \\ Introduction}

Martínez-Claros M 
Memory is a complex cognitive process and essential for developing survival strategies. It involves many different aspects with regards to learning and information storage such as the encoding, consolidation and retrieval of memories. In addition, there are different kinds of memory such as implicit and explicit or semantic and episodic. These different types of memory are associated with different neuronal structures and pathways. For example, explicit memory has been shown to be impaired after bilateral denervation of the input to the hippocampus, entorhinal, perirhinal and parahippocampal cortices, while implicit memory seems to remain intact under those conditions [1,2].

One very important modality of memory is spatial memory. Spatial memory refers to the ability to remember specific locations and places using spatial cues to obtain a spatial map. It relies in part on the integrity of the hippocampus, which is an important brain structure for the encoding, consolidation, and retrieval of memories $[3,4]$. Spatial memory is phylogenetically old and is preserved in several species. Over the ages, the hippocampus has increased in size in the groups of animals that rely on spatial abilities like birds and mammals [5]. Its evolution seems to be linked to the appearance of a home range so animals can navigate through a territory, locate food and find shelter [6]. Recent developments have begun to increase our understanding of the neural mechanisms underlying the formation of spatial memories.

Case studies on hippocampal damage show how crucial the hippocampus is for consolidation as well as retrieval of information in humans. V.C. was a patient whose complete hippocampus was removed and had retrograde amnesia for her entire lifespan. This case suggested that total hippocampal removal leads to retrograde amnesia (loss of old memories) and anterograde amnesia (inability to form new memories) for explicit information for the entire life span $[7,8,9,10]$. Other patients with similar loss of the hippocampus, including patients R.B. and G.D., seemed to have retrograde amnesia for just 1-2 years [9]. Another case (patient H.M.) has been extensively studied for his severe anterograde amnesia, which started after a bilateral medial temporal lobe resection to help with 
the patient's intractable seizures. Brain tissue removed was approximately $8 \mathrm{~cm}$ from the anterior poles, which seemed to have bilaterally destroyed the anterior two-thirds of the hippocampus and the hippocampal gyrus, the amygdala and periamygdaloid cortex $[10,11]$.

\section{The Hippocampus and Memory}

The hippocampus is a neural area, which is important in the encoding, consolidation and retrieval of memories $[3,4]$. The hippocampal formation plays a crucial role in the formation of memories, this structure is very plastic and it has often been implicated in declarative and episodic memory and in spatial learning [3]. Early anatomists named the hippocampus for its resemblance to a sea horse (in Greek 'hippos' means horse and 'kampos' means sea monster) [8,12] (Figure 1).

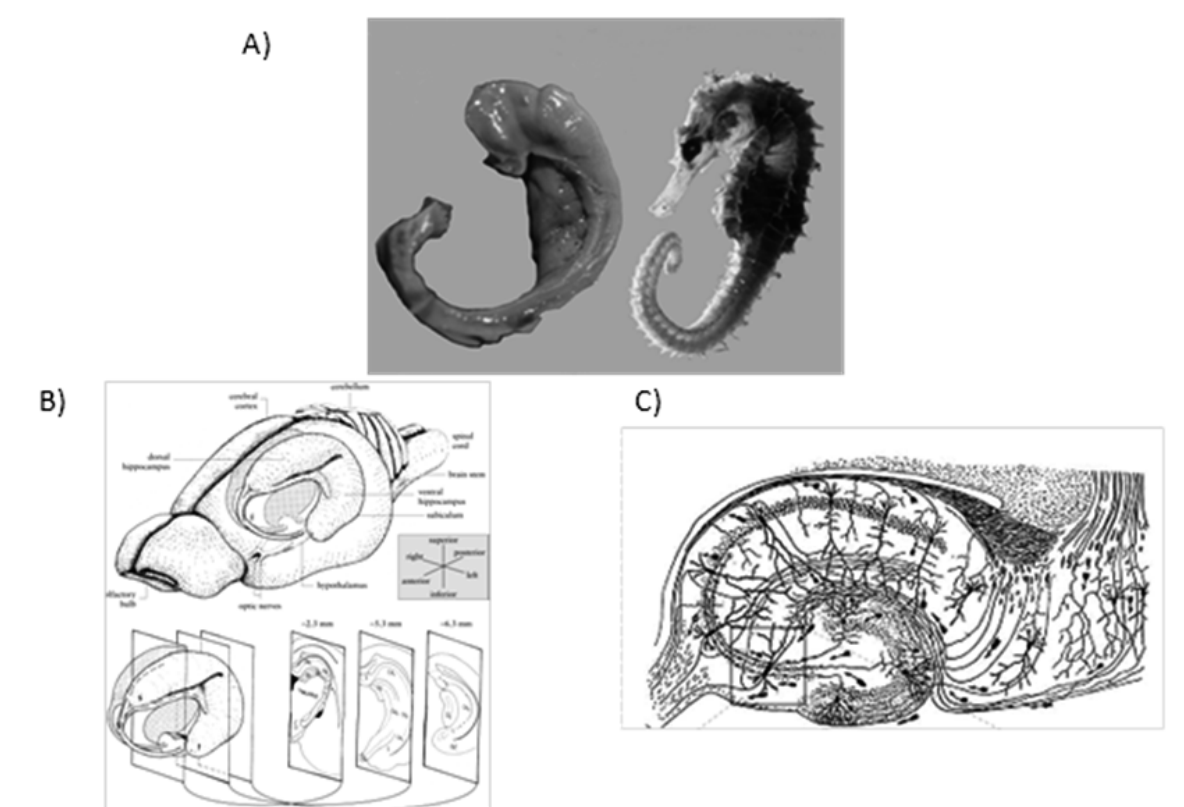

Figure 1. A) Human hippocampus dissected free (left) and compared to a specimen of Hippocampus leria (right). Photo from Professor Laszlo Seress, University of Pécs. Published in Amaral D. and Lavenex P. (2006) 'Hippocampal neuroanatomy' in Anderson C., Morris R., Amaral D., Bliss T., O'Keefe, J. (eds.) The hippocampus book. Oxford: Oxford University Press, pp.4-33. B) Diagram of the rat hippocampus. Drawings showing the three-dimensional organization of the hippocampus and related structures. Three coronal sections through the left hippocampus are shown at the bottom right of the figure, with their approximate anteroposterior coordinate relative to bregma. CA1, CA2, CA3: cornu ammonis fields 
1-3; DG: dentate gyrus; EC: entorhinal cortex; f: fornix; s: septal pole of the hippocampus; S: subiculum; t: temporal pole of the hippocampus. Figure number 3 from Cheung et al. [13] C) Classical drawing of the hippocampal formation by Santiago Ramón y Cajal Histologie du Systeme Nerveux de l'Homme et des Vertebretes, Vols. 1 and 2. A. Maloine. Paris. 1911. Adapted from [14].

The hippocampus lays in the medial temporal lobes, surrounded by the entorhinal, parahippoampal and perirhinal cortices. It is part of the limbic system and it is connected to several subcortical and cortical structures, such as the anterior thalamic nuclei, the mammillary bodies, the septal nuclei of the basal forebrain, the retrosplenial cortex and the parahippocampal cortex. It has two main pathways, the perforant pathway, which connects it to the posterior neocortex, and the fimbria-fornix, which connects it to the thalamus, hypothalamus, basal ganglia and frontal cortex. Most of the hippocampus's neocortical inputs come from the perirhinal and parahippocampal cortices, through the entorhinal cortex, and most of its neocortical output is through the subiculum, which also projects back to the entorhinal cortex [2].

The hippocampal formation, often referred to as the hippocampus, has the form of a curve that extends from the lateral neocortex of the medial temporal lobe to the midline of the brain. It is a folded structure with two gyri, i.e.,the Ammon's horn (CA) and the dentate gyrus (DG) [15]. Both gyri have different cell-types, i.e., the CA consists of pyramidal cells and the DG consists of granule cells and is one of two areas in the brain where there is a high level of neurogenesis (birth of new neurons) throughout adulthood (see Figure 2) $[15,16,17,18]$. The dentate gyrus receives the information from a large number of brain regions such as the septum and the entorhinal cortex and projects it to Ammon's horn [18,19]. Ammon's horn is divided in four regions (CA1, CA2, CA3 and CA4, see Figure 3). The most important regions of Ammon's horn implicated in memory are the CA1 and CA3 region. 

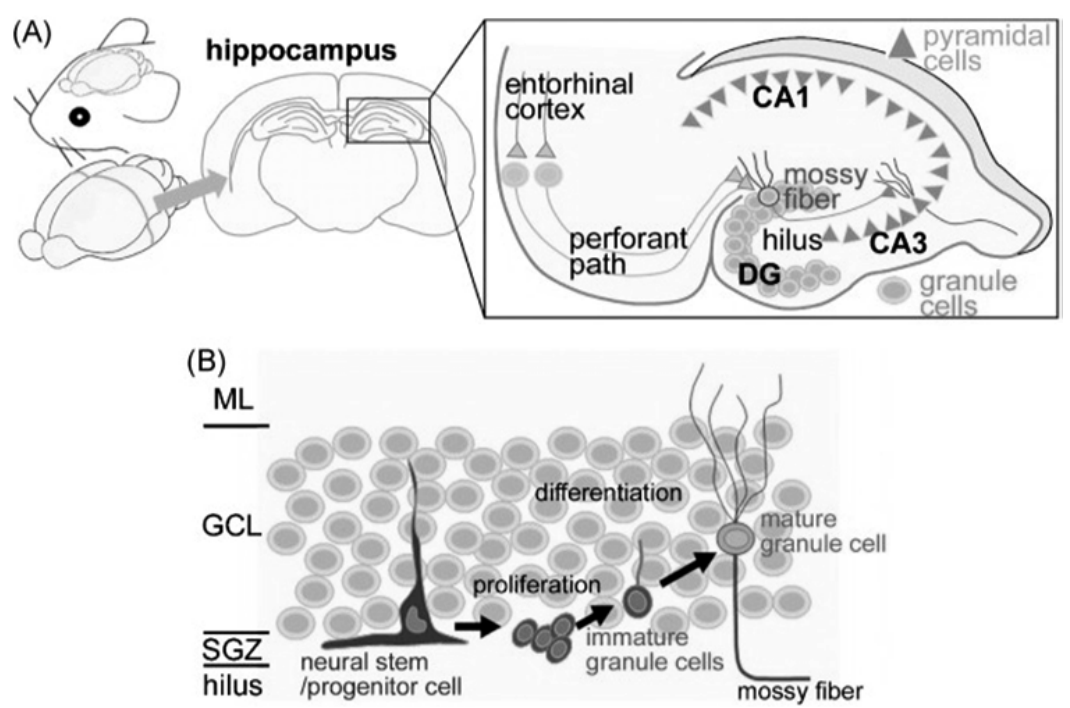

Figure 2. A) The structure and neuronal circuitry of the DG in the hippocampus of the adult rodent brain. The input to the hippocampus is mainly provided by the entorhinal cortex through the perforant path to the granule cells in the molecular layer in the DG. Each granule cell projects an axon (mossy fiber, red line) to the CA3 region, where it synapses onto pyramidal cells. B) Neurogenesis in the DG. Neural stem/progenitor cells reside in the SGZ, proliferate, and generate transiently amplifying progenitors that produce immature granule cells. These immature cells migrate into the $\mathrm{GCL}$, where they differentiate into mature granule cells that project to the CA3 (mossy fibers). It takes approximately 3 weeks to go from a proliferating cell to a mature granule neuron in the adult hippocampus. DG, dentate gyrus; GCL, granule cell layer; SGZ, subgranular zone; ML, molecular layer. Adapted from [92].

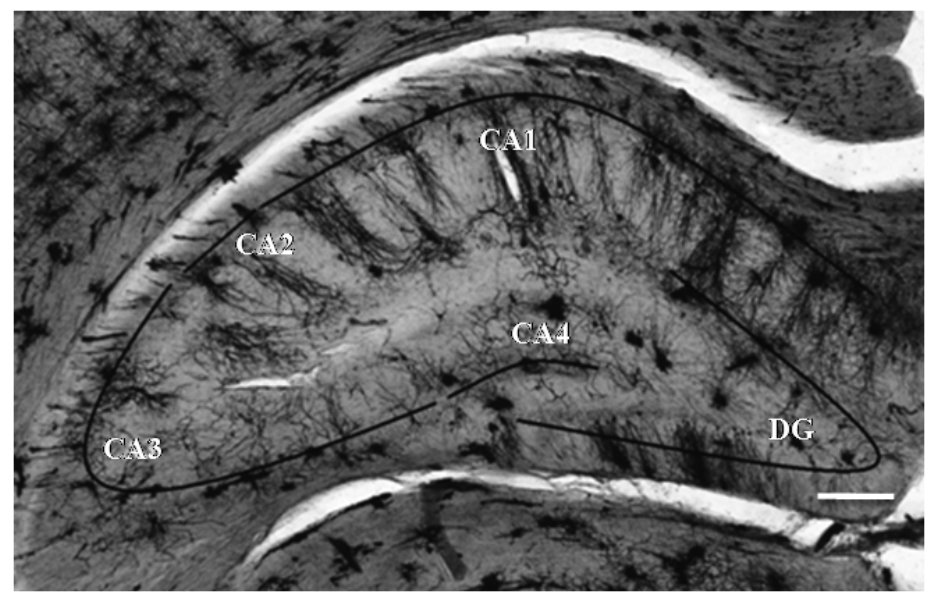

Figure 3. Photomicrograph of Golgi impregnated cells in the hippocampus where the Cornu Ammonis (CA) and the dentate gyrus (DG) are clearly visible. Scale bar represents $400 \mu \mathrm{m}$. Photomicrograph from work in Chapter 3 of this thesis 


\section{Spatial Memory}

The term spatial memory refers to the type of memory needed to acquire a spatial map and remember the locations using cues such as a building [21]. The first indication of spatial memory formation in the hippocampus was by O'Keefe and Dostrovsky [22] who discovered the so called 'place cells' in the hippocampus of rats that seemed to encode a spatial location. These cells produced action potentials when the rat was in a specific location or was moving towards that location. Further work has determined that spatial learning and memory is dependent on functioning of the hippocampus $[3,4,23,24]$.

One of the most widely used animal models of spatial learning and memory is the Morris Water Maze [24]. This task consists of a circular pool of water with an invisible platform and even though the animals are not able to smell or see the platform, they easily learn its location in the circular pool using spatial cues $[24,25]$.

Morris $[24,26]$ demonstrated that animals with lesions of the hippocampus and its extrinsic fiber connections show deficits in spatial learning and memory. Moser and Moser have gone on to demonstrate that in particular the dorsal region of the hippocampus is essential for spatial learning. Retrieval of spatial information involves a widespread network in the hippocampus, i.e.,in the dorsal $70 \%[23]$.

Memory Formation and Hippocampal Plasticity

It has been suggested that memory formation involves neural plasticity which modifies the communication between neurons $[4,27]$. As mentioned earlier, the hippocampus is one of the two structures in the brain where neurogenesis occurs at a high rate during adulthood, and thus neuronal plasticity is thought to have a function in the formation of memories $[3,27,28,29]$. Plastic changes that appear to underlie memory formation include structural changes in the neuron and the distribution and amount of synapses $[27,30]$. It has been found that long term potentiation (LTP), which is assumed to be the underlying physiological substrate of memory, 
produces mossy fiber synaptogenesis and, therefore, new connections between neurons [31,32,33].

During LTP, connections between neurons are strengthened by co-activation. Consequently, in memory traces, these assemblies of co-activated neurons can be activated by stimulation of one of the neurons in the assembly, leading to activation of the entire network [20]. Thus, when neurons are co-activated, synaptogenesis can occur, strengthening those connections, which are more often used. More specifically, spatial learning involves synaptogenesis of the mossy fiber tracks to the stratum oriens of the hippocampus $[27,30]$.

In addition, learning itself has been demonstrated to enhance the level of neurogenesis in the hippocampus $[29,34,35,36,37,38,39,40,41]$. Of particular interest is the possibility that the new synapses found in CA3 region may arise from new granular neurons in the dentate gyrus [27]. This is an interesting possibility as hippocampus-dependent behavior, such as spatial learning in the Morris water maze task, can modify both the rate of new neuronal generation [35] and the survival of new neurons $[42,43,44,45]$. Furthermore, it has been shown that when new neurons mature, their dendrites reach the outer molecular layer [46] and their axons reach the CA3 pyramidal dendrites $[47,48]$. These new neurons are functionally integrated into the hippocampal network $[49,50,51]$ in such a way that they can respond to spatial exploration $[50,51,52,53,54,55]$.

\section{The Hippocampus and Stress}

The hippocampus is a vulnerable structure known to be sensitive to the levels of glucocorticoids and demonstrating plastic changes in response to stress. It has been shown that glucocorticoids, of which corticosterone is the major stress hormone in rodents, while cortisol is the major stress hormone in humans, play a prominent role in hippocampal plasticity $[3,56,57,58]$, especially on dendritic plasticity of the pyramidal neurons in the CA3 region [57,59]. Not surprisingly, various forms of memory that rely on the functioning of the hippocampus are also affected by environmental factors such as stress and associated stress hormones [3,60,61]. For example, 
research has demonstrated that high cortisol/corticosterone levels can cause impairments in episodic and spatial memory in both humans and rodents [62].

\section{Stress}

Stress can be defined as "a threat, real or implied, to the psychological or physiological integrity of an individual" $[63,64]$. The two major hormones involved in the stress response are glucocorticoids and catecholamines. These hormones are protective in the short run, but in chronic stress they can induce damaging effects and can accelerate disease development [64].

A stress response occurs in the presence of threatening stimuli and is characterized by activation of the autonomic nervous system, resulting in the release of catecholamines in the blood stream, increased arousal and avoidance (fear) behavior. In addition, a stressor activates the hypothalamic-pituitaty-adrenal (HPA) axis, which induces the release of glucocorticoids in the blood stream which further helps the organism to cope with the stressor $[63,65,66]$. McEwen [63] proposed the term "allostatic load" to describe the process of adaptation to stress. This process refers to the effects on the body that the exposure of chronic, repetitive stress and/or an inefficient coping with it.

In response to stress the paraventricular nucleus in the hypothalamus releases corticotropin-releasing hormone $(\mathrm{CRH})$ and arginine vasopressine (AVP) into the blood of the portal circulation, which causes the anterior pituitary gland to release adrenocorticotropic hormone (ACTH). The adrenal cortex then responds by producing cortisol/corticosterone $[67,68]$. There are two kinds of corticosteroid receptors in the hippocampus: the mineralocorticoid receptor (MR) and the glucocorticoid receptor (GR). The MR-mediated effect increases cellular responsiveness to excitatory stimuli, controls the sensitivity of the stress response system and affects behavioral strategies. The GR activation suppresses excitability raised by excitatory stimuli, controls feedback action and promotes information storage (Figure 4) [63,65,69]. 


\section{Effects of Stress on the Hippocampus}

Acute and chronic stress, which are associated with marked changes in glucocorticoid levels, have been demonstrated to affect hippocampal plasticity. For example, several weeks of chronic stress causes atrophy in the apical dendrites of the pyramidal neurons in the CA3 region of Ammon's horn [71,72,73,74,75], as well impaired adult neurogenesis in the dentate gyrus in adult males $[3,41,76,77,78,79,80,81]$. All this can cause an overall reduction in the size of the hippocampus $[82,83]$. Even though the primary site of the stress-induced atrophy is the CA3 region, the damage might be mediated through the excitatory innervation from the dentate gyrus. The granule cells of the dentate gyrus are highly dependent on corticosterone and without corticosterone, atrophy and subsequent death of these cells will occur $[84,85]$. Thus, high corticosterone levels could influence the excitatory innervation from the dentate gyrus to the CA3 which could hyperactivate and promote damage to the CA3 pyramidal neurons $[72,74]$.

Besides studies investigating the effects of chronically increased corticosterone levels as mentioned above, corticosterone has also been decreased in various studies using bilateral adrenalectomy (ADX) removing both adrenal glands (which produce corticosterone) and in which it was found that ADX caused a selective degeneration of the granule cell layer (GCL) in the dentate gyrus (DG) $[60,86,87,88]$.

Rats with adrenalectomy showed impairments in their spatial memory, as shown in the Morris Water Maze, suggesting that the influence of corticosterone levels in the hippocampus is essential in this respect [60]. Thus, gluocorticoid levels apparently have an inverted U-shape relationship with respect to hippocampal plasticity and spatial memory performance $[62,89,90,91]$ such that elevating or reducing levels of circulating glucocorticoids impairs learning, likely through changes in hippocampal plasticity. Research has yet to fully determine the effects of corticosterone levels and spatial learning on hippocampal plasticity. 


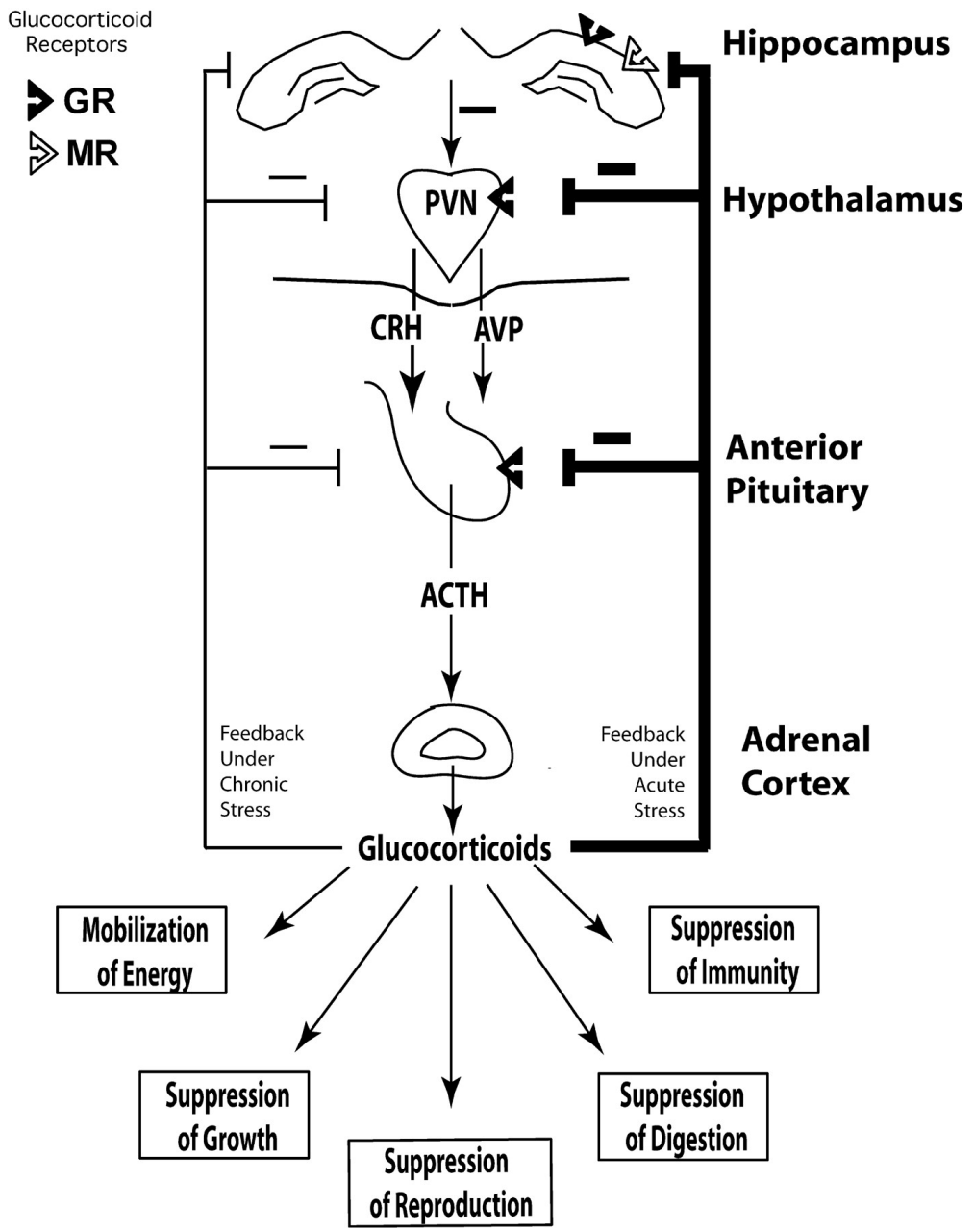

Figure 4. The hippocampus and the hypothalamic-pituitary-adrenal (HPA) axis, effects on body processes, and the glucocorticoid (GC) feedback in the mammalian brain. A stressor causes the hypothalamic paraventricular nucleus (PVN) to release corticotropin releasing hormone (CRH) and vasopressin (AVP), which causes the anterior pituitary to release adrenocorticotrophin (ACTH). ACTH initiates the synthesis and release of glucocorticoids (GCs, corticosterone in some rodents, cortisol in others) from the adrenal cortex. The HPA axis is tightly regulated through feedback (inhibition indicated by -) on glucocorticoid receptors to inhibit further HPA activity. Cortisol feeds back on hypothalamus and pituitary to cause a rapid inhibition of CRF release. Glucocorticoid (GR) and mineralocorticoid receptors (MR) occur in the limbic system (hippocampus and dentate gyrus) and GR occur in the PVN and anterior pituitary. Adapted from [70].

\section{Aims of the Present Thesis}

This thesis aimed to determine the relationship between corticosterone, hippocampal plasticity and learning and memory. The general hypothesis was that there is a complex interplay 
between these factors with moderate corticosterone levels decreasing hippocampal plasticity and further resulting in deficits in spatial learning and memory. This hypothesis was explored in the following chapters.

Chapter $\mathbf{2}$ assessed the role of corticosterone and swim stress on hippocampal dependent learning and determined how different levels of corticosterone during learning may affect memory and related measures of plasticity in the hippocampus, such as neurogenesis and synaptogenesis. Bromodeoxyuridine (BrdU) techniques were used to investigate hippocampal neurogenesis in adult male rats. To assess spatial learning, rats were trained in the Morris water maze task. Plasma corticosterone levels were measured using radioimmunoassay techniques and immunohistochemistry was used to detect newborn neurons in the dentate gyrus, while immunofluorescence techniques were used to look for synaptic plasticity measuring the amount of synaptophysin in the hippocampal CA3 region.

Chapter 3 investigated the effect of different circulating levels of corticosterone on dendritic morphology and adult neurogenesis in the hippocampus. This was done by administering corticosterone via implants to adrenalectomized adult male rats. The dendritic morphology in the CA3 region was analyzed using Golgi impregnation, and the amount of new surviving cells was assessed with BrdU techniques and immunohistochemistry.

Chapter 4 investigated how learning and memory and corticosterone levels may affect dendritic morphology in the CA3 region and neurogenesis in the dentate gyrus of the hippocampus. Similar to Chapter 3, corticosterone was administered via implants to adult adrenalectomized male rats. The dendritic morphology in the CA3 region was analyzed with Golgi impregnation, and the number of new surviving cells was assessed with BrdU techniques and immunohistochemistry. Rats were trained on a modified version of the Barnes Maze, which represents a 'dry 'cue and spatial learning task that avoids stress exposure associated with swimming as in the Morris water maze task. 
Chapter 5 assessed when new adult born neurons in the hippocampus are functionally active and incorporated to encode a specific behavioral task. Here, we studied adult male rats exposed to an exploratory task and used immunohistofluorescence techniques to investigate neurogenesis ( $\mathrm{BrdU}$ and $\mathrm{NeuN}$ ) and co-localization of activity-regulated cytoskeleton-associated protein (ARC) to determine the time when the new born cells are activated.

Finally, in Chapter 6 we provide a summary and conclusions arising from our findings. 


\section{References}

1. Zola-Morgan S, Squire LR (1993) Neuroanatomy of memory. Annu Rev Neurosci 16: 547-563.

2. Bird CM, Burgess N (2008) The hippocampus and memory: insights from spatial processing. Nat Rev Neurosci 9: 182-194.

3. McEwen BS (1999) Stress and hippocampal plasticity. Annu Rev Neurosci 22: 105-122.

4. Leuner B, Gould E, Shors TJ (2006) Is there a link between adult neurogenesis and learning? Hippocampus 16: 216-224.

5. Sherry DF, Jacobs LF, Gaulin SJ (1992) Spatial memory and adaptive specialization of the hippocampus. Trends Neurosci 15: 298-303.

6. Poucet B, Benhamou S (1997) The neuropsychology of spatial cognition in the rat. Crit Rev Neurobiol 11: 101-120.

7. Kopelman MD, Bright P, Buckman J, Fradera A, Yoshimasu H, et al. (2007) Recall and recognition memory in amnesia: patients with hippocampal, medial temporal, temporal lobe or frontal pathology. Neuropsychologia 45: 1232-1246.

8. Kolb B, Teskey GC, Gibb R (2010) Factors influencing cerebral plasticity in the normal and injured brain. Front Hum Neurosci 4: 204.

9. Bright P, Buckman J, Fradera A, Yoshimasu H, Colchester AC, et al. (2006) Retrograde amnesia in patients with hippocampal, medial temporal, temporal lobe, or frontal pathology. Learn Mem 13: 545-557.

10. Scoville WB, Milner B (2000) Loss of recent memory after bilateral hippocampal lesions. 1957. J Neuropsychiatry Clin Neurosci 12: 103-113.

11. Zola-Morgan S, Squire LR, Amaral DG (1986) Human amnesia and the medial temporal region: enduring memory impairment following a bilateral lesion limited to field CA1 of the hippocampus. J Neurosci 6: 2950-2967.

12. Giap BT, Jong CN, Ricker JH, Cullen NK, Zafonte RD (2000) The hippocampus: anatomy, pathophysiology, and regenerative capacity. J Head Trauma Rehabil 15: 875-894.

13. Cheung TH, Cardinal RN (2005) Hippocampal lesions facilitate instrumental learning with delayed reinforcement but induce impulsive choice in rats. BMC Neurosci 6: 36.

14. Nicoll RA, Schmitz D (2005) Synaptic plasticity at hippocampal mossy fibre synapses. Nat Rev Neurosci 6: 863-876.

15. Li Y, Mu Y, Gage FH (2009) Development of neural circuits in the adult hippocampus. Curr Top Dev Biol 87: 149-174.

16. Taupin P, Gage FH (2002) Adult neurogenesis and neural stem cells of the central nervous system in mammals. J Neurosci Res 69: 745-749.

17. Jacobs BL, van Praag H, Gage FH (2000) Adult brain neurogenesis and psychiatry: a novel theory of depression. Mol Psychiatry 5: 262-269. 
18. Eichenbaum H, Stewart C, Morris RG (1990) Hippocampal representation in place learning. J Neurosci 10: 3531-3542.

19. O'Keefe J (1990) A computational theory of the hippocampal cognitive map. Prog Brain Res 83: 301-312.

20. Neves G, Cooke SF, Bliss TV (2008) Synaptic plasticity, memory and the hippocampus: a neural network approach to causality. Nat Rev Neurosci 9: 65-75.

21. Burgess N, O'Keefe J (1996) Neuronal computations underlying the firing of place cells and their role in navigation. Hippocampus 6: 749-762.

22. O'Keefe J, Dostrovsky J (1971) The hippocampus as a spatial map. Preliminary evidence from unit activity in the freely-moving rat. Brain Res 34: 171175.

23. Moser MB, Moser El (1998) Distributed encoding and retrieval of spatial memory in the hippocampus. J Neurosci 18: 7535-7542.

24. Morris RG, Garrud P, Rawlins JN, O'Keefe J (1982) Place navigation impaired in rats with hippocampal lesions. Nature 297: 681-683.

25. Nerad L (1997) Lesions of the posterior insular cortex impair water maze performance in the rat. Int J Neurosci 90: 1-7.

26. Morris R (1984) Developments of a water-maze procedure for studying spatial learning in the rat. J Neurosci Methods 11: 47-60.

27. Ramirez-Amaya V, Balderas I, Sandoval J, Escobar ML, Bermudez-Rattoni $F$ (2001) Spatial long-term memory is related to mossy fiber synaptogenesis. J Neurosci 21: 7340-7348.

28. Epp JR, Scott NA, Galea LA (2011) Strain differences in neurogenesis and activation of new neurons in the dentate gyrus in response to spatial learning. Neuroscience 172: 342-354.

29. Epp JR, Spritzer MD, Galea LA (2007) Hippocampus-dependent learning promotes survival of new neurons in the dentate gyrus at a specific time during cell maturation. Neuroscience 149: 273-285.

30. Ramirez-Amaya V, Escobar ML, Chao V, Bermudez-Rattoni F (1999) Synaptogenesis of mossy fibers induced by spatial water maze overtraining. Hippocampus 9: 631-636.

31. Escobar ML, Barea-Rodriguez EJ, Derrick BE, Reyes JA, Martinez JL, Jr. (1997) Opioid receptor modulation of mossy fiber synaptogenesis: independence from long-term potentiation. Brain Res 751: 330-335.

32. Adams B, Lee M, Fahnestock M, Racine RJ (1997) Long-term potentiation trains induce mossy fiber sprouting. Brain Res 775: 193-197.

33. Bruel-Jungerman E, Davis S, Rampon C, Laroche S (2006) Long-term potentiation enhances neurogenesis in the adult dentate gyrus. J Neurosci 26: 5888-5893.

34. Aimone JB, Wiles J, Gage FH (2006) Potential role for adult neurogenesis in the encoding of time in new memories. Nat Neurosci 9: 723-727. 
35. Gould E, Beylin A, Tanapat P, Reeves A, Shors TJ (1999) Learning enhances adult neurogenesis in the hippocampal formation. Nat Neurosci 2: 260265.

36. Gould E, Tanapat P, Hastings NB, Shors TJ (1999) Neurogenesis in adulthood: a possible role in learning. Trends Cogn Sci 3: 186-192.

37. Bruel-Jungerman E, Laroche S, Rampon C (2005) New neurons in the dentate gyrus are involved in the expression of enhanced long-term memory following environmental enrichment. Eur J Neurosci 21: 513-521.

38. Bruel-Jungerman E, Davis $S$, Laroche $S$ (2007) Brain plasticity mechanisms and memory: a party of four. Neuroscientist 13: 492-505.

39. Barker JM, Wojtowicz JM, Boonstra R (2005) Where's my dinner? Adult neurogenesis in free-living food-storing rodents. Genes Brain Behav 4: 8998.

40. Abrous DN, Koehl M, Le Moal M (2005) Adult neurogenesis: from precursors to network and physiology. Physiol Rev 85: 523-569.

41. Gould E, Tanapat P (1999) Stress and hippocampal neurogenesis. Biol Psychiatry 46: 1472-1479.

42. Dobrossy MD, Drapeau E, Aurousseau C, Le Moal M, Piazza PV, et al. (2003) Differential effects of learning on neurogenesis: learning increases or decreases the number of newly born cells depending on their birth date. Mol Psychiatry 8: 974-982.

43. Dupret D, Fabre A, Dobrossy MD, Panatier A, Rodriguez JJ, et al. (2007) Spatial learning depends on both the addition and removal of new hippocampal neurons. PLoS Biol 5: e214.

44. Galea LA, Spritzer MD, Barker JM, Pawluski JL (2006) Gonadal hormone modulation of hippocampal neurogenesis in the adult. Hippocampus 16: 225-232.

45. Epp JR, Haack AK, Galea LA (2011) Activation and survival of immature neurons in the dentate gyrus with spatial memory is dependent on time of exposure to spatial learning and age of cells at examination. Neurobiol Learn Mem 95: 316-325.

46. Esposito MS, Piatti VC, Laplagne DA, Morgenstern NA, Ferrari CC, et al. (2005) Neuronal differentiation in the adult hippocampus recapitulates embryonic development. J Neurosci 25: 10074-10086.

47. Hastings NB, Gould E (1999) Rapid extension of axons into the CA3 region by adult-generated granule cells. J Comp Neurol 413: 146-154.

48. Hastings NB, Gould E (2003) Neurons inhibit neurogenesis. Nat Med 9: 264266.

49. van Praag H, Schinder AF, Christie BR, Toni N, Palmer TD, et al. (2002) Functional neurogenesis in the adult hippocampus. Nature 415: 10301034. 
50. Ramirez-Amaya V, Marrone DF, Gage FH, Worley PF, Barnes CA (2006) Integration of new neurons into functional neural networks. J Neurosci 26: 12237-12241.

51. Schmidt-Hieber C, Jonas P, Bischofberger J (2004) Enhanced synaptic plasticity in newly generated granule cells of the adult hippocampus. Nature 429: 184-187.

52. Kee N, Teixeira CM, Wang AH, Frankland PW (2007) Preferential incorporation of adult-generated granule cells into spatial memory networks in the dentate gyrus. Nat Neurosci 10: 355-362.

53. Tashiro A, Sandler VM, Toni N, Zhao C, Gage FH (2006) NMDA-receptormediated, cell-specific integration of new neurons in adult dentate gyrus. Nature 442: 929-933.

54. Tashiro A, Makino H, Gage FH (2007) Experience-specific functional modification of the dentate gyrus through adult neurogenesis: a critical period during an immature stage. J Neurosci 27: 3252-3259.

55. Sandoval CJ, Martinez-Claros M, Bello-Medina PC, Perez O, Ramirez-Amaya V (2011) When are new hippocampal neurons, born in the adult brain, integrated into the network that processes spatial information? PLoS One 6: e17689.

56. Wilson ME, Megel ME, Fredrichs AM, McLaughlin P (2003) Physiologic and behavioral responses to stress, temperament, and incidence of infection and atopic disorders in the first year of life: a pilot study. J Pediatr Nurs 18: 257-266.

57. Magarinos AM, McEwen BS (1995) Stress-induced atrophy of apical dendrites of hippocampal CA3c neurons: involvement of glucocorticoid secretion and excitatory amino acid receptors. Neuroscience 69: 89-98.

58. Wilson RS, Evans DA, Bienias JL, Mendes de Leon CF, Schneider JA, et al. (2003) Proneness to psychological distress is associated with risk of Alzheimer's disease. Neurology 61: 1479-1485.

59. Magarinos AM, McEwen BS (1995) Stress-induced atrophy of apical dendrites of hippocampal CA3c neurons: comparison of stressors. Neuroscience 69: 83-88.

60. Spanswick SC, Epp JR, Keith JR, Sutherland RJ (2007) Adrenalectomy-induced granule cell degeneration in the hippocampus causes spatial memory deficits that are not reversed by chronic treatment with corticosterone or fluoxetine. Hippocampus 17: 137-146.

61. Krishnan V, Nestler EJ (2008) The molecular neurobiology of depression. Nature 455: 894-902.

62. Magarinos AM, Verdugo JM, McEwen BS (1997) Chronic stress alters synaptic terminal structure in hippocampus. Proc Natl Acad Sci U S A 94: 1400214008.

63. McEwen BS (2001) Plasticity of the hippocampus: adaptation to chronic stress and allostatic load. Ann N Y Acad Sci 933: 265-277. 
64. McEwen BS (2000) Allostasis and allostatic load: implications for neuropsychopharmacology. Neuropsychopharmacology 22: 108-124.

65. Sapolsky RM, Meaney MJ, McEwen BS (1985) The development of the glucocorticoid receptor system in the rat limbic brain. III. Negativefeedback regulation. Brain Res 350: 169-173.

66. Sapolsky RM, Romero LM, Munck AU (2000) How do glucocorticoids influence stress responses? Integrating permissive, suppressive, stimulatory, and preparative actions. Endocr Rev 21: 55-89.

67. Newport DJ, Stowe ZN, Nemeroff CB (2002) Parental depression: animal models of an adverse life event. Am J Psychiatry 159: 1265-1283.

68. Lopez JF, Chalmers DT, Little KY, Watson SJ (1998) A.E. Bennett Research Award. Regulation of serotonin1A, glucocorticoid, and mineralocorticoid receptor in rat and human hippocampus: implications for the neurobiology of depression. Biol Psychiatry 43: 547-573.

69. De Kloet ER, Sutanto W, Rots N, van Haarst A, van den Berg D, et al. (1991) Plasticity and function of brain corticosteroid receptors during aging. Acta Endocrinol (Copenh) 125 Suppl 1: 65-72.

70. Boonstra R (2004) Coping with changing northern environments: the role of the stress axis in birds and mammals. Integr Comp Biol 44: 95-108.

71. Watanabe Y, Gould E, McEwen BS (1992) Stress induces atrophy of apical dendrites of hippocampal CA3 pyramidal neurons. Brain Res 588: 341345.

72. Woolley CS, Gould E, McEwen BS (1990) Exposure to excess glucocorticoids alters dendritic morphology of adult hippocampal pyramidal neurons. Brain Res 531: 225-231.

73. Luine V, Villegas M, Martinez C, McEwen BS (1994) Repeated stress causes reversible impairments of spatial memory performance. Brain Res 639: 167-170.

74. Watanabe Y, Gould E, Cameron HA, Daniels DC, McEwen BS (1992) Phenytoin prevents stress- and corticosterone-induced atrophy of CA3 pyramidal neurons. Hippocampus 2: 431-435.

75. Galea LA, McEwen BS, Tanapat P, Deak T, Spencer RL, et al. (1997) Sex differences in dendritic atrophy of CA3 pyramidal neurons in response to chronic restraint stress. Neuroscience 81: 689-697.

76. Tanapat P, Galea LA, Gould E (1998) Stress inhibits the proliferation of granule cell precursors in the developing dentate gyrus. Int J Dev Neurosci 16: 235-239.

77. Eriksson PS, Wallin L (2004) Functional consequences of stress-related suppression of adult hippocampal neurogenesis - a novel hypothesis on the neurobiology of burnout. Acta Neurol Scand 110: 275-280.

78. Ehninger D, Kempermann G (2006) Paradoxical effects of learning the Morris water maze on adult hippocampal neurogenesis in mice may be explained 
by a combination of stress and physical activity. Genes Brain Behav 5: 2939.

79. Mirescu C, Gould E (2006) Stress and adult neurogenesis. Hippocampus 16: 233-238.

80. Aztiria E, Capodieci G, Arancio L, Leanza G (2007) Extensive training in a maze task reduces neurogenesis in the adult rat dentate gyrus probably as a result of stress. Neurosci Lett 416: 133-137.

81. Joels M, Karst H, Krugers HJ, Lucassen PJ (2007) Chronic stress: implications for neuronal morphology, function and neurogenesis. Front Neuroendocrinol 28: 72-96.

82. McEwen BS (2005) Glucocorticoids, depression, and mood disorders: structural remodeling in the brain. Metabolism 54: 20-23.

83. Santarelli L, Saxe M, Gross C, Surget A, Battaglia F, et al. (2003) Requirement of hippocampal neurogenesis for the behavioral effects of antidepressants. Science 301: 805-809.

84. McEwen BS, Gould E (1990) Adrenal steroid influences on the survival of hippocampal neurons. Biochem Pharmacol 40: 2393-2402.

85. Gould E, Woolley CS, McEwen BS (1990) Short-term glucocorticoid manipulations affect neuronal morphology and survival in the adult dentate gyrus. Neuroscience 37: 367-375.

86. Sloviter RS, Sollas AL, Dean E, Neubort S (1993) Adrenalectomy-induced granule cell degeneration in the rat hippocampal dentate gyrus: characterization of an in vivo model of controlled neuronal death. J Comp Neurol 330: 324-336.

87. Sloviter RS, Valiquette G, Abrams GM, Ronk EC, Sollas AL, et al. (1989) Selective loss of hippocampal granule cells in the mature rat brain after adrenalectomy. Science 243: 535-538.

88. Sloviter RS, Dean E, Neubort S (1993) Electron microscopic analysis of adrenalectomy-induced hippocampal granule cell degeneration in the rat: apoptosis in the adult central nervous system. J Comp Neurol 330: 337351.

89. Aguilar-Valles A, Sanchez E, de Gortari P, Balderas I, Ramirez-Amaya V, et al. (2005) Analysis of the stress response in rats trained in the water-maze: differential expression of corticotropin-releasing hormone, CRH-R1, glucocorticoid receptors and brain-derived neurotrophic factor in limbic regions. Neuroendocrinology 82: 306-319.

90. McEwen BS, Magarinos AM (1997) Stress effects on morphology and function of the hippocampus. Ann N Y Acad Sci 821: 271-284.

91. McLay RN, Freeman SM, Zadina JE (1998) Chronic corticosterone impairs memory performance in the Barnes maze. Physiol Behav 63: 933-937.

92. Kaneko N, Sawamoto K (2009) Adult neurogenesis and its alteration under pathological conditions. Neurosci Res 63:155-164 
93. Kempermann G, Jessberger S, Steiner B, Kronenberg G (2004) Milestones of neuronal development in the adult hippocampus. Trends Neurosci 27: 447-452. 



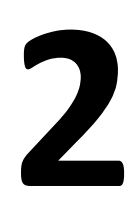

Effect of water maze training and swimming on neurogenesis and synaptogenesis in the hippocampus

Martínez-Claros M

Sandoval CJ

Bello-Medina PC

Pawluski JL

Steinbusch HWM

Ramirez-Amaya $\mathrm{V}$ 


\section{Abstract}

The hippocampus is a highly plastic structure involved in spatial learning and memory formation. It has been previously demonstrated that over-training rats in a spatial water maze task induces synaptogenesis of mossy fibers in the septal region of the CA3 stratum oriens [1,2] and there is a well-documented link between hippocampal neurogenesis and learning and memory performance. The aim of the present study is determine how several days of training in the Morris Water Maze (MWM) affects new granular neurons in the dentate gyrus (DG) and synapse formation in the CA3 stratum oriens. In addition, since there is a controversy about the effects of Morris Water Maze training in the survival of new neurons, the present study investigated how much these structural changes are affected by the swim stress induced by the training in the Morris Water Maze task. Results demonstrate that animals habituated to the MWM had significantly fewer NeuN/BrdUir cells when compared to the non-habituated animals and a greater density of synaptophysin in the stratum lucidum. This work points to the complex relationship between learning and memory performance and hippocampal plasticity in the adult brain. 


\section{Introduction}

Currently, it is well accepted that neural plasticity in the central nervous system is a very important mechanism that underlies memory formation. The storage of long-term memories is accompanied by several structural changes, such as neurite outgrowth and remodeling of neuronal varicosities. In addition, synaptic plasticity and neurogenesis are believed to be important for long-term memory formation $[3,4]$. Structural changes in the neural network, such as changes in the distribution and number of synaptic contacts as well as the addition and elimination of neural units can be considered as persistent forms of plasticity [3,5]. All these types of plasticity had been observed in the hippocampus and have been associated with behavioral experience $[1,2,6]$.

Structural synaptic plasticity occurs in the hippocampus after behavioral experience and spatial learning [7,8,9]. For example, animals living in a complex environment have increased number of dendritic spines in the CA1 region of the hippocampus [10,11,12,13]. Ramírez-Amaya et al have shown that spatial learning and memory results in an increase in the number of synaptic boutons in the septal portion of the CA3 stratum oriens in the hippocampus [1]. In addition, this increase in synaptic boutons in the CA3 region positively correlates with long-term spatial memory performance [2]. These results were confirmed by other research groups [7] and now it is clear that synaptic plasticity occurs in different rat strains [9] and other species $[5,14]$.

Interestingly, this phenomenon is observed only 4 days after the last training session in the Morris Water Maze [7] suggesting that off line reactivation [15] of the cellular mechanisms underlying this type of plasticity may play an important role in the structural rearrangement of the hippocampus.

Of particular interest is the possibility that the new synapses found in CA3 region may arise from new granular neurons in the dentate gyrus [2], where adult neurogenesis occurs $[16,17,18]$. This is an interesting possibility, since it is known that approximately nine thousand new neurons are added to the hippocampus dentate gyrus 
every day $[19,20,21]$ and hippocampal-dependent behavior, such as spatial learning in the Morris water maze task, can modify both the rate of new neuronal generation [22] and the survival of new neurons $[23,24,25,26]$. It is important to note that, this is a similar task to the one used to induce new synapses formation in the CA3 stratum oriens [2].

Furthermore, new neurons in the dentate gyrus project their axons and dendrites in the expected trajectories to the CA3 region $[18,27,28,29]$. More specifically, it has been shown that when new neurons mature, their dendrites reach the outer molecular layer [28] and their axons reach the CA3 pyramidal dendrites [27,30]. Also, these new neurons are functionally integrated into the hippocampal network $[18,31,32]$ in such a way that they can respond to spatial exploration as the rest of the granular cells does, but with different plastic properties [31,32,33,34,35,36].

It is also important to note that stress-related hormones play a significant role in structural modifications in the hippocampus $[37,38,39,40,41]$. It has been demonstrated that the first few days of water maze training activate the stress response as evidenced by increasing glucocorticoids in the hypothalamus and the amygdala. This is also associated with increased concentration of circulating glucocorticoids [42]. However, stress is known to decrease the proliferation rate of new neurons in the hippocampus $[43,44,45]$. This, in turn, may explain the controversial results obtained when evaluating the effect of water maze training on the proliferation and survival of new neurons in the hippocampus $[26,46]$

The aim of the present study is to determine how training in the Morris Water Maze (MWM) affects new granular neurons at the dentate gyrus (DG) and synapse formation in the CA3 stratum oriens and stratum lucidum. Since there is a controversy about the effects of MWM training on the survival of new neurons, we want to understand how much these structural changes are affected by the swim stress induced by the training in the MWM. We expect that the corticosterone levels, swimming, and training experience will influence the survival of new born cells in the DG and the amount of synaptic contacts in CA3 region of the hippocampus. 


\section{Methods}

\section{Animals}

Twenty-four adult male Wistar rats ( 3 months old) obtained from the Neurobiology Institute from the Universidad Nacional Autónoma de México (INB-UNAM, Querétaro, México) vivarium, were used in the present study. Animals were divided into four groups as follows: 1) Trained-habituated, 2) Trained-non-habituated, 3) Swim-habituated, and 4) Swim non-habituated. Trained animals received normal MWM training as stated below. Swim controls received the same swimming exposure as trained animals, but were not trained and therefore were not exposed to a platform location.

All animals were kept in a reversed $12 \mathrm{~h}$ dark/light cycle, fed ad libitum and individually caged. The "bioethics committee" from the INB approved all the protocols and experimental procedures perform with the animals in the present study. This was done in accordance with international ethical guidelines for animal care and handling (ID:INEU/SA/CB/034).

\section{BrdU administration}

In order to investigate the number of surviving new neurons in the hippocampus, bromodeoxiuridine (BrdU) was administered to each animal in a total dosage of $200 \mathrm{mg} / \mathrm{kg}$ as previously described $[31,36]$. BrdU was diluted in a saline basic solution (pH8). Two i.p. injections were given to each animal daily for 4 consecutive days (25 $\mathrm{mg} / \mathrm{kg}$ dosage per injection), 15 days before the first training session. Injections were given between 9 and 10 a.m. and 9 and 10 p.m. daily. See Figure 1 for a timeline.

\section{Water habituation}

The trained and swim habituated groups were exposed to the environment of the MWM tank, without learning the task one week previous to the training session. They were allowed to swim in a water bucket at $22^{\circ} \mathrm{C}$ for a one minute session for 3 days in a row. The reason for the use of this pre-habituation was to diminish the amount of stress found in these animals during water maze training [42]. The two non-habituated groups were handled and transported 
to the Water Maze room once per day for 3 days but did not have contact with the water.

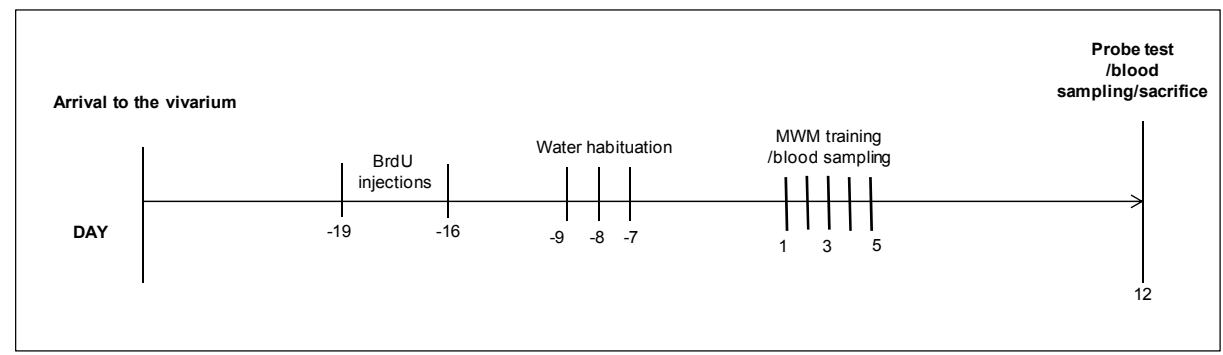

Figure 1. Timeline of experiment. The animals arrived to the vivarium on day -33, They were habituated and/or handled one week before the MWM training sessions. All animals were injected with BrdU once daily from day -19 until day -16 . They were trained from day 1 till 5 and a memory test trial was performed on day 12. Blood samples were taken on day 1, 3, 5 and 12 after the training session. They were sacrificed on day 12 .

\section{Morris Water Maze training (MWM)}

Animals were trained in the MWM task as previously reported [2], with a training protocol of 5 days with 10 essays per day. During the training session each MWM trained animal was introduced in to a tank (black circular arena, $150 \mathrm{~cm}$ diameter, $120 \mathrm{~cm}$ height) located in a room with dim light and filled $3 / 4$ with water at a temperature of 22 ${ }^{\circ} \mathrm{C} \pm 1.5^{\circ} \mathrm{C}$. Once the animals were introduced into the tank there was a maximum run time of 60 seconds where they were allowed to reach the platform $(10 \times 10 \mathrm{~cm})$ or manually led to it if the animal did not find it on time. The platform was submerged $1 \mathrm{~cm}$ bellow the water level. After the animal reached the platform they stood $30 \mathrm{~s}$ on it and they were taken out the water $30 \mathrm{~s}$ in a dry cage. Each release was considered a trial and was started from a different location each time for a total of 10 essays per day [47]. Animals from the swimming groups (Swim habituated and swim non-habituated) were immersed into the tank with no platform, and allowed to swim the average time registered for the trained group during that day in 
each trial. They were introduced 10 times to the tank and allowed to rest 30 seconds in a dry cage after each trial. Swimming behavior and the time to reach the platform, on each trial, were recorded with a DVD recorder and analyzed with the SMART ${ }^{\circledR}$ system (San Diego CA).

\section{Corticosterone levels}

In order to measure the circulating corticosteroid concentration we obtained blood from all the groups on days 1, 3 and 5 after the Morris Water Maze training and also during the memory test trial done 30 minutes before sacrifice on day 7 after the last training session. The corticosteroid serum concentration was determined by radio-immunoassay using ICN Biomedicals kit (Aurora, Ohio, USA) with antiserum at 1:1,000 dilution. Serum samples were diluted 1: 500 in $0.01 \mathrm{M}$ phosphate buffer $\mathrm{pH} 7.5,0.15 \mathrm{M} \mathrm{NaCl}$ and $0.1 \%$ gelatin and heated at $98^{\circ} \mathrm{C}$ for $10 \mathrm{~min}$ (non-heated samples give $40 \%$ less concentration). Linear portion of the standard curve: $50-2,000 \mathrm{pg}$ of corticosterone/ml, interassay variability: $6.9 \%$, intra-assay: $3.4 \%$ [42].

\section{Histological procedures}

After the last probe trial, all animals were sacrificed by rapid decapitation. Brains were carefully extracted and the brains were frozen in 2-methylbutane (Sigma) immersed in a slurry of dry ice and ethanol. The rat brains were stored at $-70^{\circ} \mathrm{C}[31,36]$.

\section{Immunostaining}

Frozen brain hemisections of the left dorsal hippocampus from six to eight rats were molded in a block with Tissue-Tek (Sakura, EU) in a plastic container as previously described $[31,36]$. Each block included brains from all groups. The blocks were cryosectioned into $20 \mu \mathrm{m}$ thick coronal sections, mounted on Superfrost Plus slides (VWR) dried, and stored at $-80^{\circ} \mathrm{C}$ until staining.

In order to maximize the detection of $\mathrm{BrdU}$ cells, 10 serial sections from the dorsal hippocampus (Range between -2.60 to -4.3 from Bregma) from each block were selected for the staining procedure. We used a double immnunostaining protocol similar to that described previously to detect NeuN and BrdU. The tissue was 
fixed in $2 \%$ paraformaldehyde, $\mathrm{pH} 7.4$, for $8 \mathrm{~min}$ at $4^{\circ} \mathrm{C}$, washed in Tris-buffered saline (TBS), pH 7.0 and quenched in TBS with $2 \% \mathrm{H}_{2} \mathrm{O}_{2}$ for $20 \mathrm{~min}$. The sections were blocked for $40 \mathrm{~min}$ in tyramide signal amplification (TSA) kit blocking buffer (Perkin Elmer Life Sciences, Emeryville, CA). The tissue was then incubated sequentially with biotinylated mouse anti-NeuN antibody (1:2000; Chemicon, Bedford, $\mathrm{MA})$ and with mouse anti-BrdU monoclonal antibody (1:100+ $3 \%$ NDS $+10 \%$ Triton-X; Roche Products, USA). For the detection of $\mathrm{BrdU}$, the tissue was taken through a DNA denaturing procedure, consisting of an incubation with $50 \%$ formamide in $2 \times S S C$ buffer (Sigma) at $65^{\circ} \mathrm{C}$ for $2 \mathrm{~h}$, washed in $2 \times S S C$ for $10 \mathrm{~min}$, incubated in $2 \mathrm{~N}$ $\mathrm{HCl}$ at $37^{\circ} \mathrm{C}$ for $30 \mathrm{~min}$, and washed in $0.1 \mathrm{M}$ boric acid, $\mathrm{pH} 8.5$, for 10 min. Biotinylated anti-NeuN was detected with the avidin-biotin $A+B$ Vectastain amplification kit (Vector laboratories, Burlingame, CA) and the cyanine-5 (Cy5) TSA fluorescence system (PerkinElmer). Mouse IgG from the first detection was blocked using the mouse-onmouse blocking kit (Vector Laboratories) before detection of BrdU. The mouse anti-BrdU antibody was detected with a biotinylated antimouse antibody in which the signal was amplified using an $A+B$ Vectastain amplification kit, and finally observed using the FITC TSA fluorescence system (PerkinElmer).

For the synaptophysin detection (1:200 mouse monoclonal anti-synaptophysin antibody SIGMA) 10 serial sections of the dorsal hippocampus (Range between -2.60 to -4.3 from Bregma) from each block were selected. We used the same immunostaining protocol of the BrdU detection except for the DNA denaturing step. The sections were mounted with VECTASHIELD ${ }^{\circledR}$ HardSet $^{\mathrm{TM}}$ with 4',6-diamidino-2phenylindole (DAPI) (Vector, USA).

\section{Imaging and analysis}

Sections were analyzed using an Olympus AX70 Fluorescence microscope, equipped with a narrow band-pass MNIBA-filter for the detection of FITC and Cy3. We used a filter with a narrow excitation band, the U-M41007A filter (both from Chrome Technologies, Rockingham, Vt, USA). The microscope is equipped with a cooled charge-coupled device, the Olympus digital video camera F-view. 
Images were stored digitally as 16 bit images by using the computer program Cell^P (Soft Imaging Systems, Olympus, Germany).

To estimate cell numbers, total BrdU-immunoreactive (ir)/NeuN (-ir) cells were counted under a 60x objective with oil on every 12th section (approx. 9-10 sections per rat) in the dorsal hippocampus. The BrdU-ir cells were counted in the granular cell layer (GCL) and were considered BrdU-ir if they were intensely stained and exhibited medium round or oval cell bodies $[48,49]$.

For the synaptophysin analysis the images were stored digitally as 16 bit images using the computer program Cell^P (Soft Imaging Systems, Olympus, Germany) and they were afterwards processed using ImageJ for microscopy (NIH) using the same method previously described by Strackx et al. [50].

\section{Statistical analysis}

A repeated measures analysis of variance test (ANOVA) was done on corticosterone levels with days (day 1, 3, 5 and 12) as within subject factor and group (trained $x$ swimming) and habituation (habituated $x$ non-habituated) as the between subjects factors. A repeated measures ANOVA was done on distance travelled and latency to reach the platform with training days (day 1-5) as within subjects factor and group (trained and trained habituated) as the between subjects factor. ANOVAs were done to determine differences in the density and proportion of BrdU-ir cells, BrdU/NeuN-ir cells and synapotophysin with group (trained $x$ swimming) and habituation (habituated $x$ non-habituated) as the between subjects factors. Posthoc comparisons utilized the Fisher LSD test. Significance was set at $p<.05$.

\section{Results}

Corticosterone levels. There was a significant day by group interaction effect $(F(3,60)=8.0703, p=.00013$; Figure 2) with swimming-control animals having significantly higher plasma levels of corticosterone in day 3 compared with trained animals, regardless of habituation $(.000001<p<.00001)$. There was also a significant main effect of day $(F(3,60)=15.476, p=.00000)$ and a significant main 
effect of group $(F(1,20)=17.981, p=.00040)$ with swim controls having significantly higher corticosterone levels compared to trained animals, regardless of habituation. There were no other significant differences between groups.

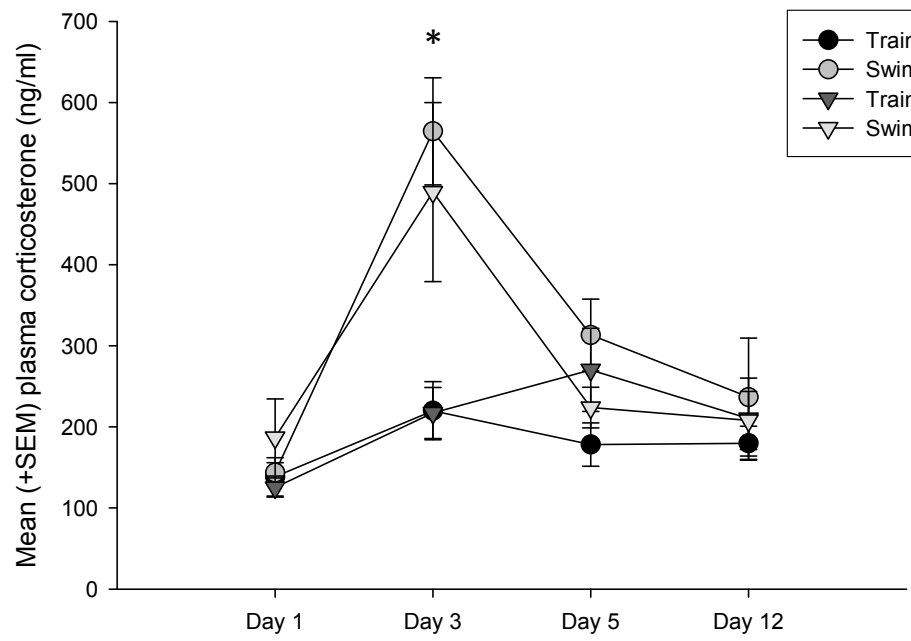

Figure 2. Mean (+SEM) plasma levels of corticosterone $(\mathrm{ng} / \mathrm{ml})$. Swimming-control animals, regardless of habituation, had significantly higher plasma levels of corticosterone on day 3 of water maze exposure compared with trained and trained-habituated animals $(p \leq .00395) .{ }^{*}$ denotes swimming controls significantly different from trained animals.

Training. There were no significant differences between trained habituated and trained non-habituated animals in ability to learn the task (.806 < p; Figure 3). There was a significant main effect of day in latency to reach the platform $(F(4,88)=8.8080, p=.00000)$ and distance to reach the platform $(F(4,88)=5.9758, p=.00027)$, indicating that all animals learned the task. 
A

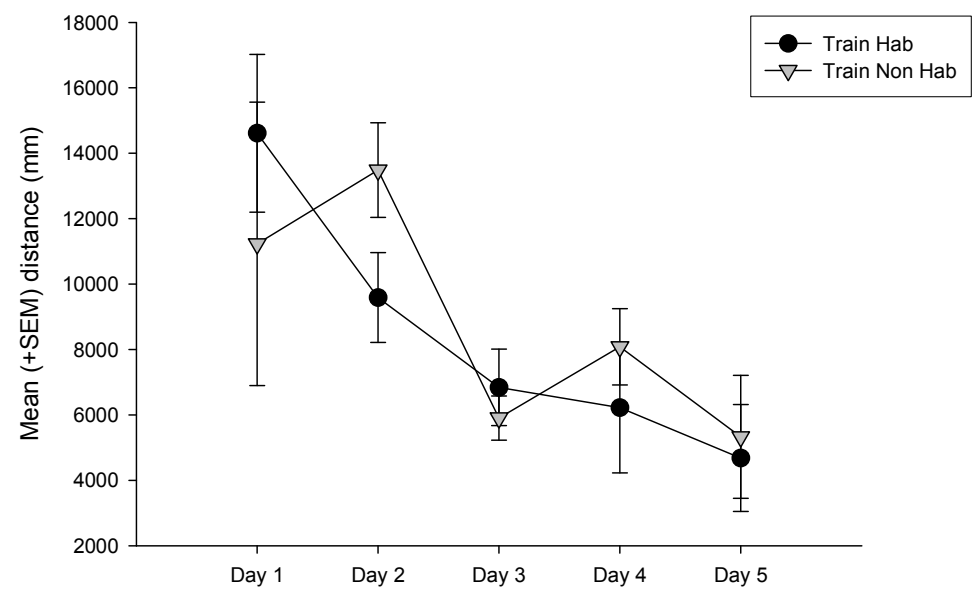

B

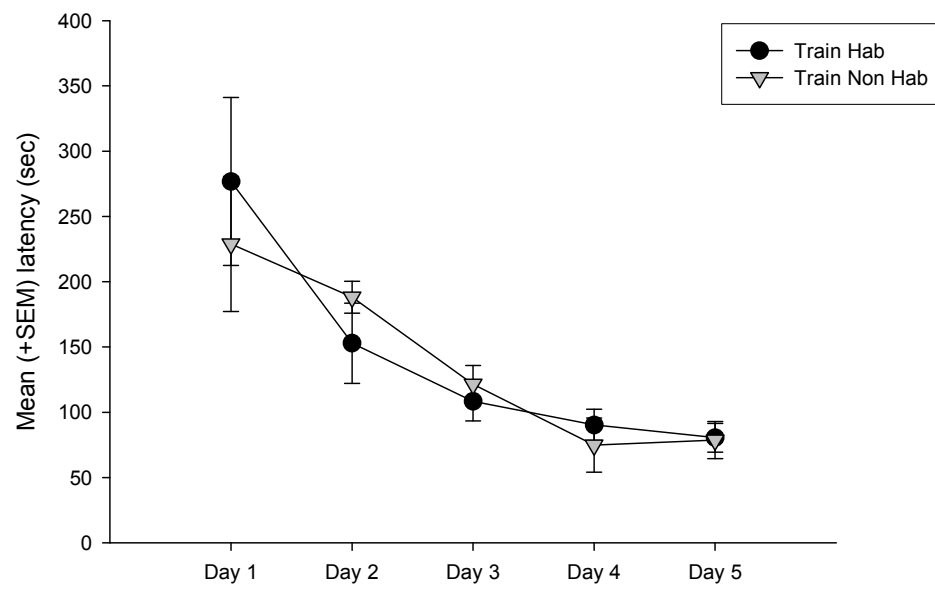

Figure 3. Mean (+SEM) A) latency and B) distance to reach the platform on the Morris water maze. There was a significant main effect of day in latency to reach the platform $(p=.00000)$ and distance to reach the platform $(p=.00027)$, indicating that all animals learned the task.

BrdU-ir/NeuN-ir cells in the dentate gyrus. There was a significant main effect of habituation in the total number of NeuN/BrdU-ir cells in the $G C L$ of the dorsal hippocampus $(F(1,20)=5.7901, p=.02590$ 
Figure 4B), with non-habituated animals having significantly more NeuN/BrdU-ir cells compared to habituated animals, regardless of training.

There was a tendency for non-habituated animals to have a greater proportion of NeuN/BrdU-ir cells in the dorsal GCL, regardless of group ( $p=.068$ Figure $4 C$ ). There were no significant differences between groups in the total amount of BrdU-ir cells in the $\mathrm{GCL}$ of the dorsal hippocampus, regardless of habituation ( $p>$ $.15)$.

A)

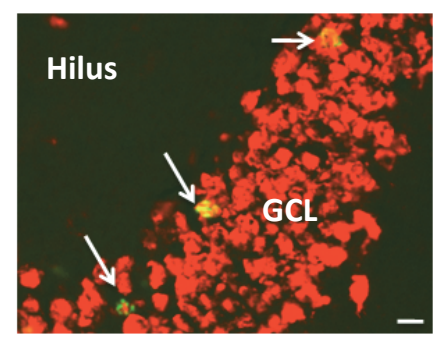

B)

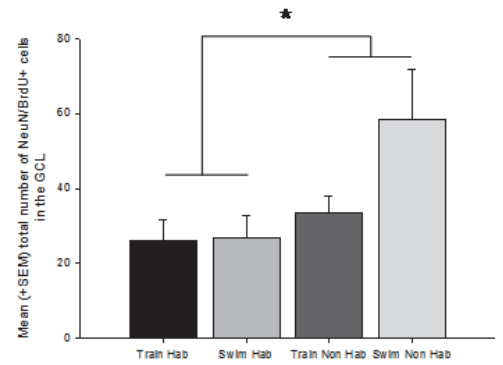

C)

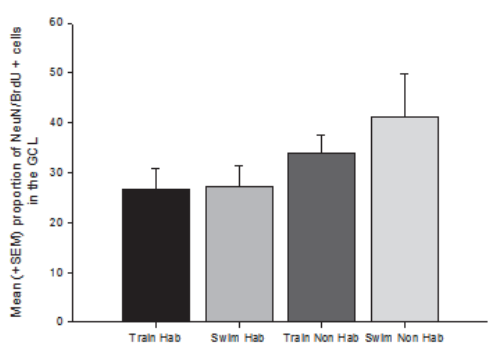

Figure 4. A) Photomicrographs of a BrdU/NeuN immunostaining. BrdU-ir cell (green)/NeuN-ir cells (red) Scale bar represents $25 \mu \mathrm{m}$. B) Mean (+SEM) of the total number of NeuN/BrdU-ir cells. There was a significant main effect of habituation in the total number of NeuN/BrdU-ir cells in the GCL of the dorsal hippocampus $(p=.02590)$, with non-habituated animals have significantly more NeuN/BrdU-ir cell compared to habituated animals, regardless of training. C) Mean (+SEM) of the proportion of NeuN/BrdU-ir cells in the GCL of the dorsal hippocampus. There was a tendency for non-habituated animals to have a greater proportion of NeuN/BrdU-ir cells in the dorsal GCL, regardless of group ( $p=$ .068).

Synaptophysin particles in the CA3. There was a tendency towards a significant interaction effect between group and habituation in total density of synaptophysin particles in the stratum oriens of the CA3 
$(F(1,20)=3.8198, p=.06478$; Figure 5B). There was a significant main effect of habituation on density of synaptophysin particles in the stratum lucidum $(F(1,20)=4.3307, p=.050$; Figure $5 C)$, with habituated animals having a greater density of synaptophysin compared to non-habituated animals. There were no other significant differences.

A)

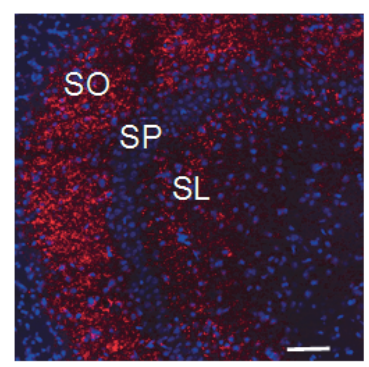

B)

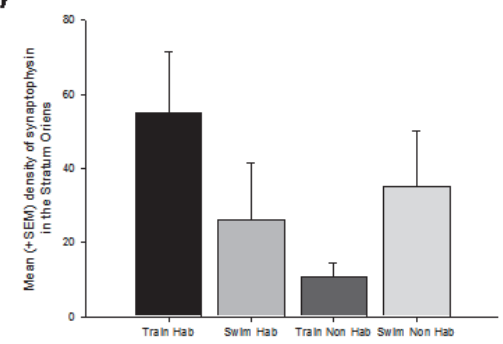

C)

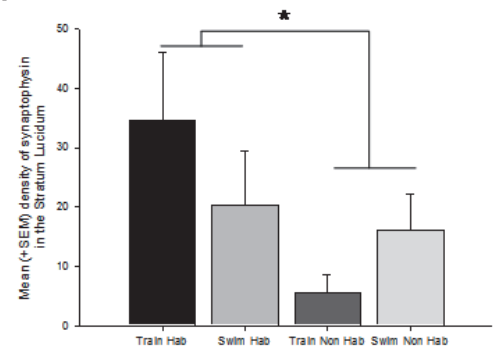

Figure 5. A) Photomicrograph of Synaptophysin (red) and 4',6-diamidino-2-phenylindole (DAPI) (blue). Scale bar represents $200 \mu \mathrm{m}$. SO=stratum oriens SP=stratum pyramidale SL=stratum lucidum. Mean (+SEM) density of synaptophysin particles in the B) stratum oriens and C) stratum lucidum. B) There was a tendency towards a significant interaction effect between group and habituation in total density of synaptophysin particles in the stratum oriens of the CA3 $(p=.064)$. C) There was a significant main effect of habituation on density of synaptophysin particles in the stratum lucidum $(p=.05)$, with habituated animals having a greater density of synaptophysin compared to non-habituated animals.

\section{Discussion}

The present study investigated changes in hippocampal plasiticy in relation to learning on the Morris Water Maze task. In addition, we investigated how habituation to the task and swimming alone affect corticosterone levels and hippocampal plasticity. As expected, all 
trained animals learned the task. We found that swim control animals had higher levels of corticosterone on training day 3.

Interestingly, habituated animals had significantly fewer NeuN/BrdU-ir cells in the dentate gyrus when compared to the nonhabituated animals, however the effects were strongest in the swimming non-habituated animals. We also found that habituated animals had a significantly greater density of synaptophysin in the Stratum lucidum.

\section{Corticosterone and MWM}

When looking at circulating corticosterone levels, we found that the water habituation had no effect in the corticosterone levels of both trained and swim control animals on days 1, 5 and 12 . However the swimming control groups, regardless the habituation, showed high levels of corticosterone on day 3. This effect maybe due to the nature of the training task in these animals, as they had no escape platform, and thus the MWM may have acted as a forced swim test for these animals and elevated corticosterone levels [51,52,53]. When designing the experiment we looked for a good control for the MWM trained animals, and as previously reported [42], swimming controls were adequate, however a better control should be found.

\section{Effects on new neuron survival in the DG}

Interestingly, we found that habituated animals had fewer NeuN/BrdU-ir cells. This is possibly due to additional swim stress with the habituation prior to MWM training or the timing of the habituation in relation to the birth of new neurons Even though, we did not find significant effects of habituation on corticosterone levels, at least at the time points we investigated.

We decided to take not basal, but learning related corticosterone levels and, thus, the levels of corticosterone levels during the habituation may actually differ between habituated and non-habituated animals $[54,55,56]$. The trained animals, regardless the habituation, learned the task, so we can conclude that the surviving new neurons observed on the habituated animals were marked outside the time frame where we could see a difference in 
the amount of survival cells due to the learning $[46,57,58,59,60,61,62]$. The swimming control non-habituated had the highest number of new neurons. This group also showed high levels of corticosterone on day 3 of the training. Looking at these data together, we can conclude we might not labeled the surviving cells related to the learning, but rather the ones related to the habituation period. In previous work found that the time window where the new cells can be responsive to a behavioral task is limited and very precise [36]. Thus, habituation itself may have occurred at a time that altered the survival of new neurons in the dentate gyrus.

Effects on synaptophysin density in the CA3 region

In the present study, we found that habituated animals, regardless of training, had a significantly greater density of synaptophysin in the stratum lucidum. Previous work has found that animals trained in the MWM for at least 5 days showed an increased amount of synaptic vesicles in the stratum oriens $[2,7,9]$. Overall we saw a tendency where trained animals, habituated to the task, had the greatest density of synaptophysin in both the stratum oriens and the stratum lucidum. The habituation to the MWM task seemed to have the greatest effect on the density of the synaptophysin after training, with habituated animals, regardless of training or swimming, having a significantly greater density of synaptophysin in the stratum lucidum.

Relationship between corticosterone, cognition and hippocampal plasticity

The MWM is a widely used and common spatial learning task to study morphological and plastic changes in the hippocampus $[1,2,40,46,61,63,64,65,66]$. Nevertheless we see in the literature and with our own results that a number of factors, besides learning may affect plasticity in the hippocampus. For example, the swimming control animals are exposed to exercise and this factor alone can affect hippocampal plasticity. Further work is needed using a task that reduces the number of variables affecting hippocampal 
plasticity in order to thoroughly investigate how learning affects both new granule neuron survival and synaptogenesis in the CA3 region.

\section{Conclusions}

Findings of the present study show that the MWM is a complicated task with multiple variables to consider in the study of hippocampal morphological and plastic changes. The water habituation appeared to have the greatest effects and reduced the NeuN/BrdU-ir cell number. This may be due to the effect of altered circulating corticosterone levels with a consequent reduction in new neuron survival. The increased amount of synaptophysin in the stratum lucidum of the habituated animals suggests an increased synaptic activity on those animals, possibly to compensate for the reduced levels of new granule neurons. However, further study is required. 


\section{References}

1. Ramirez-Amaya V, Escobar ML, Chao V, Bermudez-Rattoni F (1999) Synaptogenesis of mossy fibers induced by spatial water maze overtraining. Hippocampus 9: 631-636.

2. Ramirez-Amaya V, Balderas I, Sandoval J, Escobar ML, Bermudez-Rattoni $F$ (2001) Spatial long-term memory is related to mossy fiber synaptogenesis. J Neurosci 21: 7340-7348.

3. Barco A, Bailey CH, Kandel ER (2006) Common molecular mechanisms in explicit and implicit memory. J Neurochem 97: 1520-1533.

4. Snyder JS, Hong NS, McDonald RJ, Wojtowicz JM (2005) A role for adult neurogenesis in spatial long-term memory. Neuroscience 130: 843-852.

5. Middei S, Vetere G, Sgobio C, Ammassari-Teule M (2007) Landmark-based but not vestibular-based orientation elicits mossy fiber synaptogenesis in the mouse hippocampus. Neurobiol Learn Mem 87: 174-180.

6. Yuste R, Bonhoeffer T (2001) Morphological changes in dendritic spines associated with long-term synaptic plasticity. Annu Rev Neurosci 24: 1071-1089.

7. Rekart JL, Sandoval CJ, Bermudez-Rattoni F, Routtenberg A (2007) Remodeling of hippocampal mossy fibers is selectively induced seven days after the acquisition of a spatial but not a cued reference memory task. Learn Mem 14: 416-421.

8. Galimberti I, Gogolla N, Alberi S, Santos AF, Muller D, et al. (2006) Long-term rearrangements of hippocampal mossy fiber terminal connectivity in the adult regulated by experience. Neuron 50: 749-763.

9. Holahan MR, Rekart JL, Sandoval J, Routtenberg A (2006) Spatial learning induces presynaptic structural remodeling in the hippocampal mossy fiber system of two rat strains. Hippocampus 16: 560-570.

10. Rusakov DA, Davies HA, Harrison E, Diana G, Richter-Levin G, et al. (1997) Ultrastructural synaptic correlates of spatial learning in rat hippocampus. Neuroscience 80: 69-77.

11. Moser MB, Trommald M, Egeland T, Andersen P (1997) Spatial training in a complex environment and isolation alter the spine distribution differently in rat CA1 pyramidal cells. J Comp Neurol 380: 373-381.

12. Moser MB, Trommald M, Andersen P (1994) An increase in dendritic spine density on hippocampal CA1 pyramidal cells following spatial learning in adult rats suggests the formation of new synapses. Proc Natl Acad Sci U S A 91: 12673-12675.

13. Moser El, Moser MB, Andersen P (1994) Potentiation of dentate synapses initiated by exploratory learning in rats: dissociation from brain temperature, motor activity, and arousal. Learn Mem 1: 55-73.

14. Routtenberg A, Rekart JL (2005) Post-translational protein modification as the substrate for long-lasting memory. Trends Neurosci 28: 12-19. 
15. Ramirez-Amaya V, Vazdarjanova A, Mikhael D, Rosi S, Worley PF, et al. (2005) Spatial exploration-induced Arc mRNA and protein expression: evidence for selective, network-specific reactivation. J Neurosci 25: 1761-1768.

16. Altman J, Das GD (1965) Autoradiographic and histological evidence of postnatal hippocampal neurogenesis in rats. J Comp Neurol 124: 319-335.

17. van Praag H, Kempermann G, Gage FH (1999) Running increases cell proliferation and neurogenesis in the adult mouse dentate gyrus. Nat Neurosci 2: 266-270.

18. van Praag $H$, Schinder AF, Christie BR, Toni N, Palmer TD, et al. (2002) Functional neurogenesis in the adult hippocampus. Nature 415: 10301034.

19. Cameron HA, Woolley CS, McEwen BS, Gould E (1993) Differentiation of newly born neurons and glia in the dentate gyrus of the adult rat. Neuroscience 56: 337-344.

20. Gould E, Tanapat P, Rydel T, Hastings N (2000) Regulation of hippocampal neurogenesis in adulthood. Biol Psychiatry 48: 715-720.

21. Cameron HA, McKay RD (1999) Restoring production of hippocampal neurons in old age. Nat Neurosci 2: 894-897.

22. Gould E, Beylin A, Tanapat P, Reeves A, Shors TJ (1999) Learning enhances adult neurogenesis in the hippocampal formation. Nat Neurosci 2: 260265.

23. Dobrossy MD, Drapeau E, Aurousseau C, Le Moal M, Piazza PV, et al. (2003) Differential effects of learning on neurogenesis: learning increases or decreases the number of newly born cells depending on their birth date. Mol Psychiatry 8: 974-982.

24. Dupret D, Fabre A, Dobrossy MD, Panatier A, Rodriguez JJ, et al. (2007) Spatial learning depends on both the addition and removal of new hippocampal neurons. PLoS Biol 5: e214.

25. Galea LA, Spritzer MD, Barker JM, Pawluski JL (2006) Gonadal hormone modulation of hippocampal neurogenesis in the adult. Hippocampus 16: 225-232.

26. Epp JR, Haack AK, Galea LA (2011) Activation and survival of immature neurons in the dentate gyrus with spatial memory is dependent on time of exposure to spatial learning and age of cells at examination. Neurobiol Learn Mem 95: 316-325.

27. Hastings NB, Gould E (1999) Rapid extension of axons into the CA3 region by adult-generated granule cells. J Comp Neurol 413: 146-154.

28. Esposito MS, Piatti VC, Laplagne DA, Morgenstern NA, Ferrari CC, et al. (2005) Neuronal differentiation in the adult hippocampus recapitulates embryonic development. J Neurosci 25: 10074-10086.

29. Song H, Kempermann G, Overstreet Wadiche L, Zhao C, Schinder AF, et al. (2005) New neurons in the adult mammalian brain: synaptogenesis and functional integration. J Neurosci 25: 10366-10368. 
30. Hastings NB, Gould E (2003) Neurons inhibit neurogenesis. Nat Med 9: 264266.

31. Ramirez-Amaya V, Marrone DF, Gage FH, Worley PF, Barnes CA (2006) Integration of new neurons into functional neural networks. J Neurosci 26: 12237-12241.

32. Schmidt-Hieber C, Jonas P, Bischofberger J (2004) Enhanced synaptic plasticity in newly generated granule cells of the adult hippocampus. Nature 429: 184-187.

33. Kee N, Teixeira CM, Wang AH, Frankland PW (2007) Preferential incorporation of adult-generated granule cells into spatial memory networks in the dentate gyrus. Nat Neurosci 10: 355-362.

34. Tashiro A, Sandler VM, Toni N, Zhao C, Gage FH (2006) NMDA-receptormediated, cell-specific integration of new neurons in adult dentate gyrus. Nature 442: 929-933.

35. Tashiro A, Makino H, Gage FH (2007) Experience-specific functional modification of the dentate gyrus through adult neurogenesis: a critical period during an immature stage. J Neurosci 27: 3252-3259.

36. Sandoval CJ, Martinez-Claros M, Bello-Medina PC, Perez O, Ramirez-Amaya V (2011) When are new hippocampal neurons, born in the adult brain, integrated into the network that processes spatial information? PLoS One 6: e17689.

37. McEwen BS, Albeck D, Cameron H, Chao HM, Gould E, et al. (1995) Stress and the brain: a paradoxical role for adrenal steroids. Vitam Horm 51: 371402.

38. McEwen BS (1999) Stress and hippocampal plasticity. Annu Rev Neurosci 22: 105-122.

39. Galea LA, McEwen BS, Tanapat P, Deak T, Spencer RL, et al. (1997) Sex differences in dendritic atrophy of CA3 pyramidal neurons in response to chronic restraint stress. Neuroscience 81: 689-697.

40. Sandi C, Davies HA, Cordero MI, Rodriguez JJ, Popov VI, et al. (2003) Rapid reversal of stress induced loss of synapses in CA3 of rat hippocampus following water maze training. Eur J Neurosci 17: 2447-2456.

41. Stewart MG, Davies HA, Sandi C, Kraev IV, Rogachevsky VV, et al. (2005) Stress suppresses and learning induces plasticity in CA3 of rat hippocampus: a three-dimensional ultrastructural study of thorny excrescences and their postsynaptic densities. Neuroscience 131: 43-54.

42. Aguilar-Valles A, Sanchez E, de Gortari P, Balderas I, Ramirez-Amaya V, et al. (2005) Analysis of the stress response in rats trained in the water-maze: differential expression of corticotropin-releasing hormone, CRH-R1, glucocorticoid receptors and brain-derived neurotrophic factor in limbic regions. Neuroendocrinology 82: 306-319. 
43. Lemaire V, Koehl M, Le Moal M, Abrous DN (2000) Prenatal stress produces learning deficits associated with an inhibition of neurogenesis in the hippocampus. Proc Natl Acad Sci U S A 97: 11032-11037.

44. Brummelte S, Galea LA (2010) Chronic high corticosterone reduces neurogenesis in the dentate gyrus of adult male and female rats. Neuroscience 168: 680-690.

45. Pawluski JL, Brummelte S, Barha CK, Crozier TM, Galea LA (2009) Effects of steroid hormones on neurogenesis in the hippocampus of the adult female rodent during the estrous cycle, pregnancy, lactation and aging. Front Neuroendocrinol.

46. Mohapel P, Mundt-Petersen K, Brundin P, Frielingsdorf H (2006) Working memory training decreases hippocampal neurogenesis. Neuroscience 142: 609-613.

47. Nerad L (1997) Lesions of the posterior insular cortex impair water maze performance in the rat. Int J Neurosci 90: 1-7.

48. Ormerod BK, Galea LA (2001) Reproductive status influences cell proliferation and cell survival in the dentate gyrus of adult female meadow voles: a possible regulatory role for estradiol. Neuroscience 102: 369-379.

49. Pawluski JL, Galea LA (2007) Reproductive experience alters hippocampal neurogenesis during the postpartum period in the dam. Neuroscience 149: 53-67.

50. Strackx E, Van den Hove DL, Steinbusch HP, Steinbusch HW, Vles JS, et al. Fetal asphyxia leads to the loss of striatal presynaptic boutons in adult rats. Int J Dev Neurosci 28: 277-281.

51. Brummelte S, Pawluski JL, Galea LA (2006) High post-partum levels of corticosterone given to dams influence postnatal hippocampal cell proliferation and behavior of offspring: A model of post-partum stress and possible depression. Horm Behav 50: 370-382.

52. Rayen I, van den Hove DL, Prickaerts J, Steinbusch HW, Pawluski JL (2011) Fluoxetine during development reverses the effects of prenatal stress on depressive-like behavior and hippocampal neurogenesis in adolescence. PLoS One 6: e24003.

53. Galea LA, Wide JK, Barr AM (2001) Estradiol alleviates depressive-like symptoms in a novel animal model of post-partum depression. Behav Brain Res 122: 1-9.

54. Pawluski JL, van den Hove DL, Rayen I, Prickaerts J, Steinbusch HW (2011) Stress and the pregnant female: Impact on hippocampal cell proliferation, but not affective-like behaviors. Horm Behav 59: 572-580.

55. Gould E, Tanapat P (1999) Stress and hippocampal neurogenesis. Biol Psychiatry 46: 1472-1479.

56. Mirescu C, Gould E (2006) Stress and adult neurogenesis. Hippocampus 16: 233-238. 
57. Jessberger S, Clark RE, Broadbent NJ, Clemenson GD, Jr., Consiglio A, et al. (2009) Dentate gyrus-specific knockdown of adult neurogenesis impairs spatial and object recognition memory in adult rats. Learn Mem 16: 147154.

58. Dalla C, Bangasser DA, Edgecomb C, Shors TJ (2007) Neurogenesis and learning: acquisition and asymptotic performance predict how many new cells survive in the hippocampus. Neurobiol Learn Mem 88: 143-148.

59. Epp JR, Scott NA, Galea LA (2011) Strain differences in neurogenesis and activation of new neurons in the dentate gyrus in response to spatial learning. Neuroscience 172: 342-354.

60. Nilsson M, Perfilieva E, Johansson U, Orwar O, Eriksson PS (1999) Enriched environment increases neurogenesis in the adult rat dentate gyrus and improves spatial memory. J Neurobiol 39: 569-578.

61. Ehninger D, Kempermann G (2006) Paradoxical effects of learning the Morris water maze on adult hippocampal neurogenesis in mice may be explained by a combination of stress and physical activity. Genes Brain Behav 5: 2939.

62. Aztiria E, Capodieci G, Arancio L, Leanza G (2007) Extensive training in a maze task reduces neurogenesis in the adult rat dentate gyrus probably as a result of stress. Neurosci Lett 416: 133-137.

63. Aguilar-Valles A, Sanchez E, de Gortari P, Garcia-Vazquez Al, Ramirez-Amaya V, et al. (2007) The expression of TRH, its receptors and degrading enzyme is differentially modulated in the rat limbic system during training in the Morris water maze. Neurochem Int 50: 404-417.

64. Drapeau E, Mayo W, Aurousseau C, Le Moal M, Piazza PV, et al. (2003) Spatial memory performances of aged rats in the water maze predict levels of hippocampal neurogenesis. Proc Natl Acad Sci U S A 100: 14385-14390.

65. Kempermann G, Gage FH (2002) Genetic determinants of adult hippocampal neurogenesis correlate with acquisition, but not probe trial performance, in the water maze task. Eur J Neurosci 16: 129-136.

66. Snyder JS, Radik R, Wojtowicz JM, Cameron HA (2009) Anatomical gradients of adult neurogenesis and activity: young neurons in the ventral dentate gyrus are activated by water maze training. Hippocampus 19: 360-370. 



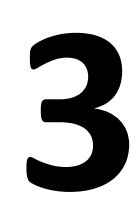

Adrenalectomy and

corticosterone replacement

differentially alter CA3 dendritic

morphology and new cell

survival in the adult rat

hippocampus

Martínez-Claros M

Steinbusch HWM

van Selm A

van den Hove DLA

Prickaerts J

Pawluski JL

Journal of Chemical Neuroanatomy, 2013,

in press 


\begin{abstract}
Plastic changes in the adult mammal hippocampus can be altered by many factors and perhaps the most well-documented is stress. Stress and elevated corticosterone levels have been shown to decrease hippocampal neurogenesis and decrease the complexity of CA3 pyramidal neurons. However, the extent of these changes in relation to low and moderately elevated levels of corticosterone has yet to be fully investigated. Therefore, the aim of the present study was to determine how low to moderately elevated circulating corticosterone levels affect dendritic morphology of CA3 pyramidal cells and hippocampal neurogenesis in adult male rats. To do this, three groups of adult male Wistar rats were used: 1 . Sham-operated, 2. Adrenalectomized (ADX), and 3. ADX + corticosterone replacement. Primary results show that adrenalectomy, but not moderately elevated levels of corticosterone replacement, resulted in significant atrophy of CA3 pyramidal neurons. Interestingly, moderate corticosterone replacement resulted in significantly more surviving new cells in the dentate gyrus when compared to sham controls. This work shows that circulating levels of corticosterone differentially affect plasticity in the CA3 region and the dentate gyrus.
\end{abstract}




\section{Introduction}

Currently, it is well accepted that neural plasticity in the central nervous system (CNS) is one of the fundamental mechanisms that underlies memory formation. The most important brain structure in the encoding, consolidation and retrieval of memories is the hippocampus [1,2]. Various forms of memory, such as spatial memory, rely on the functioning of the hippocampus and can be influenced by various factors like stress and elevated levels of corticosterone $[3,4]$. The hippocampus is sensitive to changes in corticosterone levels in response to stress. This stress effect is evidenced by changes in neurogenesis $[5,6]$, dendritic morphology, learning and memory $[7,8]$. In fact, several weeks of chronic stress, or repeated injections of high levels of corticosterone, cause atrophy in the apical dendrites of the pyramidal neurons in the CA3 region of the Ammon's horn in male rats $[9,10,11]$ and severe stress can also cause an overall reduction in the size of the hippocampus $[12,13,14,15,16,17,18]$. However, to date, very little is known about the effects of moderately elevated levels of glucocorticoids on dendritic morphology in the CA3 region of the hippocampus.

In addition, it has been well documented that corticosterone plays an important role in hippocampal neurogenesis $[6,19,20,21,22]$. For example, acute or chronic stress consistently results in decreased hippocampal neurogenesis in adult males. Interestingly, preventing the elevation of corticosterone levels during aging increases hippocampal neurogenesis in aged rats [23].

Previous work has also shown that adrenalectomy, and thus very low levels of corticosterone, have a beneficial effect on hippocampal neurogenesis $[24,25,26,27]$. Others have also shown that corticosterone replacement to adrenalectomized animals, that results in corticosterone levels equivalent to basal levels, reduces the increased levels of hippocampal cell proliferation seen with adrenalectomy [27]. However, the role corticosterone replacement on new cell survival in the hippocampus has yet to be fully determined. 
Eventhough the most marked effect of corticosterone action is on CA3 pyramidal cell morphology; these changes in morphology might be mediated through the excitatory innervation from the dentate gyrus (DG). The granule cells of the DG are highly dependent on corticosterone and without corticosterone many of these cells die [28]. Thus, corticosterone levels may influence the excitatory innervation from the DG to the CA3 and affect morphology of CA3 pyramidal neurons $[12,18,29]$. The relationship between circulating corticosterone levels, neurogenesis in the DG and subsequent CA3 morphology has yet to be assessed.

Although most studies have investigated the effects of stress and elevated levels of corticosterone on hippocampus plasticity, the aim of the present study was to investigate how low to moderately elevated levels of corticosterone affect hippocampus plasticity in both the DG and the CA3. To do this, adult male Wistar rats were used. Animals were divided into three groups: 1 . Sham-operated rats, 2. Adrenalectomized (ADX) rats and 3. rats exposed to $A D X+c o r t i c o s t e r o n e ~ r e p l a c e m e n t$. Hippocampal new cell survival was assessed in the DG using bromodeoxyuridine (BrdU), a marker for cell synthesis, and CA3 dendritic morphology was assessed using Golgi impregnation.

\section{Methods}

\section{Animals}

Seventeen adult male Wistar rats ( 3 months of age; Harlan, The Netherlands) were used in the present study. Animals were divided into three groups consisting as follows: $A D X+$ cort (adrenalectomized ( $A D X)$ receiving a corticosterone (CORT) pellet: $n=5), A D X$ ( $A D X$ receiving a placebo pellet: $n=5$ ), and sham (receiving a placebo pellet: $n=7)$. Adrenalectomy and sham surgeries were performed by the supplier (Harlan, The Netherlands) in a regular surgical setting, with aseptic technique, one week prior to shipping. ADX+cort animals were classified as receiving moderately elevated levels of corticosterone and ADX animals were classified as receiving low levels of corticosterone based on previous literature [26]. Corticosterone levels were taken to verify this (see Section 2.4). One 
week after the surgery, animals arrived in our laboratory and were singly housed in individually ventilated transparent polyurethane cages with controlled humidity $(42 \%)$ and temperature $\left(22^{\circ} \mathrm{C}\right)$ on corncob bedding on an inverted light-dark cycle (lights on at 19:00; lights off at 7:00h).

All animals had ad libitum access to pellet food (Sniff, The Netherlands) and tap water. ADX animals that were not receiving a corticosterone pellet had their water substituted with a saline solution $(9 \mathrm{~g} / \mathrm{l} \mathrm{NaCl})$. All experimental procedures were approved by the research ethics committee of Maastricht University for animal experiments (DEC 2008-159) and were in accordance with governmental guidelines.

\section{BrdU administration}

BrdU was used to detect new cells as previously described $[30,31,32,33]$. BrdU was administered to all animals in a total dosage of $200 \mathrm{mg} / \mathrm{kg}$ diluted in a basic saline solution $(\mathrm{pH} 8)$. One intraperitoneal (i.p.) injection of BrdU solution was done daily for 4 days $(50 \mathrm{mg} / \mathrm{kg} /$ day, $4 \mathrm{ml} / \mathrm{kg}$ ) between 8:00 and 10:00a.m.

\section{Pellet implantation}

All rats received a subcutaneous pellet implantation of $100 \mathrm{mg}$ release CORT ( $A D X+$ cort) or a placebo pellet (sham and $A D X$ ) (Innovative research of America, FL, USA) 15 days after the last BrdU injection. For pellet implantation, animals were briefly anesthetized with isofluorane, a small incision was made, and a pellet was placed subcutaneously in the dorsal region of the rat. The incision was sutured after pellet implantation. For a timeline, see Figure 1. 


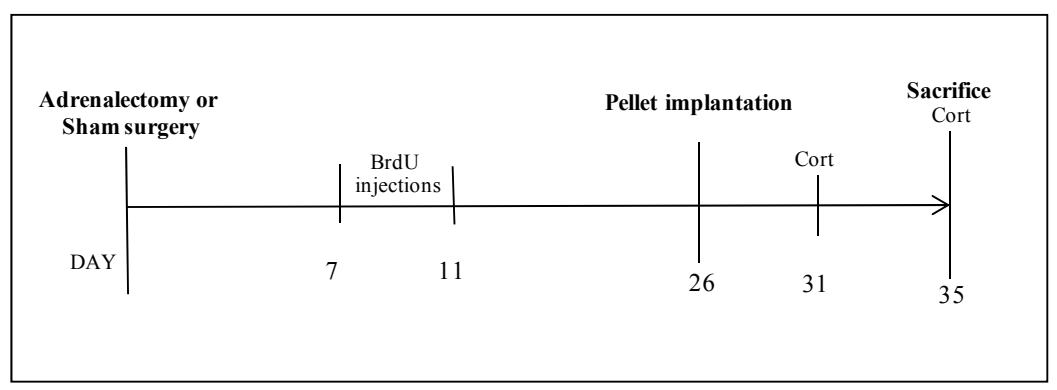

Figure 1. Timeline of experiment. Animals arrived on day zero to our laboratory vivarium. ADX and sham operated animals were injected with BrdU once daily from day 7 until day 11. Corticosterone pellet implantations were performed 15 days after the last BrdU injection. Blood samples for corticosterone measurements were taken five days after pellet implantation and immediately before sacrifice.

\section{Corticosterone levels}

Blood samples for corticosterone levels were taken, via tail nicks, at two time points, i.e.,five days after the pellet implantation and immediately before sacrifice (between 8am and $11 \mathrm{am}$ ). Each blood collection was timed to not exceed 3 minutes as corticosterone levels are elevated after 3 minutes of handling $[34,35,36]$. Approximately $300 \mu \mathrm{l}$ of blood were collected in heparanized tubes (Microvette ${ }^{\circledR}$ CB 300, Sarstedt, Germany). Samples were centrifuged for 5 minutes at $4000 \mathrm{rpm}$ at $4^{\circ} \mathrm{C}$ and plasma was collected and stored at $-80^{\circ} \mathrm{C}$. Total plasma corticosterone levels were detected by radioimmunoassay using the Double Antibody ${ }^{125}$ I RIA Kit for rat corticosterone (MP Biomedicals, Orangeburg, NY). All samples were run in duplicate. The average intra-assay coefficient of variation for all assays was below $10 \%$. The assay had a sensitivity of $7.7 \mathrm{ng} / \mathrm{ml}$. Plasma corticosterone levels were averaged across the two timepoints and used for analysis.

\section{Histological procedures}

Four weeks after BrdU injections, and two weeks after corticosterone pellet implantation, all animals were sacrificed by rapid decapitation. Brains were carefully extracted and the right hemispheres of the brains were used for Golgi impregnation. The left hemispheres of the brains were frozen in 2-methylbutane (Sigma) immersed in a slurry of dry ice and ethanol. The left hemisphere of 
the brains was stored at $-80^{\circ} \mathrm{C}$ to be used for BrdUimmunohistochemistry [33].

\section{Golgi impregnation}

The right hemispheres of the brains were processed for Golgi impregnation using the FD Rapid GolgiStain Kit $^{\text {TM }}$ (FD Neurotechnologies Consulting \& Services, Elliot City, MD) adapted for vibratome $[37,38]$. Briefly, at decapitation $1 \mathrm{~cm}$ blocks of brain tissue were rinsed with distilled water and immersed in impregnation solution containing potassium dichromate, mercuric chloride and potassium chromate. Brains were left undisturbed in the dark for 2.5 weeks. After the 2.5 weeks, brains were immersed in $30 \%$ of sucrose at $4^{\circ} \mathrm{C}$. Two to four days later coronal sections $(200 \mu \mathrm{m})$ were cut using a vibratome (Leica VT6000) in a bath of $15 \%$ sucrose and the slices stored in the dark at $4^{\circ} \mathrm{C}$ in $15 \%$ sucrose solution until mounting. Sections were mounted on gelatin-coated slides and firmly pressed using moist filter paper to prevent the slices from falling off the slide during development [38]. Slides were placed in a humidity chamber in the dark and were stored at $4^{\circ} \mathrm{C}$ over night. For development, slides were rinsed with distilled water twice for 2 min and then placed in developing solutions provided in the FD GolgiStain Kit, dehydrated via graded alcohol series (50\%-96\%, 4min each rinse), cleared with xylene for 8 minutes, and coverslipped with Permount $^{\circledR}$.

An experimenter blind to conditions analyzed dendritic morphology in the CA3 region of the hippocampus. Dendritic length and number of branch points were analyzed as previously described $[9,39,40,41]$. For analysis of dendritic morphology, a pyramidal cell had to meet the following criteria: 1 . the cell body and its dendrites had to be fully impregnated; 2 . the cell had to be relatively isolated from any other cells to obtain a clear image of the entire cell; 3 . the cell had to be located in the CA3 region of the dorsal hippocampus (Figure 3A). For analysis, a light microscope with a drawing tube was used to draw the cells and the Neurolucida program (MicroBrightField Inc.) was used to analyze, the drawings. The following variables were measured in both apical and basal regions 
of each cell: the number of branch points and the total dendritic length. Six CA3 pyramidal cells from each brain were analyzed based on previous work $[9,39]$. Pyramidal cells were sampled throughout the dorsal region of the hippocampus.

\section{BrdU Immunohistochemistry}

Frozen brain hemisections of the left dorsal hippocampus from six to eight rats were molded in a block with Tissue-Tek (Sakura, EU) in a plastic container as previously described [32,33]. Each block included brains from all groups. The blocks were cryosectioned into $20 \mu \mathrm{m}$ thick coronal sections, mounted on Superfrost Plus slides (VWR) dried, and stored at $-80^{\circ} \mathrm{C}$ until staining.

For immunohistochemistry, the tissue was fixed in $2 \%$ paraformaldehyde, $\mathrm{pH} 7.4$, for $5 \mathrm{~min}$, washed in TBS, $\mathrm{pH} 7.0$, and quenched in TBS with $2 \% \mathrm{H} 2 \mathrm{O} 2$ for $15 \mathrm{~min}$. For the detection of $\mathrm{BrdU}$, the DNA was denatured with a $50 \%$ formamide in $2 x$ SSC buffer (Sigma) at $65^{\circ} \mathrm{C}$ for $2 \mathrm{~h}$, washed in $2 \mathrm{x}$ SSC for $10 \mathrm{~min}$, incubated in $2 \mathrm{~N} \mathrm{HCl}$ at $37^{\circ} \mathrm{C}$ for $30 \mathrm{~min}$, and washed in $0.1 \mathrm{M}$ boric acid, $\mathrm{pH} 8.5$, for $10 \mathrm{~min}$. After blocking with 3\% normal donkey serum (NDS,Sigma The Netherlands) the slides were incubated with mouse anti-BrdU monoclonal antibody (1:100+ 3\%NDS+ 10\%Triton$X$; Roche Products, Welwyn Garden City, UK). The mouse anti-BrdU antibody was detected after one day of incubation with a donkey anti-mouse secondary antibody incubated for 4 hours at room temperature (1:500 + 3\% NDS; Vector Laboratories). The brain tissue was further processed for immunohistochemistry by using the avidine-biotin complex ( $A B C$ Elite kit; 1:1000; Vector laboratories) for 2 hours. To complete the staining, 3,3-diaminobenzidine (DAB; Sigma, The Netherlands) was used as a substrate to obtain a color.

To estimate cell numbers, total BrdU-immunoreactive (-ir) cells were counted under a $60 \times$ objective with oil on every 12 th section (approx. 9-10 sections per rat). The BrdU-ir cells were counted in the granular cell layer $(\mathrm{GCL})$ and in the hilus to determine whether effects are due to generalized effects on blood brain permeability. Cells were considered BrdU-ir if they were intensely stained and exhibited medium round or oval cell bodies (Figure 4A $[30,42,43]$ ). 
We did not determine whether the new BrdU-labelled cells were new neurons, as the majority of BrdU-labeled cells after 3 weeks of age generally are new neurons [43].

\section{Statistical analysis}

A one-way analysis of variance test (ANOVA) was done on the average corticosterone levels with group (Sham, ADX, ADX+cort) as the between subjects factor. One way ANOVAs were also done to determine differences in the number of CA3 apical and basal branching points and dendritic lengths between groups (Sham, ADX, $A D X+c o r t)$. A repeated measures ANOVA was calculated for density of BrdU-ir cells in the dorsal dentate gyrus with region (GCL and hilus) as the within subjects factor and group (Sham, ADX, ADX+cort) as the between subjects factor. Correlations were assessed between corticosterone levels and measures of hippocampal plasticity (CA3 morphology and BrdU-ir cells) using Pearson's correlation analysis. Post-hoc comparisons utilized the Fisher LSD test.

\section{Results}

Corticosterone levels. As expected there was a significant difference between groups in average serum corticosterone levels $(F(2,14)=$ 4.97, $p=.023$; Figure 2 ), with ADX animals having significantly lower serum levels of corticosterone compared to sham and $A D X+$ cort animals $(.01<p<.02)$. There were no other significant differences between groups in corticosterone levels. 


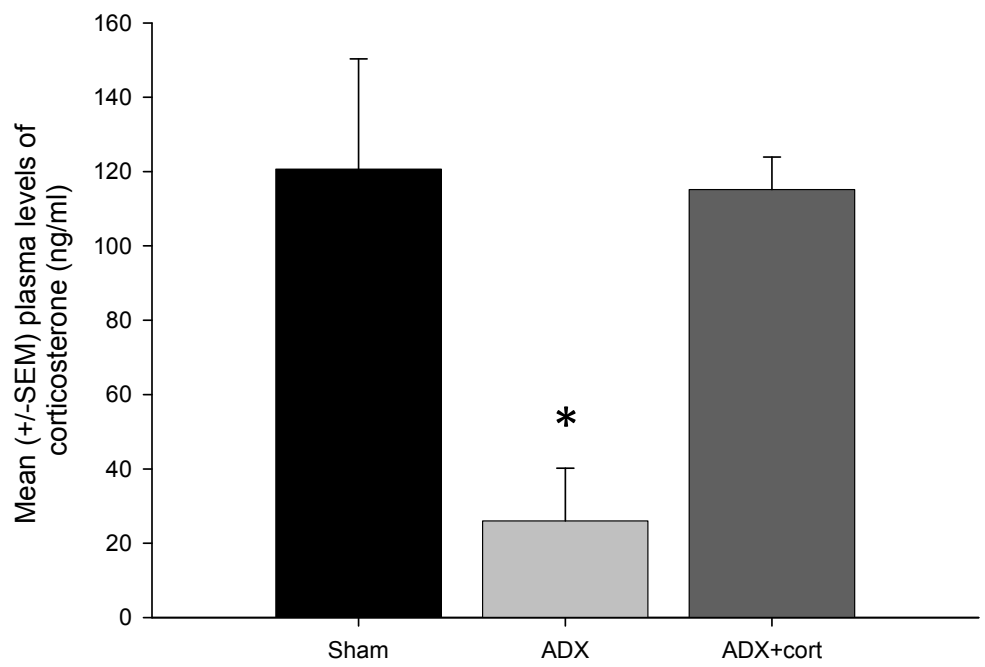

Figure 2. Mean ( \pm SEM) serum levels of corticosterone $(\mathrm{ng} / \mathrm{ml})$. There was a significant difference between groups, with ADX animals having significantly lower serum levels of corticosterone compared to sham and $A D X+$ cort animals. ${ }^{*}$ denotes significantly different from all other groups. ( $\left.n=5-7 / g r o u p\right)$.

CA3 dendritic morphology. There were significant differences in the percentage of change from sham animals in CA3 apical dendritic length $(F(2,15)=3.87, p=0.044$; Figure 3$)$ with $A D X$ animals having the greatest change in apical dendritic length compared to sham and $A D X+c o r t$ animals. There were no other significant differences between groups regarding basal dendritic length (Figure 3), number of apical branch points or number of basal branch points $(0.40<p<$ 0.88 ; Table 1). There were also no significant correlations between serum corticosterone levels and measures of CA3 dendritic morphology $(0.13<p<0.78)$. 
Table 1. Mean ( \pm SEM) percent change from sham controls in apical branch points, basal branch points and basal dendritic length in the CA3 region of the hippocampus. There were no significant differences between groups.

\begin{tabular}{|c|c|c|c|}
\hline & $\begin{array}{c}\text { \% change in number of } \\
\text { apical branch points }\end{array}$ & $\begin{array}{c}\text { \% change in number of } \\
\text { basal branch points }\end{array}$ & $\begin{array}{c}\text { \% change in } \\
\text { basal length }\end{array}$ \\
\hline Sham & $0 \pm 7$ & $0 \pm 8$ & $0 \pm 9$ \\
\hline ADX & $-15 \pm 8$ & $-0 \pm 13$ & $-8 \pm 9$ \\
\hline ADX+cort & $-8 \pm 9$ & $-7 \pm 11$ & $5 \pm 5$ \\
\hline
\end{tabular}

BrdU-ir cells in the dentate gyrus. There was a tendency toward an interaction effect between region and groups $(p=0.074)$. There was also a significant main effect of region $(F(1,14)=42.11, p=0.0001)$ with significantly more BrdU-labeled cells in the $\mathrm{GCL}$ compared to the hilus. However, a priori, we expected there would be a difference in hippocampal neurogenesis between groups due to well-known effects of corticosterone on hippocampal neurogenesis $[6,19]$. A priori tests revealed that $A D X+$ cort animals had significantly more BrdU-labeled cells in the GCL compared to sham animals ( $p=$ .014; Figure 4). There were no significant correlations between serum corticosterone levels and BrdU-ir cells $(0.12<p<0.14)$. 
A)
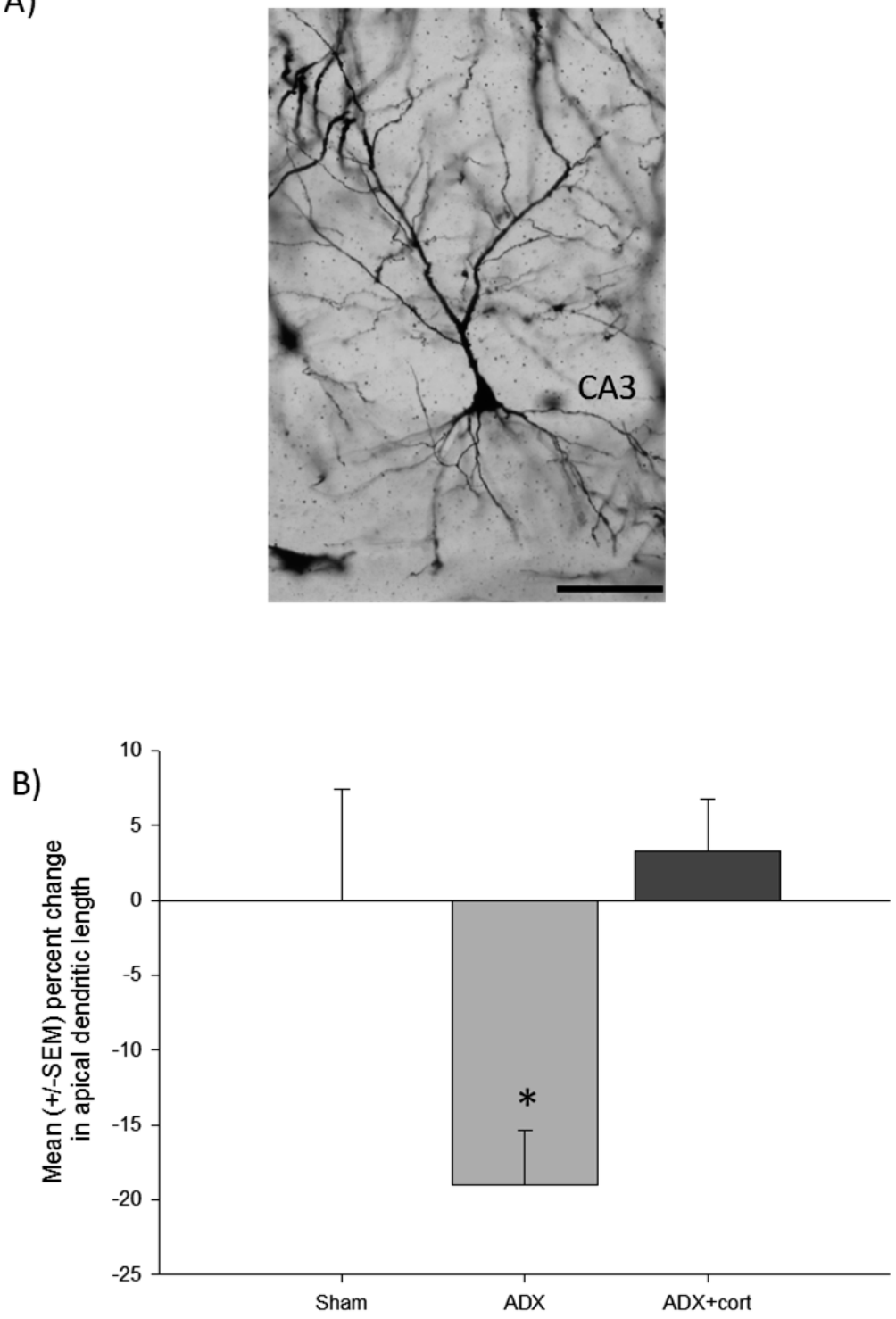

Figure 3. A) Photomicrograph of a hippocampal CA3 pyramidal cell at 10x. The scale bar represents 100 $\mu \mathrm{m}$. B) Mean ( \pm SEM) percent change in CA3 apical dendritic length. There was a significant difference in the percentage of change in the CA3 apical dendritic length, with ADX animals having decreased apical dendritic length compared to sham and $A D X+$ cort animals. * denotes significantly different from all other groups. ( $n=5-7 /$ group). 
A)
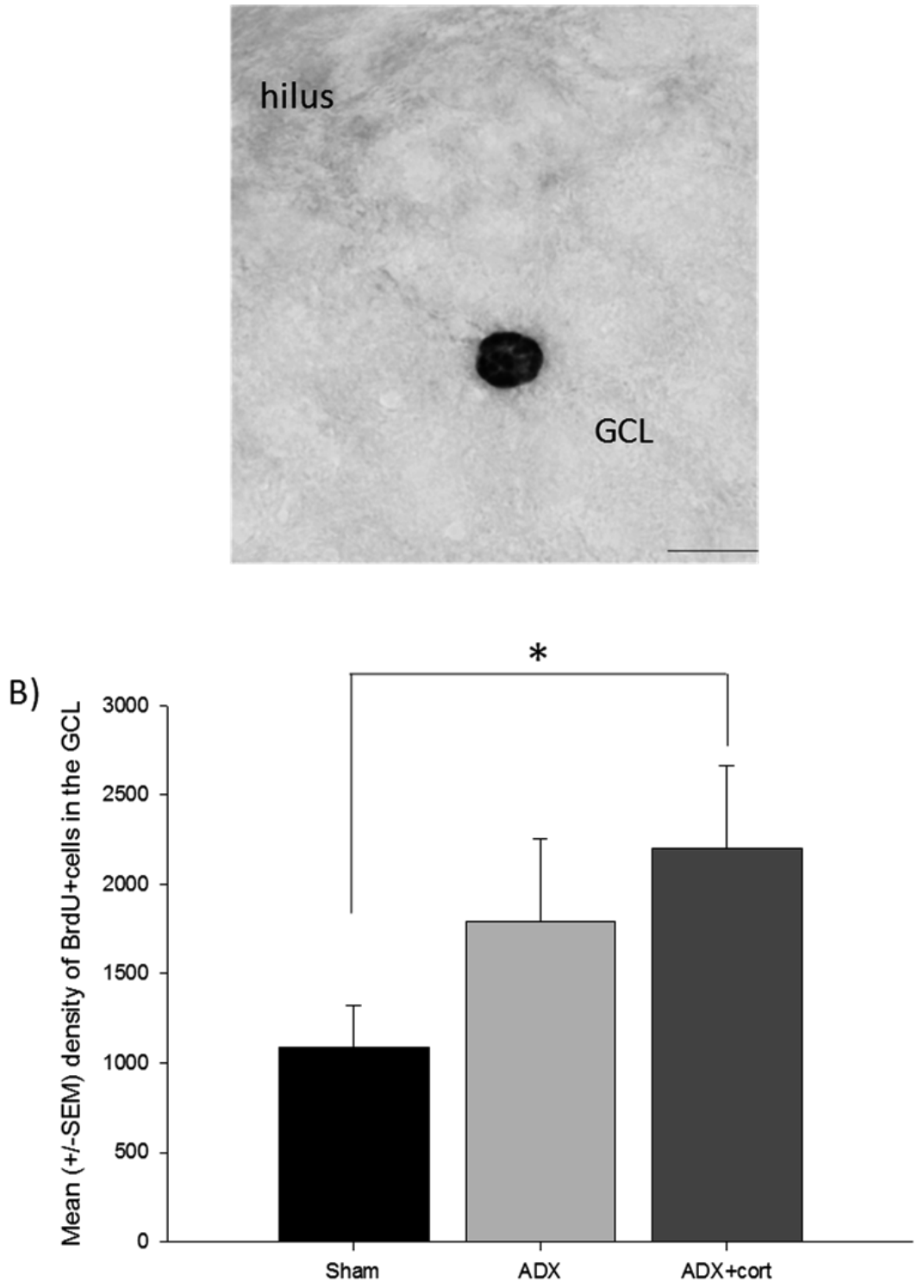

Figure4. A) Photomicrograph of a BrdU-ir cell in the GCL of the hippocampus at 100x. The scale bar represents $10 \mu \mathrm{m}$. B) Mean ( \pm SEM) density of BrdU-ir cells in the $G C L$ of the hippocampus. Sham animals had significantly fewer BrdU-ir cells in the GCL compared to ADX+cort animals. ( $n=5-7 /$ group). 


\section{Discussion}

In the present study, we found that low corticosterone levels, as resulting from adrenalectomy, significantly decreased dendritic complexity in the apical region of CA3 neurons compared to sham controls and ADX animals receiving moderately elevated corticosterone replacement. Interestingly, both adrenalectomy and moderately elevated corticosterone replacement appeared to increase new cell survival in the DG compared to controls. As expected basal serum corticosterone levels in the adrenalectomized rats were significantly lower compared with the controls and ADX animals receiving moderately elevated corticosterone replacement.

Effects of corticosterone levels on CA3 dendritic morphology.

Previous work has shown that stress and high corticosterone levels consistently decrease apical dendritic branches and length in the apical region of CA3 pyramidal neurons in adult male rodents $[9,29,44]$. We found that adrenalectomy, and consequently low levels of corticosterone, also resulted in apical dendritic atrophy in CA3 region of the hippocampus. Taken together, these findings show that low and high levels of corticosterone decrease apical dendritic arborization of CA3 pyramidal neurons compared to replacement with moderate levels of corticosterone, or naturally circulating levels of corticosterone in non-stressed animals.

This suggests an inverted U-shape relationship between corticosterone levels and dendritic complexity of neurons in the CA3 region, with sustained high or low levels of corticosterone resulting in dendritic atrophy. Clinical research has also shown that hippocampal atrophy and neuronal loss can occur with prolonged high levels of stress or high levels of cortisol, as seen in Cushing's syndrome and major depression $[13,45,46,47]$.

Adrenalectomy, and low glucocorticoid levels, have also been linked to decreased memory performance on hippocampusdependent tasks in adult rats [4]. Therefore, it is possible that CA3 dendritic atrophy contributes to these deficits in memory function. The exact role of glucocorticoids and glucocorticoid receptors in these effects have yet to be fully determined, but it is clear that an 
optimal level of corticosterone is needed to prevent hippocampal neuronal atrophy from occurring and with it the detrimental effects in cognition and memory.

Effects of corticosterone replacement on new cell survival in the DG. In the present study, we found that adrenalectomy, regardless of subsequent corticosterone replacement, increased new cell survival in the adult dentate gyrus when compared to sham control animals. It has been previously shown that both proliferation and survival of newborn cells in the dentate gyrus are increased after adrenalectomy $[23,24,26,27,48,49,50,51]$. This effect of increased hippocampal cell proliferation can be reversed with corticosterone treatment [27]. However, weeks after adrenalectomy the increase in hippocampal cell proliferation is no longer evident [26]. Thus, our work extends these previous findings by showing that moderately elevated corticosterone replacement in adrenalectomized animals, weeks after adrenalectomy, significantly increases new cell survival in the hippocampus when compared to sham control animals. In addition, adrenalectomy itself appeared to increase cell survival compared to sham controls, however this effect did not reach significance.

Previous work has shown that the initial increase in hippocampal cell proliferation soon after adrenalectomy likely acts to compensate for the significant loss of granule cells through apoptosis $[28,49,52]$. Apoptosis is a phenomenon strongly related with hippocampal neurogenesis, as only half of the new cells produced will survive within 28 days $[53,54,55,56]$. With adrenalectomy, increased cell death in the dentate gyrus is evident up to 10 days following the procedure[28,52,57,58,59]. Therefore adrenalectomy, itself appears to initially result in enhanced cell birth, through the lack of adrenal steroids, and the increased degeneration of cells. However, this increase in cell proliferation and cell death in the dentate gyrus after adrenalectomy is not long lasting [26,58]. In the present study, it is likely that cell proliferation and cell death rates between adrenalectomised animals and sham controls were similar at the time of the corticosterone treatment. However, we 
show that adrenalectomised animals have increased new cell survival and that moderately elevated corticosterone treatment after progenitor devision enhances this new cell survival. Previous research has shown that low or high levels of corticosterone prior to progenitor division can decrease the survival rate of new cells $[56,60]$. Our work extends these previous findings and demonstrates that the timing and level of corticosterone differentially alters new cell survival in the hippocampus.

Regarding the mechanisms underlying the effect of glucocorticoids on hippocampal neurogenesis, it is important to mention the differential activation of both the mineralocorticoid (MR) and glucocorticoid (GR) receptors in the dentate gyrus. The stimulation of the MR is sufficient to mediate the effects of corticosterone on neurogenesis, reducing cell proliferation [27] and protecting mature cells from death [61]. The activation of the MR has also a long term trophic effect on the dentate gyrus [62]. The activation of the GR modulates different molecules, such as PSANCAM, that are associated with the maintenance of plasticity, activity induced plasticity and cognitive functions [61]. The GR also play a key role in mediating the synaptic connectivity and functional integration of newborn hippocampal neurons into mature hippocampal circuits [63]. In the present study it is likely that the corticosterone replacement after progenitor division further enhanced new cell survival through activation of both the GR and $M R$, but further work is needed in this area [56].

Relationship between corticosterone levels, the CA3 and DG.

In recent studies, it has been shown that there is a strong relationship between neurogenesis in the DG, the plasticity of CA3 and cognition $[64,65,66,67,68,69,70,71,72]$. In turn, corticosterone plays an important role in all three of these factors. Therefore, our aim was to discover the consequences of the different levels of corticosterone on new cell survival in the DG and CA3 morphology.

Here we show that corticosterone levels differentially affect neural morphology of CA3 cells and new cell survival in the DG with the greatest variation between the $C A 3$ and $D G$ in the sham 
operated and adrenalectomized animals. These animals showed opposite effects in the CA3 and DG. For example, we found that sham operated animals had decreased new cell survival, but no change in cell morphology in the CA3, whereas adrenalectomized animals had increased new cell survival but decreased cell complexity in the CA3. These differences may be related to differences in cognitive function. For example, in the study of Lanfield [50] the behavior of adrenalectomized animals was tested and compared with young and old animals, and they didn't show improved cognition. Therefore, it may be that increased number of new cells surviving in the hippocampus of adrenalectomized animals, as found in the present study, does not improve memory performance due to a lack of integration of these cells into the neuronal network, disrupting their connectivity and physiology. In addition, it may be that the structure and function of the mature granule neurons are altered with changes in the glucocorticoid environment.

\section{Conclusions}

Findings of the present study show that low and moderately elevated corticosterone levels differentially affect plasticity in both the CA3 and DG. Here we show that adrenalectomized animals have decreased dendritic complexity in the apical region of CA3, but they have an increased number of surviving new cells in the DG, regardless of moderately elevated corticosterone replacement.

Future work should look at the function of CA3 pyramidal cells and the role of cell death in the hippocampal circuitry in order to determine the physiological consequences related to our morphological findings. 


\section{References}

1. Nadel L (1987) A brain structure: the hippocampus. Science 235: 1682a.

2. Scoville WB, Milner B (2000) Loss of recent memory after bilateral hippocampal lesions. 1957. J Neuropsychiatry Clin Neurosci 12: 103-113.

3. Shors TJ (2001) Acute stress rapidly and persistently enhances memory formation in the male rat. Neurobiol Learn Mem 75: 10-29.

4. Spanswick SC, Epp JR, Keith JR, Sutherland RJ (2007) Adrenalectomy-induced granule cell degeneration in the hippocampus causes spatial memory deficits that are not reversed by chronic treatment with corticosterone or fluoxetine. Hippocampus 17: 137-146.

5. Gould E, Woolley CS, Cameron HA, Daniels DC, McEwen BS (1991) Adrenal steroids regulate postnatal development of the rat dentate gyrus: II. Effects of glucocorticoids and mineralocorticoids on cell birth. J Comp Neurol 313: 486-493.

6. Mirescu C, Gould E (2006) Stress and adult neurogenesis. Hippocampus 16: 233238.

7. Magarinos AM, McEwen BS (1995) Stress-induced atrophy of apical dendrites of hippocampal CA3C neurons: comparison of stressors. Neuroscience 69: 83-88.

8. McEwen BS (1999) Stress and hippocampal plasticity. Annu Rev Neurosci 22: 105-122.

9. Galea LA, McEwen BS, Tanapat P, Deak T, Spencer RL, et al. (1997) Sex differences in dendritic atrophy of CA3 pyramidal neurons in response to chronic restraint stress. Neuroscience 81: 689-697.

10. Gould E, Woolley CS, Frankfurt M, McEwen BS (1990) Gonadal steroids regulate dendritic spine density in hippocampal pyramidal cells in adulthood. J Neurosci 10: 1286-1291.

11. Luine VN, Spencer RL, McEwen BS (1993) Effects of chronic corticosterone ingestion on spatial memory performance and hippocampal serotonergic function. Brain Res 616: 65-70.

12. Watanabe Y, Gould E, McEwen BS (1992) Stress induces atrophy of apical dendrites of hippocampal CA3 pyramidal neurons. Brain Res 588: 341-345.

13. Bodnoff SR, Humphreys AG, Lehman JC, Diamond DM, Rose GM, et al. (1995) Enduring effects of chronic corticosterone treatment on spatial learning, synaptic plasticity, and hippocampal neuropathology in young and midaged rats. J Neurosci 15: 61-69.

14. Coburn-Litvak PS, Tata DA, Gorby HE, McCloskey DP, Richardson G, et al. (2004) Chronic corticosterone affects brain weight, and mitochondrial, but not glial volume fraction in hippocampal area CA3. Neuroscience 124: 429438. 
15. Magarinos AM, Verdugo JM, McEwen BS (1997) Chronic stress alters synaptic terminal structure in hippocampus. Proc Natl Acad Sci U S A 94: 1400214008.

16. Sapolsky RM, Krey LC, McEwen BS (1985) Prolonged glucocorticoid exposure reduces hippocampal neuron number: implications for aging. J Neurosci 5: 1222-1227.

17. Watanabe Y, Gould E, Cameron HA, Daniels DC, McEwen BS (1992) Phenytoin prevents stress- and corticosterone-induced atrophy of CA3 pyramidal neurons. Hippocampus 2: 431-435.

18. Woolley CS, Gould E, Frankfurt M, McEwen BS (1990) Naturally occurring fluctuation in dendritic spine density on adult hippocampal pyramidal neurons. J Neurosci 10: 4035-4039.

19. Mirescu C, Peters JD, Noiman L, Gould E (2006) Sleep deprivation inhibits adult neurogenesis in the hippocampus by elevating glucocorticoids. Proc Natl Acad Sci U S A 103: 19170-19175.

20. McEwen BS, Gould E (1990) Adrenal steroid influences on the survival of hippocampal neurons. Biochem Pharmacol 40: 2393-2402.

21. Brummelte S, Galea LA (2010) Chronic high corticosterone reduces neurogenesis in the dentate gyrus of adult male and female rats. Neuroscience 168: 680-690.

22. Gould E, Cameron HA, Daniels DC, Woolley CS, McEwen BS (1992) Adrenal hormones suppress cell division in the adult rat dentate gyrus. J Neurosci 12: 3642-3650.

23. Montaron MF, Drapeau E, Dupret D, Kitchener P, Aurousseau C, et al. (2006) Lifelong corticosterone level determines age-related decline in neurogenesis and memory. Neurobiol Aging 27: 645-654.

24. Cameron HA, Gould E (1994) Adult neurogenesis is regulated by adrenal steroids in the dentate gyrus. Neuroscience 61: 203-209.

25. Montaron MF, Petry KG, Rodriguez JJ, Marinelli M, Aurousseau C, et al. (1999) Adrenalectomy increases neurogenesis but not PSA-NCAM expression in aged dentate gyrus. Eur J Neurosci 11: 1479-1485.

26. Spanswick SC, Epp JR, Sutherland RJ (2011) Time-course of hippocampal granule cell degeneration and changes in adult neurogenesis after adrenalectomy in rats. Neuroscience 190: 166-176.

27. Wong EY, Herbert J (2005) Roles of mineralocorticoid and glucocorticoid receptors in the regulation of progenitor proliferation in the adult hippocampus. Eur J Neurosci 22: 785-792.

28. Sloviter RS, Valiquette G, Abrams GM, Ronk EC, Sollas AL, et al. (1989) Selective loss of hippocampal granule cells in the mature rat brain after adrenalectomy. Science 243: 535-538.

29. Woolley CS, Gould E, McEwen BS (1990) Exposure to excess glucocorticoids alters dendritic morphology of adult hippocampal pyramidal neurons. Brain Res 531: 225-231. 
30. Pawluski JL, Galea LA (2007) Reproductive experience alters hippocampal neurogenesis during the postpartum period in the dam. Neuroscience 149: 53-67.

31. Pawluski JL, van den Hove DL, Rayen I, Prickaerts J, Steinbusch HW (2011) Stress and the pregnant female: Impact on hippocampal cell proliferation, but not affective-like behaviors. Horm Behav 59: 572-580.

32. Sandoval CJ, Martinez-Claros M, Bello-Medina PC, Perez O, Ramirez-Amaya V (2011) When are new hippocampal neurons, born in the adult brain, integrated into the network that processes spatial information? PLoS One 6: e17689.

33. Ramirez-Amaya V, Vazdarjanova A, Mikhael D, Rosi S, Worley PF, et al. (2005) Spatial exploration-induced Arc mRNA and protein expression: evidence for selective, network-specific reactivation. J Neurosci 25: 1761-1768.

34. Pawluski JL, Brummelte S, Barha CK, Crozier TM, Galea LA (2009) Effects of steroid hormones on neurogenesis in the hippocampus of the adult female rodent during the estrous cycle, pregnancy, lactation and aging. Front Neuroendocrinol.

35. Pawluski JL, Charlier TD, Lieblich SE, Hammond GL, Galea LA (2009) Reproductive experience alters corticosterone and CBG levels in the rat dam. Physiol Behav 96: 108-114.

36. Vahl TP, Ulrich-Lai YM, Ostrander MM, Dolgas CM, Elfers EE, et al. (2005) Comparative analysis of ACTH and corticosterone sampling methods in rats. Am J Physiol Endocrinol Metab 289: E823-828.

37. Dalla C, Whetstone AS, Hodes GE, Shors TJ (2009) Stressful experience has opposite effects on dendritic spines in the hippocampus of cycling versus masculinized females. Neurosci Lett 449: 52-56.

38. Gibb R, Kolb B (1998) A method for vibratome sectioning of Golgi-Cox stained whole rat brain. J Neurosci Methods 79: 1-4.

39. Pawluski JL, Galea LA (2006) Hippocampal morphology is differentially affected by reproductive experience in the mother. J Neurobiol 66: 71-81.

40. Pawluski JL, Vanderbyl BL, Ragan K, Galea LA (2006) First reproductive experience persistently affects spatial reference and working memory in the mother and these effects are not due to pregnancy or 'mothering' alone. Behav Brain Res 175: 157-165.

41. Pawluski JL, Walker SK, Galea LA (2006) Reproductive experience differentially affects spatial reference and working memory performance in the mother. Horm Behav 49: 143-149.

42. Ormerod BK, Galea LA (2001) Reproductive status influences cell proliferation and cell survival in the dentate gyrus of adult female meadow voles: a possible regulatory role for estradiol. Neuroscience 102: 369-379.

43. Brown JP, Couillard-Despres S, Cooper-Kuhn CM, Winkler J, Aigner L, et al. (2003) Transient expression of doublecortin during adult neurogenesis. J Comp Neurol 467: 1-10. 
44. Conrad CD, McLaughlin KJ, Harman JS, Foltz C, Wieczorek L, et al. (2007) Chronic glucocorticoids increase hippocampal vulnerability to neurotoxicity under conditions that produce CA3 dendritic retraction but fail to impair spatial recognition memory. J Neurosci 27: 8278-8285.

45. Lucassen PJ, Muller MB, Holsboer F, Bauer J, Holtrop A, et al. (2001) Hippocampal apoptosis in major depression is a minor event and absent from subareas at risk for glucocorticoid overexposure. Am J Pathol 158: 453-468.

46. Belanoff JK, Gross K, Yager A, Schatzberg AF (2001) Corticosteroids and cognition. J Psychiatr Res 35: 127-145.

47. Lupien SJ, de Leon M, de Santi S, Convit A, Tarshish C, et al. (1998) Cortisol levels during human aging predict hippocampal atrophy and memory deficits. Nat Neurosci 1: 69-73.

48. Cameron HA, Gould E (1996) Distinct populations of cells in the adult dentate gyrus undergo mitosis or apoptosis in response to adrenalectomy. J Comp Neurol 369: 56-63.

49. Krugers HJ, van der Linden S, van Olst E, Alfarez DN, Maslam S, et al. (2007) Dissociation between apoptosis, neurogenesis, and synaptic potentiation in the dentate gyrus of adrenalectomized rats. Synapse 61: 221-230.

50. Landfield PW, Baskin RK, Pitler TA (1981) Brain aging correlates: retardation by hormonal-pharmacological treatments. Science 214: 581-584.

51. Meaney MJ, Aitken DH, van Berkel C, Bhatnagar S, Sapolsky RM (1988) Effect of neonatal handling on age-related impairments associated with the hippocampus. Science 239: 766-768.

52. Jaarsma D, Postema F, Korf J (1992) Time course and distribution of neuronal degeneration in the dentate gyrus of rat after adrenalectomy: a silver impregnation study. Hippocampus 2: 143-150.

53. Cameron HA, McKay RD (2001) Adult neurogenesis produces a large pool of new granule cells in the dentate gyrus. J Comp Neurol 435: 406-417.

54. Cameron HA, Woolley CS, McEwen BS, Gould E (1993) Differentiation of newly born neurons and glia in the dentate gyrus of the adult rat. Neuroscience 56: 337-344.

55. Dayer AG, Ford AA, Cleaver KM, Yassaee M, Cameron HA (2003) Short-term and long-term survival of new neurons in the rat dentate gyrus. J Comp Neurol 460: 563-572.

56. Wong EY, Herbert J (2004) The corticoid environment: a determining factor for neural progenitors' survival in the adult hippocampus. Eur J Neurosci 20: 2491-2498.

57. Sloviter RS, Dean E, Neubort S (1993) Electron microscopic analysis of adrenalectomy-induced hippocampal granule cell degeneration in the rat: apoptosis in the adult central nervous system. J Comp Neurol 330: 337351. 
58. Gould E, Woolley CS, McEwen BS (1990) Short-term glucocorticoid manipulations affect neuronal morphology and survival in the adult dentate gyrus. Neuroscience 37: 367-375.

59. Sloviter RS, Sollas AL, Dean E, Neubort S (1993) Adrenalectomy-induced granule cell degeneration in the rat hippocampal dentate gyrus: characterization of an in vivo model of controlled neuronal death. J Comp Neurol 330: 324336.

60. Heine VM, Maslam S, Zareno J, Joels M, Lucassen PJ (2004) Suppressed proliferation and apoptotic changes in the rat dentate gyrus after acute and chronic stress are reversible. Eur J Neurosci 19: 131-144.

61. Montaron MF, Piazza PV, Aurousseau C, Urani A, Le Moal M, et al. (2003) Implication of corticosteroid receptors in the regulation of hippocampal structural plasticity. Eur J Neurosci 18: 3105-3111.

62. Gass P, Kretz O, Wolfer DP, Berger S, Tronche F, et al. (2000) Genetic disruption of mineralocorticoid receptor leads to impaired neurogenesis and granule cell degeneration in the hippocampus of adult mice. EMBO Rep 1: 447451.

63. Fitzsimons $C P$, van Hooijdonk LW, Schouten $M$, Zalachoras I, Brinks V, et al. (2012) Knockdown of the glucocorticoid receptor alters functional integration of newborn neurons in the adult hippocampus and impairs fear-motivated behavior. Mol Psychiatry.

64. Abrous DN, Koehl M, Le Moal M (2005) Adult neurogenesis: from precursors to network and physiology. Physiol Rev 85: 523-569.

65. Aimone JB, Wiles J, Gage FH (2009) Computational influence of adult neurogenesis on memory encoding. Neuron 61: 187-202.

66. Becker S (2005) A computational principle for hippocampal learning and neurogenesis. Hippocampus 15: 722-738.

67. Bruel-Jungerman E, Laroche S, Rampon C (2005) New neurons in the dentate gyrus are involved in the expression of enhanced long-term memory following environmental enrichment. Eur J Neurosci 21: 513-521.

68. Clelland CD, Choi M, Romberg C, Clemenson GD, Jr., Fragniere A, et al. (2009) A functional role for adult hippocampal neurogenesis in spatial pattern separation. Science 325: 210-213.

69. Drapeau E, Mayo W, Aurousseau C, Le Moal M, Piazza PV, et al. (2003) Spatial memory performances of aged rats in the water maze predict levels of hippocampal neurogenesis. Proc Natl Acad Sci U S A 100: 14385-14390.

70. Farioli-Vecchioli S, Saraulli D, Costanzi M, Pacioni S, Cina I, et al. (2008) The timing of differentiation of adult hippocampal neurons is crucial for spatial memory. PLoS Biol 6: e246.

71. Galimberti I, Gogolla N, Alberi S, Santos AF, Muller D, et al. (2006) Long-term rearrangements of hippocampal mossy fiber terminal connectivity in the adult regulated by experience. Neuron 50: 749-763. 
72. Ge S, Sailor KA, Ming GL, Song H (2008) Synaptic integration and plasticity of new neurons in the adult hippocampus. J Physiol 586: 3759-3765. 

Adrenalectomy, regardless of corticosterone replacement, affects memory and hippocampal morphology

Martínez-Claros M

Pawluski JL

Steinbusch HWM

van den Hove DLA

Prickaerts J 


\section{Abstract}

Plastic changes in the adult mammal hippocampus can be modulated by many factors, some of them from the environment. Hippocampus-dependent learning can increase the number of newborn cells in the dentate gyrus, as well as the number of synaptic contacts and dendritic branch length in the hippocampal CA3 and CA1 regions respectively. However, the literature reports contradictory results on the relationship between hippocampal plasticity and hippocampus-dependent learning and this may depend on many factors, including the stress experienced during the behavioral task used. Therefore, the aim of the present study was to determine how corticosterone levels affect spatial learning and hippocampal plasticity using a modified version of the Barnes maze, i.e., the Koopmaze. For this purpose, three groups of adult male Wistar rats were used: 1 . Sham-operated animals, 2. Adrenalectomized (ADX) rats, and 3. ADX-rats receiving corticosterone replacement. The results showed that, compared to controls, adrenalectomized rats, regardless of corticosterone replacement, have poorer performance on this dry-land maze and also show dendritic atrophy in the CA3 region of the hippocampus. No marked effects were seen on new cell survival in the hippocampus. The activity of the HPA axis and the consequent variation of corticosterone levels seem to be needed for learning and its related plasticity. 


\section{Introduction}

Persistent types of synaptic plasticity are believed to be important for long- term memory [1]. Structural changes in the neural network such as changes in the morphology, distribution and number of synaptic contacts, as well as the addition and elimination of neural units, can be considered as persistent forms of synaptic plasticity. All these types of plasticity have been observed in the hippocampus and have been associated with memory formation [2,3,4,5].

Exposure to hippocampal-dependent learning task can increase the number of new-born cells in the dentate gyrus $[6,7,8]$, the number of synaptic contacts in CA3 region [2,5], as well as dendritic branch length in the CA1 region of the hippocampus $[9,10,11]$. However, there are contradictory reports on the relationship between hippocampus-dependent learning and hippocampal plasticity, which may be related to various methodological factors, implicating, for example, effects of physical activity and stress related to the type of task used. Stress and exercise play an important role in adult hippocampal neurogenesis $[12,13,14,15,16]$. For example a decrease in neurogenesis in animals that were trained on working memory in the Morris Water Maze has been found $[17,18]$ and this variation may be due to altered corticosterone levels as a result of swimming.

The hippocampus is a vulnerable structure, sensitive to circulating levels of gluococorticoids and it is well documented that stress and corticosterone levels decrease dendritic complexity in the CA3 region of the hippocampus and decrease hippocampal neurogenesis in adult male rats $[19,20,21,22,23,24,25,26,27,28]$. In addition, high corticosterone levels, related to chronic stress, decrease spatial learning and memory in adult males [29,30].

The aim of the present study was to determine how corticosterone levels affect spatial memory and hippocampal plasticity using a modified version of the Barnes maze, i.e., the Koopmaze [31]. This maze is a dry-land maze that avoids stress related to swimming as well as the amount of physical activity needed to perform the task. Further, we controlled the amount of 
circulating corticosterone by using adrenalectomized (ADX) rats as well as ADX rats receiving corticosterone replacement.

\section{Methods}

\section{Animals}

Twenty-seven adult male Wistar rats (3 months of age; Harlan, The Netherlands) were used in the present study. Animals were divided into three groups as follows: ADX+cort (adrenalectomized (ADX) receiving a corticosterone (Cort) pellet: $n=8$ ); see below for more details), ADX (receiving a placebo pellet: $n=9$ ), and sham (receiving a placebo pellet: $n=10)$. ADX and sham surgeries were performed by the supplier (Harlan, The Netherlands). ADX animals were considered as having low corticosterone levels [32,33] and ADX+cort animals were considered to have corticosterone levels [20,34]. Circulating corticosterone levels were verified in the present study from plasma as described below.

One week after the surgery, animals arrived in our laboratory and were singly housed in individually ventilated transparent polyurethane cages with controlled humidity (42\%) and temperature $\left(22^{\circ} \mathrm{C}\right)$ on corncob bedding in a reversed light-dark cycle (lights on at 19:00; lights off at 7:00h). All animals had ad libitum access to food (Sniff, The Netherlands) and tap water. ADX animals that received a placebo pellet had their water substituted with a saline solution $(9 \mathrm{~g} / \mathrm{I}$ $\mathrm{NaCl}$ ). All experimental procedures were approved by the research ethics committee of Maastricht University for animal experiments (DEC 2008-159) and were in accordance with governmental guidelines. All efforts were made to minimize the pain and stress levels experienced by the animals.

\section{BrdU administration}

Bromodeoxyuridine (BrdU) was used as a marker of new cell survival in the dentate gyrus of the hippocampus as previously described $[35,36]$. BrdU was administered to each animal in a total dosage of $200 \mathrm{mg} / \mathrm{kg}$, diluted in a saline solution $(\mathrm{pH} 8)$. One intraperitoneal (i.p.) injection of BrdU solution (injection volume $4 \mathrm{ml} / \mathrm{kg}$ ) was done daily between $10-12$ a.m. for 4 consecutive days $(50 \mathrm{mg} / \mathrm{kg} /$ day). 


\section{Pellet implantation}

Rats received either a subcutaneous pellet implantation of $100 \mathrm{mg}$ CORT (ADX+cort) or a placebo pellet (sham, ADX) (Innovative research of America, FL, USA) 15 days after the last BrdU injection and 4 days before behavioral training. For a timeline see Figure 1 . For pellet implantation, animals were anesthetized with isoflurane, a small incision was made, and a pellet was placed subcutaneously in the dorsal region of the rat, after which the incision was closed with a suture.

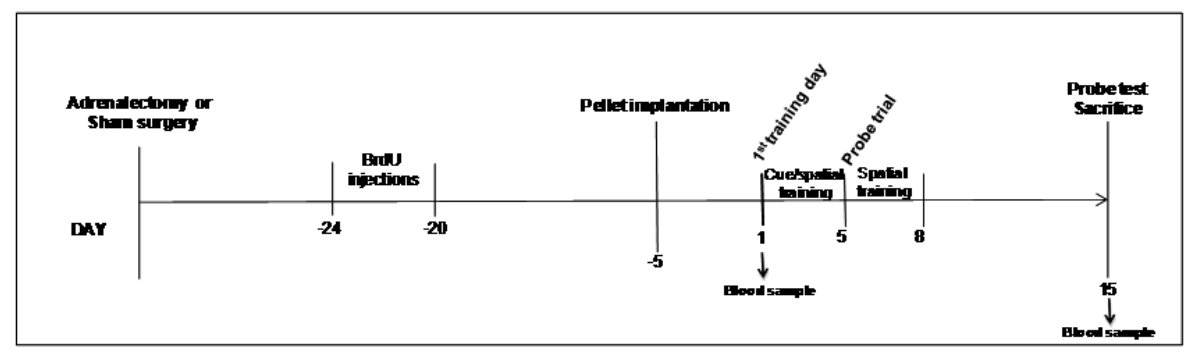

Figure 1. Timeline of experiment. ADX and sham operated animals arrived on day zero to our laboratory vivarium. All animals were injected with BrdU once daily from day -24 until day -20 . Pellet implantations were performed 15 days after the last BrdU injection. Five days after pellet implantation blood samples were taken after the first training day session and after the probe test immediately before sacrifice.

\section{Modified Barnes maze}

In order to train the animals on a spatial task, we used a modified version of the Barnes maze, i.e., the Koopmaze [31,37] Figure 2.The maze was placed in an illuminated room with various distal spatial cues such as posters in various shapes on the wall. For training, one tunnel was chosen as the target tunnel, which led to the animal's home cage. All trained animals ( $A D X+$ cort, $A D X$, sham) received three subsequent acquisition trials per day during eight consecutive days.

Each trial lasted for $3 \mathrm{~min}$ with a break of $1 \mathrm{~min}$ in-between trials. The apparatus was cleaned with a damp sponge (70\% ethanol) and dried between trials. For each trial, rats were always started from a different position facing a randomly chosen hole. If an animal did not find the target tunnel within $3 \mathrm{~min}$ (which occurred rarely), it was picked up by the experimenter and placed into the target 
tunnel. Once the animal entered the target tunnel, the tunnel was closed at the side of entrance with an object so the animal could not re-enter the circular arena. The first four days of training were both cue and spatial learning in which the home cage was presented at the end of a fixed target tunnel exit during the training sessions. This implies that rats can use the odor of its home cage as a cue, but at the same time they can apply a spatial strategy, since the target tunnel was always at the same spatial location. The last four days of training involved pure spatial learning during which the home cage was only presented after the animal had entered the target tunnel. Different target tunnels were used for the cue/spatial and pure spatial version of the task.

Probe trials were given to assess if the animals had learned the task and which strategy they had used; cue or spatial [38]. A probe session was done for the cue/spatial task on day 5 before pure spatial learning started, and for the pure spatial task 7 days after the last training session (see Figure 1). For a probe trial, animals were put in the arena for three minutes, and the home cage was not presented. With the video tracking system, data from each trial was compiled for velocity, distance, and time spent in the different zones (including target zone, i.e.,where the exit hole was located).

The amount of time spent in the target zone within the first 30 sec of the probe trials (Day 5 and Day 15) was analyzed and compared to chance level (30sec/12 arms, i.e.,2.5 seconds). The first $30 \mathrm{sec}$ provides the most reliable measures for a spatial probe trial as longer durations may involve set-shifting, thereby masking possible effects of prior hippocampus-dependent learning [39]. 


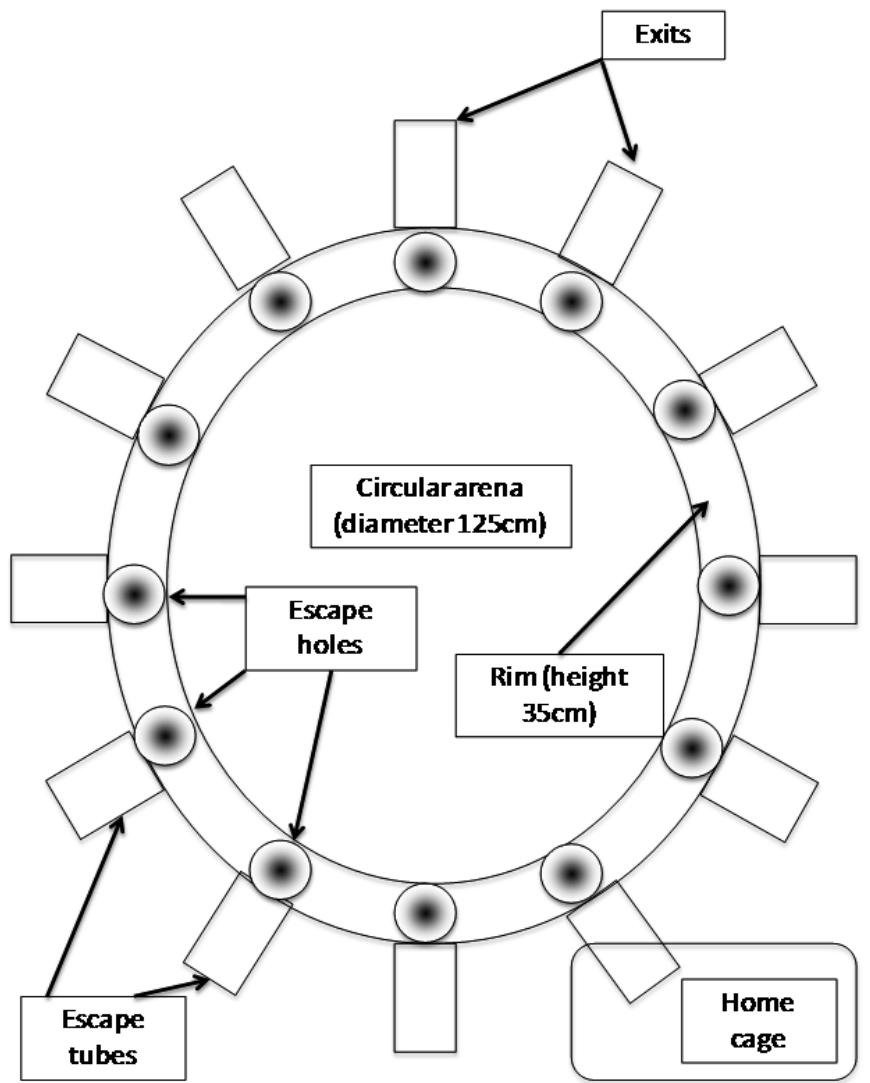

Figure 2. Schematic drawing of the modified Barnes maze. The maze consisted of a circular arena made of polyvinylchloride $(125 \mathrm{~cm}$ diameter) with 12 equally spaced holes $(10 \mathrm{~cm}$ diameter) in the rim $(35 \mathrm{~cm}$ high) which gave access to horizontal exit tunnels $(20 \mathrm{~cm}$ long). The floor of the maze was grey (RAL 7035) which allowed for detection of the white Wistar rats using a video tracking system (Ethovision, Noldus, Wageningen, The Netherlands).

\section{Corticosterone levels}

Blood samples for corticosterone levels were taken via tail nicks at two time points: five days after the pellet implantation, i.e., day 1 of training and immediately before sacrifice, i.e., day 20 after pellet placement (between 8am and $11 \mathrm{am}$ ). Each blood collection was 20 min after behavioral testing and timed to not exceed 3 minutes as corticosterone levels are elevated after 3 minutes of handling $[40,41]$. Approximately $300 \mu$ l of blood was collected in heparanized tubes (Microvette ${ }^{\circledR}$ CB 300, Sarstedt, Germany). Samples were centrifuged for 5 minutes at $4000 \mathrm{rpm}$ at $4^{\circ} \mathrm{C}$ and plasma was 
collected and stored at $-80^{\circ} \mathrm{C}$. Total plasma corticosterone levels were detected by radioimmunoassay using the Double Antibody ${ }^{125}$ I RIA Kit for rat corticosterone (MP Biomedicals, Orangeburg, NY). All samples were run in duplicate. The average intra-assay coefficient of variation for all assays was below $10 \%$. The assay had a sensitivity of $7.7 \mathrm{ng} / \mathrm{ml}$. Plasma corticosterone levels were averaged across the two time points and used for analysis.

\section{Histological procedures}

After the last probe trial, all animals were sacrificed by rapid decapitation. Brains were carefully extracted and the right hemispheres of the brains were used for Golgi impregnation ( $n=5 /$ group). The left hemispheres of the brains were frozen in 2methylbutane (Sigma, St.Louis, MO) immersed in a slurry of dry ice and ethanol and was subsequently stored at $-80^{\circ} \mathrm{C}$ to be used for BrdU-immunohistochemistry ( $n=5 /$ group).

\section{Golgi impregnation}

Tissue was processed for Golgi impregnation using the FD Rapid GolgiStain Kit ${ }^{\mathrm{TM}}$ (FD Neurotechnologies Consulting \& Services, Elliot City, MD) adapted for vibratome [19,42]. Briefly, after decapitation $1 \mathrm{~cm}$ blocks of brain tissue were rinsed with distilled water and immersed in impregnation solution containing potassium dichromate, mercuric chloride and potassium chromate. Brains were left undisturbed in the dark for 2.5 weeks. Afterwards, brains were immersed in $30 \%$ of sucrose at $4^{\circ} \mathrm{C}$. Two to four days later, coronal sections $(200 \mu \mathrm{m})$ were cut using a vibratome (Leica VT6000) in a bath of $15 \%$ sucrose and the slices stored in the dark at $4^{\circ} \mathrm{C}$ in $15 \%$ sucrose solution. Sections were mounted on gelatin coated slides and firmly pressed using moist filter paper to prevent the slices from falling off the slide during development [42]. Slides were placed in a humidity chamber in the dark and were stored at $4^{\circ} \mathrm{C}$ over night. Subsequently, slides were rinsed with distilled water twice for $2 \mathrm{~min}$ and then placed in developing solutions provided in the FD GolgiStain Kit, dehydrated via graded alcohol series (50\%-96\%, 4min 
each rinse), cleared with xylene for 8 minutes, and coverslipped with Permount $^{\circledR}$.

An experimenter blind to conditions analyzed the dendritic morphology in the CA3 region of the hippocampus. Dendritic length and number of branch points were analyzed as previously described $[23,43]$. For analysis of dendritic morphology, a pyramidal cell had to meet the following criteria: 1) the cell body and its dendrites were fully impregnated; 2 ) the cell was relatively isolated from any other cells to obtain a clear image of the entire cell; 3 ) the cell was located in the CA3 region of the dorsal hippocampus (Figure $3 \mathrm{~A}$ ). A light microscope with a drawing tube was used to draw the cells and the Neurolucida program (MicroBrightField Bioscience; Williston, VT) was used to analyze, the drawings. Accordingly, the number of branch points and the total dendritic length were measured in both apical and basal regions of each cell. In total, for each animal, six CA3 pyramidal cells located in the dorsal hippocampus were analyzed.

\section{BrdU Immunohistochemistry}

Frozen brain hemisections of the left dorsal hippocampus from six to eight rats were molded in a block with Tissue-Tek (Sakura, EU) in a plastic container as previously described $[36,44]$. Each block included brains from all groups. The blocks were cryosectioned into $20 \mu \mathrm{m}$ thick coronal sections, mounted on Superfrost Plus slides (VWR, Amsterdam, NL) dried, and stored at $-80^{\circ} \mathrm{C}$ until staining.

For immunohistochemistry, the tissue was fixed in $2 \%$ paraformaldehyde, $\mathrm{pH} 7.4$, for $5 \mathrm{~min}$, washed in TBS, $\mathrm{pH} 7.0$, and quenched in TBS with $2 \% \mathrm{H}_{2} \mathrm{O}_{2}$ for 15 min. For the detection of $\mathrm{BrdU}$, the DNA was denatured with a $50 \%$ formamide in $2 x$ saline-sodium citrate (SSC) buffer (Sigma, St.Louis, MO) at $65^{\circ} \mathrm{C}$ for $2 \mathrm{~h}$, washed in 2x SSC for $10 \mathrm{~min}$, incubated in $2 \mathrm{~N} \mathrm{HCl}$ at $37^{\circ} \mathrm{C}$ for $30 \mathrm{~min}$, and washed in $0.1 \mathrm{M}$ boric acid, $\mathrm{pH} 8.5$, for $10 \mathrm{~min}$.

After blocking with 3\% normal donkey serum (NDS, Sigma, St.Louis, MO) the slides were incubated with mouse anti-BrdU monoclonal antibody (1:100+3\%NDS+ 10\%Triton-X; Roche Products, Welwyn Garden City, UK). The mouse anti-BrdU antibody was detected after one day of incubation with a donkey anti-mouse 
secondary antibody incubated for 4 hours at room temperature $(1: 500+3 \%$ NDS; Vector Laboratories, Burlingame, CA). The brain tissue was further processed for immunohistochemistry by using the avidine-biotin complex (ABC Elite kit; 1:1000; Vector laboratories, Burlingame, $C A)$ for 2 hours. To complete the staining, 3,3diaminobenzidine (DAB; Sigma, St.Louis, MO) was used as a substrate to obtain a color reaction.

To estimate cell numbers, total BrdU-immunoreactive (-ir) cells were counted under a $60 \times$ objective with oil on every 12 th section (approx. 9-10 sections per rat) in the dorsal hippocampus. The BrdUir cells were counted in the granular cell layer (GCL) and were considered BrdU-ir if they were intensely stained and exhibited medium round or oval cell bodies Figure 3B $[35,45]$.

A)

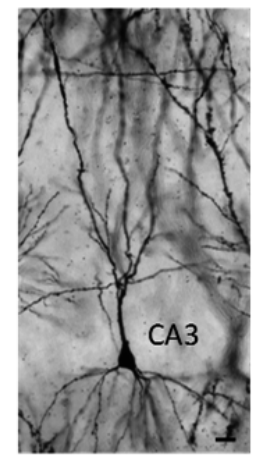

B)

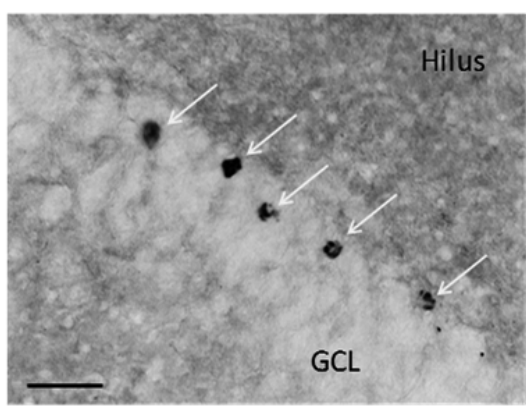

Figure 3. Photomicrographs of $A$ ) a Golgi impregnated $C A 3$ pyramidal cell and $B$ ) BrdU-ir cells in the $\mathrm{GCL}$ of the hippocampus. The sale bar represents $25 \mu \mathrm{m}$.

\section{Statistical analysis}

A one-way analysis of variance test (ANOVA) was done, as we found no differences between the two measurements, on the average corticosterone, levels with group (Sham, ADX, ADX+cort) as the between subjects factor. One way ANOVAs were also done to determine differences in the number of CA3 apical and basal branching points, $C A 3$ dendritic lengths between groups and density of BrdU-ir cells (Sham, ADX, ADX+cort). A repeated measures ANOVA 
was done on distance travelled with training days (Day 1-8) as within subject factors and group (Sham, ADX, ADX+cort) as the between subjects factor. A one-way ANOVA was done to determine differences in the time spent in the target zone between groups. The amount of time spent in the target zone within the first $30 \mathrm{sec}$ of the probe trials at 1 day after cue-spatial learning and 6 days after pure spatial learning, respectively, was analyzed with a paired t-test comparing the chance time ( 2.5 seconds) with the time spent in the target zone. Post-hoc comparisons utilized the Fisher LSD test. Pearson correlations were run between measures where appropriate. Significance was set at $p<.05$.

\section{Results}

Corticosterone levels. There was a significant difference between groups in plasma corticosterone levels $(F(2,12)=16.67, p \leq .001$; Figure 4), with ADX animals having significantly lower plasma levels of corticosterone compared to sham and ADX+cort animals. There were no other significant differences between groups (LSD post-hoc tests: $0.63 \leq p \leq 0.08$ ).

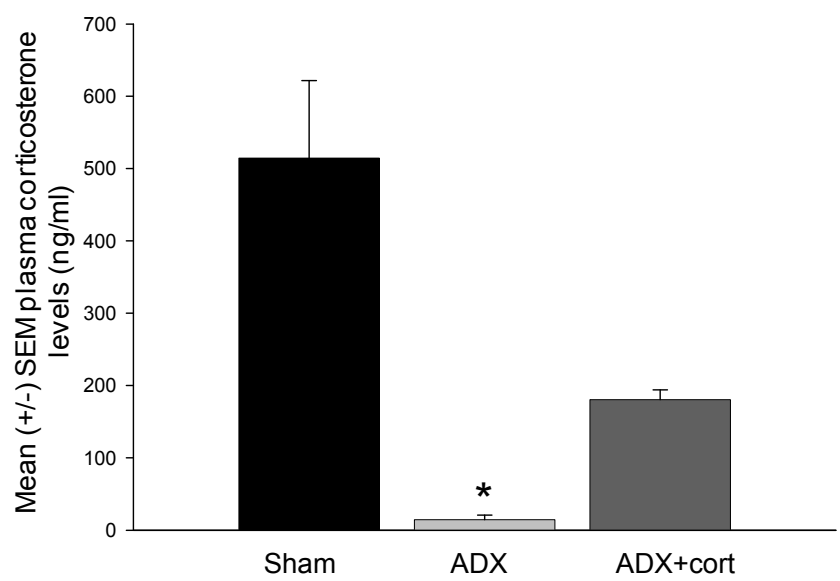

Figure 4. Mean ( \pm SEM) plasma levels ot two averaged cortıcosterone measurements $(\mathrm{ng} / \mathrm{ml})$ after the first and last test session, respectively. There was a significant difference between groups $(p \leq .001)$, with ADX animals having significantly lower plasma levels of corticosterone compared to sham and ADX+cort animals. * denotes significantly different from all other groups (LSD post-hoc tests). ( $n=5$ /group). 
Training. There were no significant differences between groups in distance travelled in the maze across training days of both the cuespatial and pure spatial learning tasks $(0.39 \leq p \leq 0.57$; Figure 5$)$. Only sham animals spent in the probe trial on day 5 significantly more time in the target cue-spatial zone when compared with chance level (paired t-test: $p \leq 0.01$ ). There was a significant difference between groups in time spent in the target cue-spatial zone during the day 5 probe trial $(F(2,24)=30.03, p \leq 0.03$ : Figure 6$)$. LSD Post-hoc tests revealed that sham animals spent significantly more time in the target cue-spatial zone compared with both the ADX animals during the day 5 probe trial $(p \leq 0.01)$ and spent more time than the $A D X+c o r t$ animals during the day 5 probe trial $(p \leq 0.07)$. There were no significant differences in time spent in the spatial target zone on day 15 i.e.,last training session $(0.22 \leq p \leq 0.63)$.

A)

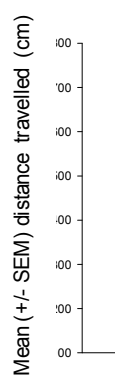

B)

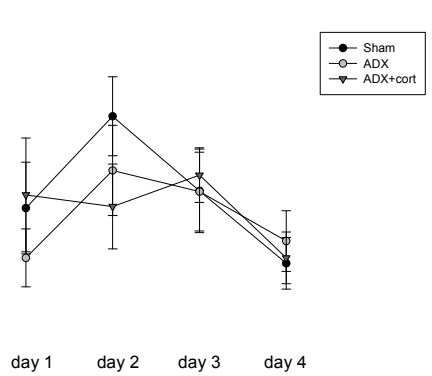

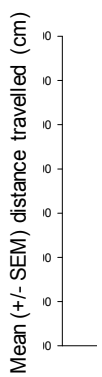

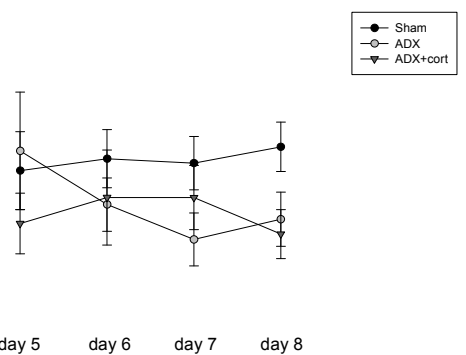

Figure 5. Mean ( \pm SEM) distance travelled $(\mathrm{cm})$ in the modified Barnes Maze from A) days 1-4, when the animal performed a cue-spatial training and B) days 5-8 when the animal performed a spatial training. There were no significant differences between groups in distance travelled across training days $(0.39 \leq$ $p \leq 0.57)$. ( $n=5-8 /$ group). 


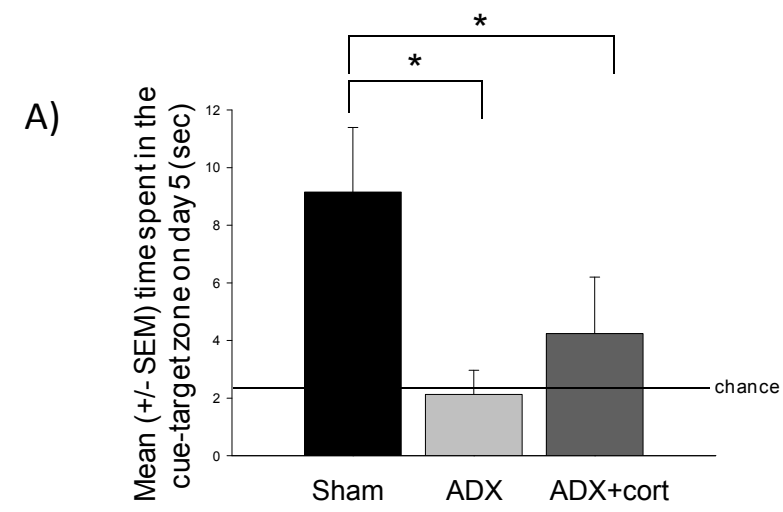

B)
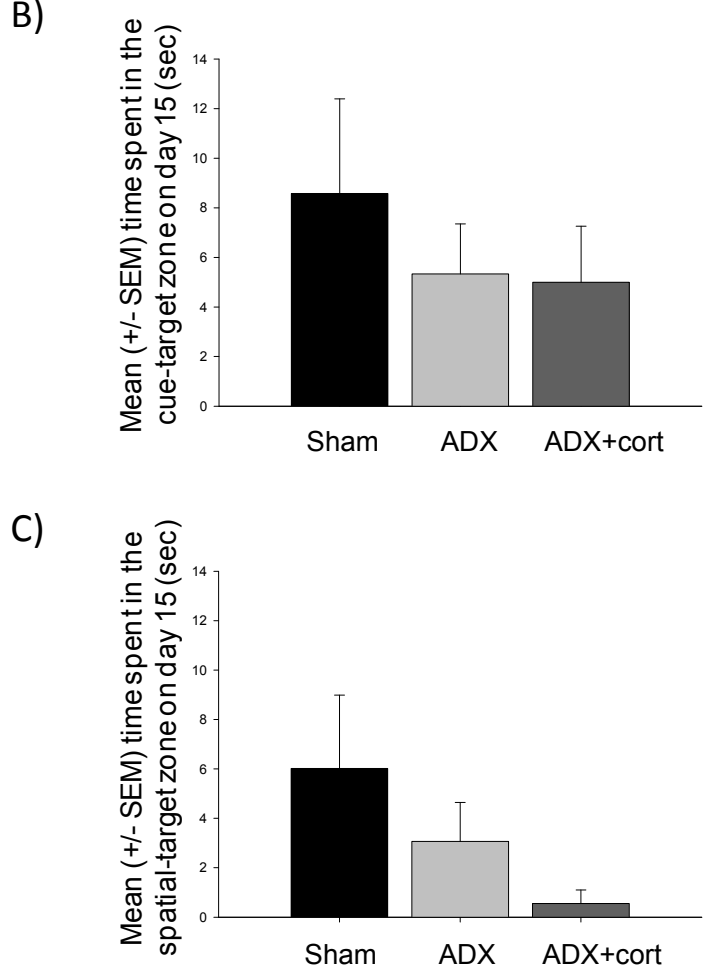

Figure 6. Mean ( \pm SEM) time (sec) spent in the A) cue-spatial target zone in the day 5 probe trial B) cuespatial target zone in the day 15 probe trial, and C) spatial target zone in the day 15 probe trial. Sham animals spent more time in the target zone when compared chance level at day 5 ( 2.5 seconds; paired t-test: $\mathrm{p} \leq 0.02$ ) and also when compared to ADX and ADX+cort animals (LSD post-hoc tests: $0.01 \leq \mathrm{p} \leq$ 0.07 ), and also. None of the groups spent above chance level in the target zones at day 15 and there were no differences between groups on day 15 (LSD post-hoc tests: $0.22 \leq p \leq 0.63$ ). ${ }^{*}$ denotes significantly different from all other groups. ( $n=8-10 /$ group) 
CA3 dendritic morphology. There was a significant difference between groups in CA3 apical dendritic length $(F(2,12)=5.56, p \leq$ 0.02 ) with post-hoc tests revealing that $A D X$ and $A D X+c o r t$ animals had decreased apical dendritic lengths compared to sham animals $(0.01 \leq p \leq 0.04$; Figure 7$)$. There was a tendency for a difference in number of CA3 apical branch points between groups ( $\leq 0.06)$. There were no significant differences between groups regarding basal dendritic length or number of basal branch points in the CA3 region $(0.77 \leq p \leq 0.89)$. There were also no significant correlations between plasma corticosterone levels or learning and memory performance and measures of CA3 dendritic morphology $(0.12 \leq p \leq$ $0.80)$.

A)

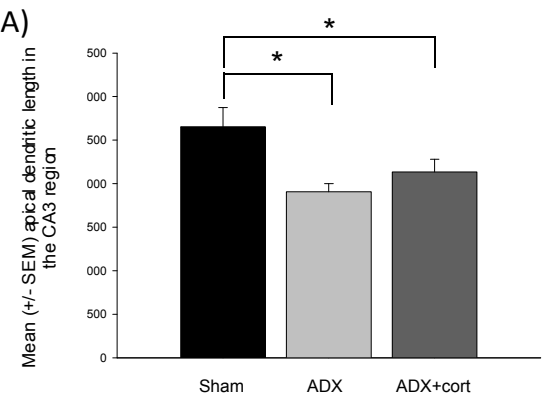

B)

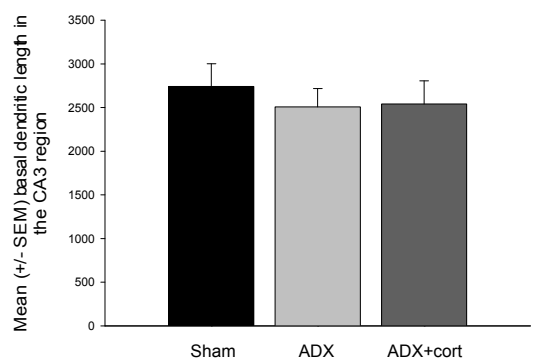

C)

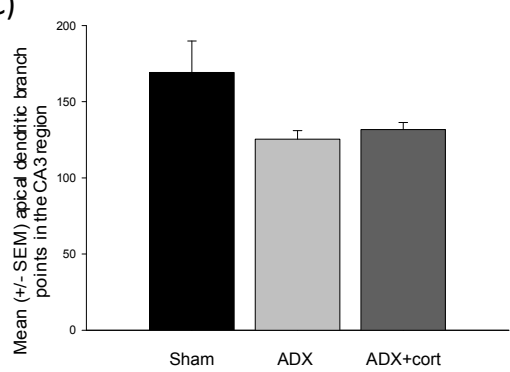

D)

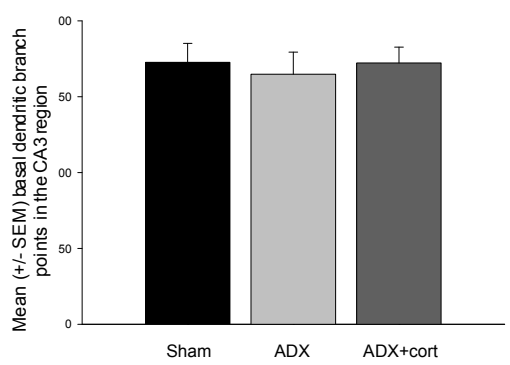

Figure 7. Mean ( \pm SEM) CA3 A) apical dendritic length, B) number of apical dendritic branch points, $C$ ) basal dendritic length, and $D$ ) number of basal branch points. There was a significant difference in the $C A 3$ apical dendritic length with $A D X$ and $A D X+c o r t$ animals having decreased apical dendritic length compared to sham animals (LSD post hoc tests: $0.01 \leq p \leq 0.04$ ). There was a tendency toward a difference in number of CA3 apical branch points between groups $(p \leq 0.06)$. There were no other significant differences between groups $(0.77 \leq p \leq 0.89) .{ }^{*}$ denotes significantly different from all other groups. ( $n=5 /$ group). 


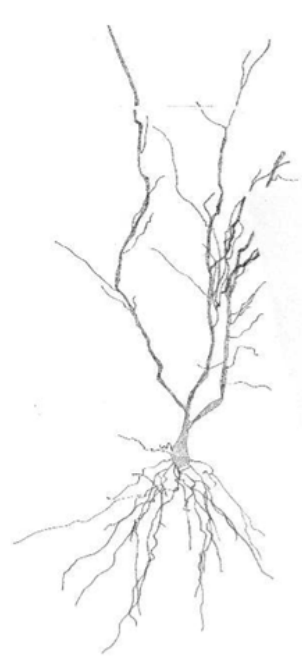

Sham Trained

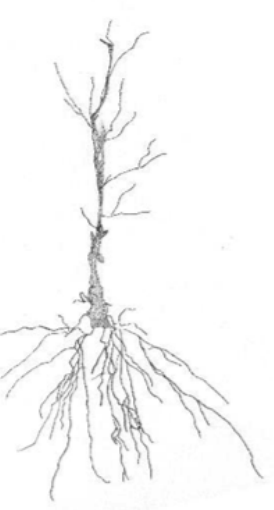

ADX Trained

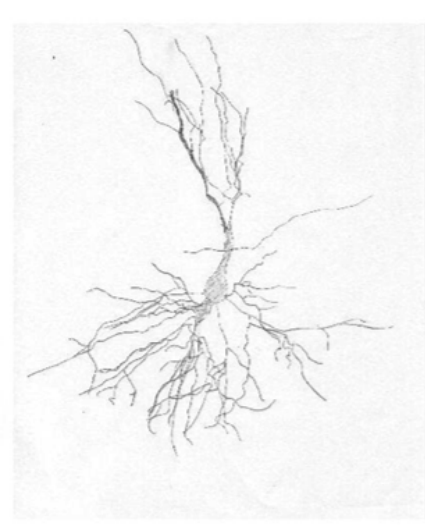

ADX-CORT Trained

Figure 8. Representative camera lucida drawings of Golgi impregnated hippocampal CA3 pyramidal cells of a sham, ADX and ADX+cort animal.

BrdU-ir cells in the dentate gyrus. There were no significant differences between groups in density of BrdU-ir cells in the GCL at the dorsal hippocampus ( $p \leq 0.90 ;$ Table 1 ). There were no significant correlations between plasma corticosterone levels or learning and memory performance, and density of BrdU-ir cells $(0.13 \leq p \leq 0.85)$.

Table 1. Mean ( \pm SEM) granular cell layer density of BrdU-ir cells. There were no significant differences between groups in density of BrdU-ir cells $(0.13 \leq p \leq 0.88)$.

\begin{tabular}{|l|l|}
\hline & Density of BrdU-ir cells \\
\hline Sham & $1323.80 \pm 197.89$ \\
\hline ADX & $1515.97 \pm 304.45$ \\
\hline ADX+cort & $1418.45 \pm 366.15$ \\
\hline
\end{tabular}

\section{Discussion}

In the present study we found that adrenalectomy, regardless of corticosterone replacement, resulted in impairments in spatial learning in the modified Barnes/Koopmaze. We saw in the first probe trial that the sham animals learned the spatial location. The second 
probe trial showed that actually none of the experimental groups had reversal learning. Further, regardless of corticosterone replacement in adrenalectomized animals, we observed a decrease in dendritic complexity in the apical region of CA3 pyramidal neurons, although only in terms of total length and not in number of branch points. We did not find an effect of adrenalectomy or corticosterone replacement on the survival of new cells in the dentate gyrus.

Corticosterone and the dry maze performance

When looking at circulating corticosterone levels, we found that overall the levels of corticosterone in the sham group were significantly higher compared to adrenalectomized rats. Interestingly sham animals performed better than ADX rats regardless corticosterone replacement, suggesting that a more profound increase in corticosterone may be important for the consolidation and/or retrieval of memory.

Adrenalectomy, and low to moderate glucocorticoid levels, have previously been linked to decreased memory performance on hippocampus-dependent tasks in adult rats [33]. For example Spanswick and colleagues [33] showed that ADX rats have a deficit in spatial memory performance, regardless the administration of corticosterone or fluoxetine. They also found an extensive loss of granule cells in the DG and no differences in cell proliferation in the DG between groups. Therefore, our work extends these findings as it demonstrates that ADX has an evident effect on hippocampusdependent memory formation and that this deficit is not related to diminished cell proliferation.

Effects of corticosterone levels and behavioral training on CA3 dendritic morphology.

Interestingly, we found that trained ADX rats, regardless of corticosterone replacement, had fewer apical branch points and shorter dendritic lengths on pyramidal cells in the CA3 region of the hippocampus. Our previous work showed that, in the absence of 
behavioral training, only ADX rats alone had atrophy in the CA3 region of the hippocampus [34]. In line with the current findings, this demonstrates that training itself is a factor that can modulate dendritic morphology in the CA3 region of the hippocampus.

As mentioned previously, ADX, and low glucocorticoid levels, have been linked to decreased memory performance on hippocampus-dependent tasks in adult rats [33]. Therefore, it is likely that CA3 dendritic atrophy contributes to the deficit observed in performance of the adrenalectomized rats on the dry maze and it is evident that corticosterone is needed to prevent hippocampal neuronal atrophy and to contribute to learning and memory.

Effects of corticosterone replacement on new cell survival in the DG. In the present study we found no effects of training or corticosterone levels on new cell survival in the dentate gyrus of the hippocampus. It may be that there is a critical time window in which corticosterone acts to alter new cell survival in the hippocampus [46]. In addition, it may be that different levels of corticosterone, in combination with learning and memory performance affect other aspects of hippocampal neurogenesis such as cell proliferation.

Relationship between corticosterone, cognition and hippocampal plasticity.

In line with previous work by our group, the present study shows that adrenalectomy, itself, has a strong influence on dendritic morphology of the CA3 area as wells as on new-born cells in the DG [34]. In addition, with these findings, we also saw a detrimental correlate of these morphological findings on the behavior, with adrenalectomy resulting in poorer memory performance. One possible mechanism behind this relationship is changes in long term potentiation (LTP). LTP is an important link between changes in synaptic plasticity and learning and memory in the hippocampus $[47,48]$. There is also an inverted U-shaped dose-response relationship between corticosterone levels and hippocampal LTP such that LTP is impaired by very low and very high corticosterone levels [48]. Hippocampal LTP is optimal when glucocorticoid levels 
are mildly elevated $[48,49]$. LTP induces morphological changes in the dendritic morphology of hippocampal cells [50]. With this evidence we can propose that the morphological changes we report in the CA3 dendrites of the adrenalectomized animals may have a functional consequence i.e.,less plasticity and consequently impaired learning and memory.

\section{Conclusions}

Findings of the present study show that adrenalectomy, regardless of corticosterone replacement, results in poorer learning and memory as well as dendritic atrophy of CA3 pyramidal neurons. This work adds to a growing body of literature indicating a close link between hippocampal new-born cell survival, morphological plasticity and cognition. Future work should analyze the possible mechanisms including the differential activation and effects of glucocorticoid receptors on neurotrophic factors linking these phenomena. The functional characterization of the new-born cells in a glucocorticoid deprived environment should be also further done. 


\section{References}

1. Barco A, Bailey CH, Kandel ER (2006) Common molecular mechanisms in explicit and implicit memory. J Neurochem 97: 1520-1533.

2. Ramirez-Amaya V, Escobar ML, Chao V, Bermudez-Rattoni F (1999) Synaptogenesis of mossy fibers induced by spatial water maze overtraining. Hippocampus 9: 631-636.

3. Ramirez-Amaya V, Balderas I, Sandoval J, Escobar ML, Bermudez-Rattoni F (2001) Spatial long-term memory is related to mossy fiber synaptogenesis. J Neurosci 21: 7340-7348.

4. Rekart JL, Sandoval CJ, Bermudez-Rattoni F, Routtenberg A (2007) Remodeling of hippocampal mossy fibers is selectively induced seven days after the acquisition of a spatial but not a cued reference memory task. Learn Mem 14: 416-421.

5. Holahan MR, Rekart JL, Sandoval J, Routtenberg A (2006) Spatial learning induces presynaptic structural remodeling in the hippocampal mossy fiber system of two rat strains. Hippocampus 16: 560-570.

6. Sisti HM, Glass AL, Shors TJ (2007) Neurogenesis and the spacing effect: learning over time enhances memory and the survival of new neurons. Learn Mem 14: 368-375.

7. Dalla C, Bangasser DA, Edgecomb C, Shors TJ (2007) Neurogenesis and learning: acquisition and asymptotic performance predict how many new cells survive in the hippocampus. Neurobiol Learn Mem 88: 143-148.

8. Dupret D, Fabre A, Dobrossy MD, Panatier A, Rodriguez JJ, et al. (2007) Spatial learning depends on both the addition and removal of new hippocampal neurons. PLoS Biol 5: e214.

9. Moser MB, Trommald M, Egeland T, Andersen P (1997) Spatial training in a complex environment and isolation alter the spine distribution differently in rat CA1 pyramidal cells. J Comp Neurol 380: 373-381.

10. Leuner B, Shors TJ (2004) New spines, new memories. Mol Neurobiol 29: 117130.

11. Moser MB, Trommald M, Andersen P (1994) An increase in dendritic spine density on hippocampal CA1 pyramidal cells following spatial learning in adult rats suggests the formation of new synapses. Proc Natl Acad Sci U S A 91: 12673-12675.

12. Naylor AS, Bull C, Nilsson MK, Zhu C, Bjork-Eriksson T, et al. (2008) Voluntary running rescues adult hippocampal neurogenesis after irradiation of the young mouse brain. Proc Natl Acad Sci U S A 105: 14632-14637.

13. Olson AK, Eadie BD, Ernst C, Christie BR (2006) Environmental enrichment and voluntary exercise massively increase neurogenesis in the adult hippocampus via dissociable pathways. Hippocampus 16: 250-260.

14. Rhodes JS, van Praag H, Jeffrey S, Girard I, Mitchell GS, et al. (2003) Exercise increases hippocampal neurogenesis to high levels but does not improve 
spatial learning in mice bred for increased voluntary wheel running. Behav Neurosci 117: 1006-1016.

15. van Praag H, Kempermann G, Gage FH (1999) Running increases cell proliferation and neurogenesis in the adult mouse dentate gyrus. Nat Neurosci 2: 266-270.

16. van Praag H, Shubert T, Zhao C, Gage FH (2005) Exercise enhances learning and hippocampal neurogenesis in aged mice. J Neurosci 25: 8680-8685.

17. Ehninger D, Kempermann G (2006) Paradoxical effects of learning the Morris water maze on adult hippocampal neurogenesis in mice may be explained by a combination of stress and physical activity. Genes Brain Behav 5: 2939.

18. Aztiria E, Capodieci G, Arancio L, Leanza G (2007) Extensive training in a maze task reduces neurogenesis in the adult rat dentate gyrus probably as a result of stress. Neurosci Lett 416: 133-137.

19. Dalla C, Whetstone AS, Hodes GE, Shors TJ (2009) Stressful experience has opposite effects on dendritic spines in the hippocampus of cycling versus masculinized females. Neurosci Lett 449: 52-56.

20. Brummelte S, Galea LA (2010) Chronic high corticosterone reduces neurogenesis in the dentate gyrus of adult male and female rats. Neuroscience 168: 680-690.

21. Conrad CD, McLaughlin KJ, Harman JS, Foltz C, Wieczorek L, et al. (2007) Chronic glucocorticoids increase hippocampal vulnerability to neurotoxicity under conditions that produce CA3 dendritic retraction but fail to impair spatial recognition memory. J Neurosci 27: 8278-8285.

22. Donohue HS, Gabbott PL, Davies HA, Rodriguez JJ, Cordero MI, et al. (2006) Chronic restraint stress induces changes in synapse morphology in stratum lacunosum-moleculare CA1 rat hippocampus: a stereological and three-dimensional ultrastructural study. Neuroscience 140: 597-606.

23. Galea LA, McEwen BS, Tanapat P, Deak T, Spencer RL, et al. (1997) Sex differences in dendritic atrophy of CA3 pyramidal neurons in response to chronic restraint stress. Neuroscience 81: 689-697.

24. Gould E, Woolley CS, McEwen BS (1990) Short-term glucocorticoid manipulations affect neuronal morphology and survival in the adult dentate gyrus. Neuroscience 37: 367-375.

25. Magarinos AM, McEwen BS (1995) Stress-induced atrophy of apical dendrites of hippocampal CA3c neurons: involvement of glucocorticoid secretion and excitatory amino acid receptors. Neuroscience 69: 89-98.

26. Magarinos AM, McEwen BS (1995) Stress-induced atrophy of apical dendrites of hippocampal CA3c neurons: comparison of stressors. Neuroscience 69: 83-88.

27. Magarinos AM, Verdugo JM, McEwen BS (1997) Chronic stress alters synaptic terminal structure in hippocampus. Proc Natl Acad Sci U S A 94: 1400214008. 
28. McEwen BS, Magarinos AM (1997) Stress effects on morphology and function of the hippocampus. Ann N Y Acad Sci 821: 271-284.

29. Bodnoff SR, Humphreys AG, Lehman JC, Diamond DM, Rose GM, et al. (1995) Enduring effects of chronic corticosterone treatment on spatial learning, synaptic plasticity, and hippocampal neuropathology in young and midaged rats. J Neurosci 15: 61-69.

30. Luine VN, Beck KD, Bowman RE, Frankfurt M, Maclusky NJ (2007) Chronic stress and neural function: accounting for sex and age. J Neuroendocrinol 19: 743-751.

31. Koopmans G, Blokland A, van Nieuwenhuijzen P, Prickaerts J (2003) Assessment of spatial learning abilities of mice in a new circular maze. Physiol Behav 79: 683-693.

32. Prickaerts J, van den Hove DL, Fierens FL, Kia HK, Lenaerts I, et al. (2006) Chronic corticosterone manipulations in mice affect brain cell proliferation rates, but only partly affect BDNF protein levels. Neurosci Lett 396: 12-16.

33. Spanswick SC, Epp JR, Keith JR, Sutherland RJ (2007) Adrenalectomy-induced granule cell degeneration in the hippocampus causes spatial memory deficits that are not reversed by chronic treatment with corticosterone or fluoxetine. Hippocampus 17: 137-146.

34. Martinez-Claros M, Steinbusch HW, A. vS, van den Hove DL, Prickaerts J, et al. (submitted) Adrenalectomy and corticosterone replacement differentially alter CA3 dendritic morphology and new cell survival in the adult rat hippocampus.. J Chem Neuroanat.

35. Pawluski JL, Galea LA (2007) Reproductive experience alters hippocampal neurogenesis during the postpartum period in the dam. Neuroscience 149: 53-67.

36. Sandoval CJ, Martinez-Claros M, Bello-Medina PC, Perez O, Ramirez-Amaya V (2011) When are new hippocampal neurons, born in the adult brain, integrated into the network that processes spatial information? PLoS One 6: e17689.

37. Barnes CA (1979) Memory deficits associated with senescence: a neurophysiological and behavioral study in the rat. J Comp Physiol Psychol 93: 74-104.

38. Schwabe L, Schachinger H, de Kloet ER, Oitzl MS (2010) Corticosteroids operate as a switch between memory systems. J Cogn Neurosci 22: 1362-1372.

39. Blokland A, Geraerts E, Been M (2004) A detailed analysis of rats' spatial memory in a probe trial of a Morris task. Behav Brain Res 154: 71-75.

40. Pawluski JL, Charlier TD, Lieblich SE, Hammond GL, Galea LA (2009) Reproductive experience alters corticosterone and CBG levels in the rat dam. Physiol Behav 96: 108-114. 
41. Vahl TP, Ulrich-Lai YM, Ostrander MM, Dolgas CM, Elfers EE, et al. (2005) Comparative analysis of ACTH and corticosterone sampling methods in rats. Am J Physiol Endocrinol Metab 289: E823-828.

42. Gibb R, Kolb B (1998) A method for vibratome sectioning of Golgi-Cox stained whole rat brain. J Neurosci Methods 79: 1-4.

43. Pawluski JL, Galea LA (2006) Hippocampal morphology is differentially affected by reproductive experience in the mother. J Neurobiol 66: 71-81.

44. Ramirez-Amaya V, Marrone DF, Gage FH, Worley PF, Barnes CA (2006) Integration of new neurons into functional neural networks. J Neurosci 26: 12237-12241.

45. Ormerod BK, Galea LA (2001) Reproductive status influences cell proliferation and cell survival in the dentate gyrus of adult female meadow voles: a possible regulatory role for estradiol. Neuroscience 102: 369-379.

46. Epp JR, Haack AK, Galea LA (2011) Activation and survival of immature neurons in the dentate gyrus with spatial memory is dependent on time of exposure to spatial learning and age of cells at examination. Neurobiol Learn Mem 95: 316-325.

47. Bliss TV, Collingridge GL (1993) A synaptic model of memory: long-term potentiation in the hippocampus. Nature 361: 31-39.

48. Prickaerts J, Streckler T (2005) Effects of glucocorticoids on emotion and cognitive processes in animals. In: Steckler T, Kalin NH, Reul JMHM, editors. Handbook of Stress and the Brain part 1: the Neurobiology of stress. Amsterdam: Elsevier Science.

49. Diamond DM, Bennett MC, Fleshner M, Rose GM (1992) Inverted-U relationship between the level of peripheral corticosterone and the magnitude of hippocampal primed burst potentiation. Hippocampus 2: 421-430.

50. Yuste R, Bonhoeffer T (2001) Morphological changes in dendritic spines associated with long-term synaptic plasticity. Annu Rev Neurosci 24: 1071-1089. 


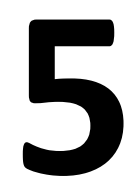

\section{When are new hippocampal neurons, born in the adult brain, integrated into the network that process spatial information?}

Sandoval CJ

Martínez-Claros M

Bello-Medina PC

Pérez $\mathrm{O}$

Ramírez-Amaya $\mathrm{V}$

PLOS ONE, (2011) 6(3): e17689.

doi:10.1371/journal.pone.001768 


\section{Abstract}

Adult-born neurons in the dentate gyrus (DG) functionally integrate into the behaviorally relevant hippocampal networks, showing a specific Arc-expression response to spatial exploration when mature. However, it is not clear when, during the critical time for survival and maturation of these neurons, this specific response develops. This critical time period lasts 4 to 6 weeks. Therefore, we characterized Arc expression after spatial exploration or cage control conditions, in adult-born neurons from rats that were injected with BrdU on one day and were sacrificed 1, 7, 15, 30, and 45 days post BrdU injection (PBI). Triple immunostaining for NeuN, Arc, and BrdU was analyzed through the different DG layers. Arc protein in BrdU-positive cells was observed from day 1 until day $15 \mathrm{PBI}$, but this expression was not related to behavioral stimulation. The specific Arc-expression response to spatial exploration was observed from day 30 and 45 in about $5 \%$ of the BrdU-positive cell population. Most of the BrdUpositive neurons expressing Arc in response to spatial exploration ( 90\%) were located in DG layer 1, and no Arc expression was observed in cells located in the subgranular zone (SGZ). Using the current data and that obtained previously, we generate a hypothesis based on numerical calculations, suggesting that new neurons are unlikely to respond to exploration by expressing Arc after they are 337 days old. Finally, in a rat about 5 months old the majority (99\%) of the neurons that respond to exploration must have been born after the DG was fully assembled, which supports our hypothesis that adult DG neurogenesis plays a major role in spatial information processing. 


\section{Introduction}

New neurons born in the adult mammal dentate gyrus (DG) functionally integrate into the hippocampal network $[1,2,3]$. The integration process resembles the one described during early development $[4,5]$ but is slower $[6,7]$. Throughout the first 4 weeks $\sim 80 \%$ of the new neurons die and the remaining $20 \%$ survive for at least 11 months [8]. Thus, the first 4 weeks after their birth are critical for the survival of these new neurons and also for their maturation $[9,10]$. For example, in the first week after birth, new neurons are partially differentiated [11] and express doublecortin (DCX), which is important for neuronal migration [12], and by the third week $\sim 90 \%$ of the new neurons express NeuN, a marker of mature neurons [12, 8]. New neurons do not show electrophysiological features of maturity until the third week [13, 14], their GABAergic response, which is initially depolarizing, becomes hyperpolarizing around this time, $[15,16]$ and the glutamatergic input matures during weeks 3 and $4[13,14,15]$. Anatomically, the axon, dendrites, and their spines reach maturity around weeks 3 to $4[14,17,18]$.

By detecting the expression of the immediate early gene (IEG) Arc induced by spatial exploration, we previously examined the functional integration of 5-month-old, adult-born granular neurons into the behaviorally relevant hippocampal network [2]. We found that more adult-born neurons expressed Arc in animals allowed to explore, than in cage control animals, indicating a specific Arc expression response in adult born neurons to spatial exploration [2]. Nevertheless, it is not clear when this specific response to behavioral exploration appears.

By detecting the expression of the IEGs cFos and Arc evoked during a water-maze task in previously trained animals, Kee and colleagues [19] observed that 6-week-old new neurons, but not younger ones, are recruited into circuits that can be re-activated at 10 weeks. They also showed that the expression of cFos after a single water-maze session occurs only in 6-week- but not 1-week-old new neurons, similar to previous findings showing cFos expression after 
seizures only in 3-week-old new neurons [19]. Similarly, Tashiro and colleagues found that new neurons are preferentially recruited into circuits, that process information from an enriched environment experience that enhance the amount of new neurons survival, when this neurons are 2 weeks old [20].

However, the question remains as to when, during this critical period for survival and maturation, do adult-born neurons integrate into the behaviorally relevant hippocampal network, developing a specific response to spatial exploration? The expression of the IEG Arc and its protein product, stimulated by behaviorally induced neural activity [24] and important for synaptic plasticity [21, 22], is detected as early as 24 hours after the birth of adult-born granular neurons [23]. Therefore, this question can be answered by comparing Arc protein expression in new granular neurons 30 minutes after spatial exploration or cage control conditions during their critical time for survival and maturation, without affecting them by behavioral stimulation.

Animals were administered with BrdU on day 0 and sacrificed on day $1,7,15,30$ or 45 , thirty minutes after a 5-minute exploration session or cage control conditions (Fig. 1). Their brains were processed for triple immunohistochemistry for NeuN, Arc and BrdU, semi-confocal and confocal microscopy images were made for further analysis.

We found that the expression of Arc occurs without stimulation in 1- to 15-day-old new granular neurons. A specific response to exploration was observed in $\sim 5 \%$ of the 30 - to 45 -dayold new-neurons. This pattern of Arc expression in response to spatial exploration reflects the course of selective survival and integration in a network that process spatial information. Ninety percent of the BrdU-positive cells expressing Arc in response to spatial exploration were located in DG layer 1 (L1), and no Arc expression was detected in new cells located in the subgranular zone (SGZ). By using the current data and that obtained previously [2], we propose a hypothesis based on our calculations suggesting that new neurons may no longer respond to spatial exploration after they are 337 days old, and that in a 5 months old animal the majority (99\%) of 
the neurons that respond to exploration were born after the hippocampal DG was fully assembled.

\section{Methods}

\section{Animals}

Thirty-five adult male Wistar rats ( 4 months of age) were provided by the bioterium of the Institute of Neurobiology, Mexico. Rats were individually housed, had access to water and food ad libitum, and were maintained on an inverted $12: 12 \mathrm{hr}$ light-dark cycle, with lights on at 9: $00 \mathrm{AM}$. The animals were allowed to habituate to the room conditions and handled for at least 10 days before experiments began. The "bioethics committee" from our institute, which is headed by Dr. Ma Magdalena Giordano Noyola, approved all the protocols and experimental procedures performed with the animals in the present study. This was done in accordance with international ethical guidelines for animal care and handling (ID:INEU/SA/CB/034).

\section{BrdU administration}

Given that our goal was to accurately establish the date on which new neurons were able to respond to the behavioral stimulation, we compared different bromodeoxyuridine (BrdU) (Sigma, St Louis MO ) administration procedures to maximize the number of neurons born during a single day. A dose of $200 \mathrm{mg} / \mathrm{Kg}$, divided into four, $50 \mathrm{mg} / \mathrm{Kg}$ injections (diluted in $0.15 \mathrm{M} \mathrm{NaCl}$ solution) and administered every 4 hrs gave the highest number of BrdU-positive cells in the hippocampal dentate gyrus, as compared to other procedures tested. The first BrdU injection was at 9:30 am and the last was at 9:30 pm on the same day. After the BrdU administration, the animals remained undisturbed in their home cages until they were sacrificed after or without a 5 min spatial exploration session (see Fig. 1). 


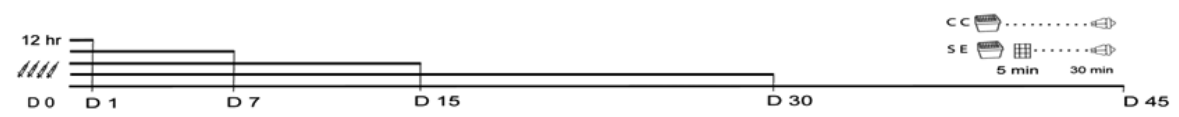

Figure 1. Schematic representation of the experimental procedures. BrdU was administered on day 0 in 4 separate ip injections (50 mg/Kg each) every $4 \mathrm{hrs}$ from 9:00 A.M to 9:00 P.M. Animals were sacrificed 1, 7, 15, 30, or 45 days post BrdU injections (PBI), either from their home cages (cage control, $\mathrm{CC}$ ) or $30 \mathrm{~min}$ after a 5 -min spatial exploration (SE).

\section{Spatial exploration}

In order to examine the response of new neurons to spatial exploration at different maturation times, 1, 7, 15, 30 or 45 days post BrdU injections (PBI), the animals were exposed to a 5-min exploration session ( $n=5,4,4,4$, and 3 respectively) and were sacrificed 30 min later (Fig. 1). The exploration environment was an open square box, $70 \times 70 \mathrm{~cm}$, with 20 -cm-high walls made of translucent acrylic. All the walls were covered with orange foamy paper, and the floor was partitioned into nine grids using black foamy paper strips. Each rat was fully covered with a white towel, then individually transported to the behavioral room, and placed in the center of one of the grids in the apparatus, and it was moved to the center of a different grid every $15 \mathrm{~s}$. This ensures that each of the grids was visited two or three times during the 5-min exploration session [24]. Immediately after exploration, the animal was placed back in its home cage and kept undisturbed. Cage control animals for each PBI group $(n=3)$, remained in their home cages undisturbed during the behavioral session and were sacrificed the same day and time as their respective exploration group, without being exposed to exploration.

\section{Brain extraction}

Thirty min after the exploration session, each animal was killed by quick decapitation. The rat's brain was quickly and carefully extracted and frozen in 2-methylbutane (Sigma) by immersing it in a dry ice/ethanol slurry. The rat brains were stored at $-70^{\circ} \mathrm{C}$.

\section{Blocking and sectioning}

Using a stainless still matrix (Electron Microscopy Sciences, Hatfield, $\mathrm{PA})$, brain hemisections including the whole hippocampi were 
obtained. From 8 to 10 brain sections were molded into a block with Tissue-Tec OCT compound ${ }^{\circledR}$ (Sakura Finetek, Torrance, CA), such that each block contained brains from all groups and the position of each group differed in each block. The blocks ( 4 total) were cryosectioned into $20-\mu \mathrm{m}$-thick coronal sections at $-18^{\circ} \mathrm{C}$ in a CM1850 Leica cryostat (Nussloch, Germany), captured on slides (Lauka, MEX) previously treated with diethyl-polycarbonate (Sigma) solution and kept in a sealed box at $-70{ }^{\circ} \mathrm{C}$ before the immunostaining procedure.

\section{Immunostaining}

In order to maximize the detection of BrdU cells expressing Arc, 30 to 40 serial sections from the dorsal hippocampus (range between 2.60 to -4.3 from bregma) from each block were selected for the staining procedure. We used a triple immnunostaining protocol similar to that described previously to detect NeuN, Arc and BrdU [2]. The tissue was fixed in 2\% paraformaldehyde, $\mathrm{pH} 7.4$, for $8 \mathrm{~min}$ at $4^{\circ} \mathrm{C}$, washed in Tris-buffered saline (TBS), pH 7.0 and quenched in TBS with $2 \% \mathrm{H}_{2} \mathrm{O}_{2}$ for 20 min. The sections were blocked for $40 \mathrm{~min}$ in tyramide signal amplification (TSA) kit blocking buffer (Perkin Elmer Life Sciences, Emeryville, CA). The tissue was then incubated sequentially with biotinylated mouse anti-NeuN antibody (1:2000; Chemicon, Bedford, MA), with polyclonal rabbit anti-Arc antibody for the second detection (1:500; a kind gift from Paul F. Worley's laboratory), and for the third detection with mouse anti-BrdU monoclonal antibody (1:500 BD biosciences México DF, México). After detecting NeuN and before Arc antibody incubation, the tissue was permeabilized with acetone/methanol (50:50, v/v; Sigma) at $4^{\circ} \mathrm{C}$ for 15 minutes. For the detection of $\mathrm{BrdU}$, the tissue was taken through a DNA denaturing procedure, consisting of an incubation with $50 \%$ formamide in $2 \times S S C$ buffer (Sigma) at $65^{\circ} \mathrm{C}$ for $2 \mathrm{~h}$, washed in $2 \times S S C$ for $10 \mathrm{~min}$, incubated in $2 \mathrm{~N} \mathrm{HCl}$ at $37^{\circ} \mathrm{C}$ for $30 \mathrm{~min}$, and washed in $0.1 \mathrm{M}$ boric acid, $\mathrm{pH} 8.5$, for $10 \mathrm{~min}$. Biotinylated antiNeuN was detected with the avidin-biotin $A+B$ Vectastain amplification kit (Vector laboratories, Burlingame, CA) and the cyanine-5 (Cy5) TSA fluorescence system (PerkinElmer); before Arc 
detection, the $A / B$ blocking kit (Vector laboratories) was used to block the remaining $A+B$, and the rabbit anti-Arc was detected with biotinylated anti-rabbit antibody (Vector Laboratories), amplified with the $A+B$ Vectastain amplification kit (Vector Laboratories), and finally visualized with the Cy3 TSA fluorescence system (PerkinElmer). Mouse IgG from the first detection was blocked using the mouse-on-mouse blocking kit (Vector Laboratories) before detection of BrdU. The mouse anti-BrdU antibody was detected with a biotinylated anti-mouse antibody in which the signal was amplified using an $A+B$ Vectastain amplification kit, and finally observed using the FITC TSA fluorescence system (PerkinElmer).

In order to determine the neuronal lineage of BrdU cells detected early in their maturation, a double staining for doublecortin (DCX) and BrdU was done. In this case, BrdU detection as described above was carried out first, and DCX was detected afterwards using a goat 1:200 anti-DCX antibody (Santa $\mathrm{Cruz}^{\circledR}$ ) then amplified with $\mathrm{A}+\mathrm{B}$ Vectastain amplification kit and revealed with $\mathrm{Cy} 3$. We also performed a double immunohistochemistry for ArC and DCX combining the methods described above. No staining was observed in the absence of the primary or secondary antibodies, for all antigens.

\section{Imaging and Analysis}

MosaiX module for the APOTOME system (Carl Zeiss, México, DF. México) with the 25X/0.80NA LCl Plan-Apochromat oil immersion objective, was used to obtain whole dentate gyrus (DG) mosaic image stacks (with $1.5-\mu \mathrm{m}$ optical $Z$ sections). About 8 to 12 individual image stacks were collected and assembled by the MosaiX system (Carl Zeiss) for each DG. About twenty-three whole DG mosaics, taken from the serial stained sections, were imaged for each animal, corresponding to a dorsoventral length of $\sim 460 \mathrm{~mm}$ from the dorsal hippocampus. It is to be noted that only those sections that were optimally stained were included in the analysis. The most anterior section was $\sim 6.0 \mathrm{~mm}$ and the most posterior was $\sim 4.7 \mathrm{~mm}$ from the interaural plane [25]. 
Using the Metamorph imaging software, a 2D image was constructed using the middle plane image from each DG MosaiX stack. This was used as the reference image, in which the DG granular layer was partitioned into 4 layers [8] (Fig. 1C), one representing the subgranular zone (SGZ) and the other 3 , the inner (L1), middle (L2), and outer (L3) part of the DG granular layer. It is important to note that the DG granular layer thickness varies across the length of the blade; for this reason, the proportion was adjusted throughout the whole length of the DG granular layer, assuring that the inner, middle, and outer DG granular layers always represented $33 \%$ of the whole layer thickness in order to analyze the position of the new granular neurons along the DG granular layer. Meanwhile, the MosaiX stack was used to identify the NeuN-positive cells (image in blue), the cells that incorporated BrdU (image in green), and those expressing Arc (image in red). The BrdU-positive cells co-localized with NeuN, particularly in the animals sacrificed 15 or more days after BrdU administration; in animals sacrificed earlier, BrdU colocalized primarily with DCX (Fig. $2 \mathrm{~A}$ and B).

We found very few BrdU-positive cells that did not co-localize with DCX in days 1 to 15 , and most of them co-localized with NeuN from day 30 onwards. These expression time points are similar to what has been reported before [12], in which the DCX or NeuN cells represented $\sim 90 \%$ of the total BrdU-positive population. Moreover we found that in animals sacrificed at early time points (1-15 days $\mathrm{PBI})$ throughout the maturation of the new neurons, Arc expression was found in DCX cells (Fig. 4). For this reason, we included all BrdUpositive cells in the study, and the NeuN staining was used to delineate the DG granular layer. The Arc-positive cells were considered to be the activated neurons. Each cell was classified as BrdU positive, Arc positive or both and its classification was marked in the reference image, according to its position in the granular layer. It is important to clarify that the image stack was used to properly classify each cell as Arc positive or BrdU positive: additionally, when a cell was classified as both BrdU positive and Arc positive, a 40X confocal image stack was projected as a 3D image to confirm this classification (see Fig. $3 \mathrm{D}$ to $\mathrm{H}$ ). After classification, the DG granular 
layer volume was calculated in the reference image, using the size of the $Z$ section and the area of the DG granular layer. With the volume of the DG granular layer, the total number of granular cells was estimated for each animal, as described before [24,26]. We estimated that about 80,000 granular neurons per animal were included in the analysis. Using the total number of granular cells per animal, the proportions of BrdU-positive cells, Arc-expressing cells, and BrdU- positive Arc expressing cells were calculated.

\section{Statistics}

One-way ANOVA with Bonferroni as a Post-hoc, MANOVA or a t-test was used where appropriate to compare the proportion of BrdUpositive, Arc-expressing, and BrdU-positive Arc-expressing cells in the different conditions and throughout the DG granular layer.

\section{Results}

New neuronal survival and migration

Notably, the proportion of BrdU-positive cells in the DG upper blade significantly varied across the different maturation times $\left(F_{4,30}=\right.$ 29.771, $P<0.001$ ) (Fig. 2C). One day post BrdU injection (PBI) the proportion of DG cells that incorporated BrdU from the whole granular cell population included in the study was $0.26 \%$, and seven days $\mathrm{PBI}$, the proportion of BrdU-positive cells (0.35\%) was significantly higher (Bonferroni yield a $\mathrm{p}<0.01$ ). At 15 days $\mathrm{PBI}$, the proportion of new granular cells was $0.23 \%$, which was significantly lower than on day $7(p<0.01)$ but not statistically different from day 1. Thirty days PBI, the proportion of BrdU-positive cells was only $0.17 \%$ and was significantly lower than the proportion of cells found on days 1,7 , and $15 \mathrm{PBI}\left(p^{\prime} s<0.01\right)$. Finally, 45 days $\mathrm{PBI}$, the proportion of BrdU-positive cells was only $0.15 \%$, which was significantly lower than day 1,7 , and 15 ( $\left.p^{\prime} s<0.01\right)$ but was not different from day 30 . The analysis of the absolute BrdU-positive cell counts revealed a similar pattern throughout time (data not shown). 

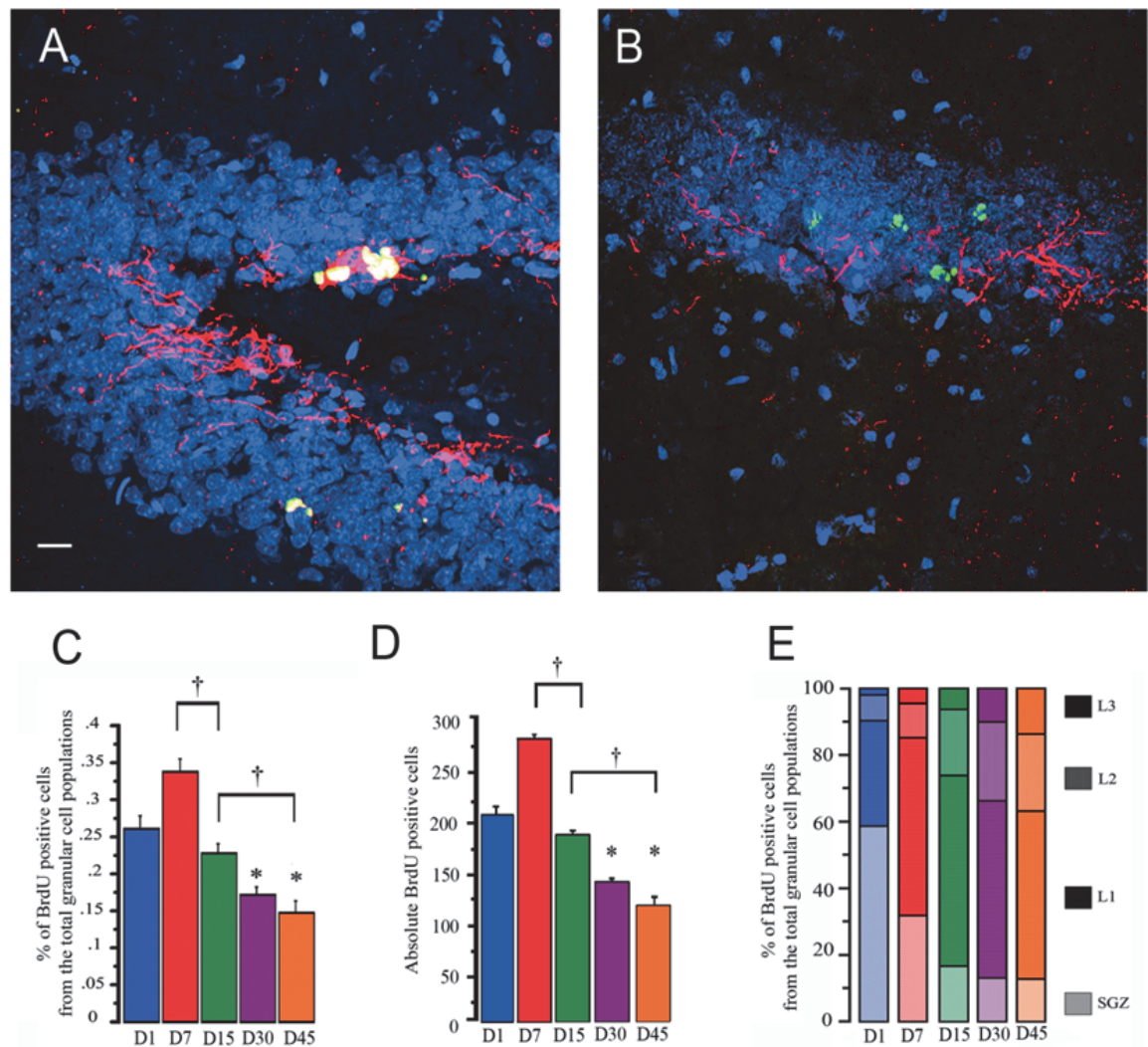

D

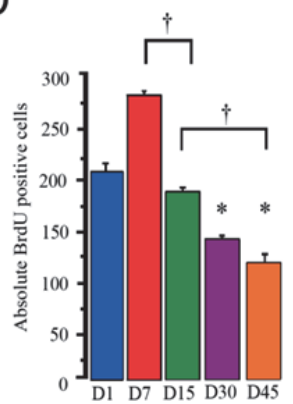

$E$

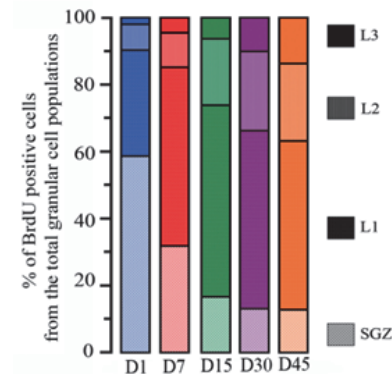

Figure 2. Survival and migration of adult-born granular cells. Confocal images, taken with a 256 objective, of the DG stained with DCX in red, BrdU in green, and counterstained with DAPI in blue. A) shows BrdU-positive cells co-localizing (yellow) with DCX from an animal sacrificed 7 days PBI; B) shows BrdU-positive cells from an animal sacrificed 45 days PBI that do not co-localize with DCX. C) Average proportion of BrdU-positive cells from the total granular cell population found in each $(1,7,15,30$, and 45 days) PBI group. ${ }^{*} \mathrm{P}, 0.01$ as compared to day $1 \mathrm{PBI}$ group, $\{\mathrm{P}, 0.01$ between indicated groups. Note the significant decrease in the proportion of BrdU-positive cells found with time after new neurons were born. D) Absolute BrdU-positive cell counts found in each PBI group (1, 7, 15, 30 and 45 days); note that the results are very similar to the proportions shown in C. E) Percentage of BrdU-positive cells from the total BrdU-positive cell population found in each DG layer: the subgranular zone (SGZ), DG layer 1 (L1), DG layer 2 (L2), and DG layer 3 (L3), for the different PBI times. The different proportions of BrdU-positive cells found in the various layers with increasing time suggest that new cells migrate through the DG layers.

In the animals sacrificed on day $1 \mathrm{PBI}$, (Fig. 2D) $60 \%$ of the BrdU-positive cells were located in the sub granular zone (SGZ), 32\% in DG layer 1 (L1), $7 \%$ in layer 2 (L2) and only the remaining $1 \%$ were found in layer 3 (L3) (For DG layers distinction see Fig. 7B). On day 7 $\mathrm{PBI}, 32 \%$ of the BrdU-positive cells were located in the SGZ, $54 \%$ in 
$\mathrm{L} 1,11 \%$ in $\mathrm{L} 2$, and $3 \%$ in $\mathrm{L} 3$. On day $15 \mathrm{PBI}, 16 \%$ of the BrdU-positive cells were located in the SGZ, $58 \%$ in L1, $19 \%$ in L2, and $6 \%$ in L3. At 30 days $\mathrm{PBI}, 13 \%$ of the BrdU-positive cells were located in the SGZ, $54 \%$ in L1, $24 \%$ in L2, and $10 \%$ in L3. Finally, at 45 days PBI, $12 \%$ of the BrdU-positive cells were located in the SGZ, $51 \%$ in L1, 23\% in L2, and $13 \%$ in L3.

The proportion of cells found in each DG layer was compared among the different PBI groups using one-way ANOVA. The proportion of cells in the SGZ differed statistically among groups $\left(F_{4,30}=176.086, P<0.001\right)$, where the proportion of BrdU-positive cells found in animals sacrificed on day 1 PBI was significantly different (using the Bonferroni correction as a post hoc) from all other groups $(p<0.01)$. For $L 1$, the proportion of BrdU-positive neurons differed significantly among groups $\left(F_{4,30}=47.687, P<\right.$ 0.001 ), and the post hoc analysis showed differences between animals sacrificed at day $1 \mathrm{PBI}$ and the rest of the groups $(p<0.01)$. Differences were also found between animals sacrificed at day 15 and day $45 \mathrm{PBI}(\mathrm{P}<0.01)$. In $\mathrm{L} 2$, significant differences were found in the proportion of BrdU-positive cells among groups $\left(F_{4,30}=40.070, P\right.$ $<0.001)$, and the post hoc analysis revealed differences between animals sacrificed at day $1 \mathrm{PBI}$ and the animals sacrificed 15,30 , and 45 days $\mathrm{PBI}(\mathrm{p}<0.01)$; differences were also found between animals sacrificed at day $7 \mathrm{PBI}$ and those sacrificed at days 15,30 , and $45 \mathrm{PBI}$ $(p<0.01$ ); finally in L2, significant differences were found between animals sacrificed on day 15 and those sacrificed on day $30 \mathrm{PBI}(\mathrm{p}<$ $0.01)$. In $L 3$, significant differences were found among groups $\left(F_{4,30}=\right.$ $35.403, P<0.001)$, and the post hoc analysis revealed that most of the $\mathrm{PBI}$ groups differed from each other $(p<0.01)$, except those sacrificed on day 1 as compared to those sacrificed on day $7 \mathrm{PBI}$ and animals sacrificed on day 7 compared to those sacrificed on day 15 $\mathrm{PBI}$.

The differences in the proportion of cells located in the different regions between the animals sacrificed at different PBI times indicate that the newly incorporated cells migrate through the different DG layers. 


\section{Sparse Arc expression in DG granular cells after spatial exploration}

After spatial exploration, the expression of the immediate early gene Arc was observed in $\sim 1.5 \%$ of the granular cell population, while in the cage control animals only $\sim 0.3 \%$ granular cells were classified as Arc positive. The proportion of cells expressing Arc between cage control and exploration treated animals was significantly different $\left(F_{1,33}=12.042, P<0.001\right)$, demonstrating that a small population of granular neurons in the DG expressed Arc in response to a novel spatial exploration in an open box (Fig. 3A), as previously reported $[24,26,27]$, and suggesting a sparse DG code for spatial information.
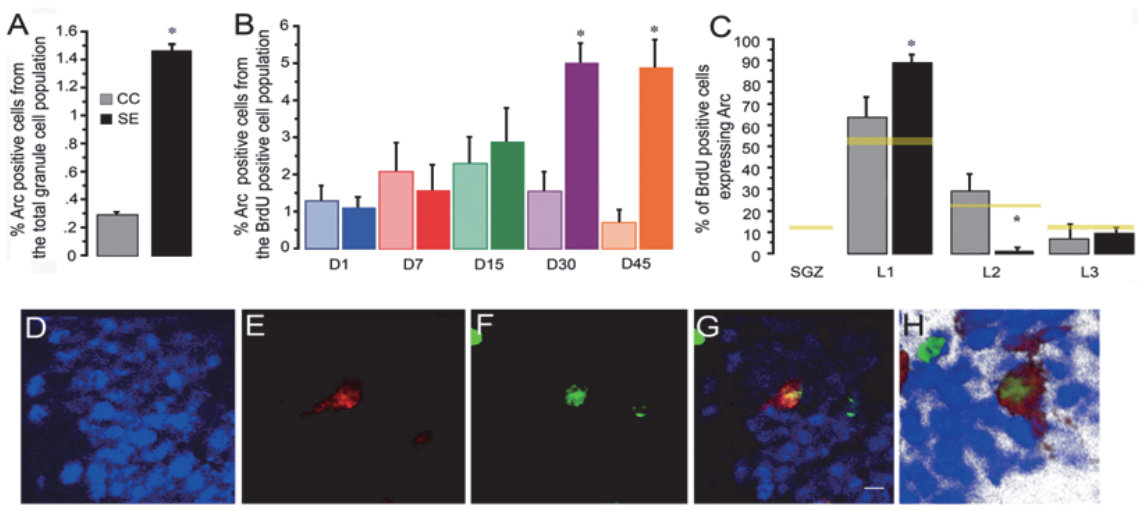

Figure 3. Arc expression after spatial exploration A) Percentage of the whole granular cell population that expresses Arc after spatial exploration. Note that Arc expression is observed in a higher proportion of cells in the exploration group (solid bar) than in cage controls (pattern bar). ${ }^{*} P, 0.001$. B) Percentage of BrdU-positive cells that expressed Arc in each PBI group, i.e., sacrificed either directly from its home cage (CC, pattern bar) or after spatial exploration (SE, solid bar). Arc expression in BrdU-positive cells occurs with no behavioral stimulation from day 1 until day 15 PBI, but on days 30 and 45 PBI, ArC expression was observed in significantly more BrdU-positive neurons from exploration animals than from cage controls. ${ }^{*} P, 0.01$. C) Percentage of BrdU-positive cells expressing Arc in each DG layer, either after cage control conditions (patterned bar) or spatial exploration (solid bar). The yellow horizontal bars represent the proportion of the total BrdU-positive cells found in each layer on days 30 and 45 . Note that no Arc expression was found in BrdU-positive neurons in the SGZ. In L1, the IEG Arc was expressed in a larger proportion of new neurons from exploration animals than from the cage controls, ${ }^{*} \mathrm{P}, 0.01$, indicating that BrdU-positive neurons located in $\mathrm{L} 1$ are more likely to respond to exploration. The opposite was observed in L2, i.e.,the proportion of BrdU-positive cells in L2 that expressed Arc was much lower in SE than in CC animals. D to H) 406confocal images taken from the middle plane of a confocal microscope image stack were used to verify the co-localization of Arc and BrdU. D) NeuN in blue, E) Arc protein in red, F) BrdU in green, G) NeuN, Arc, and BrdU merge; note that BrdU-positive neurons expressing Arc appear yellow. H) Flat image obtained from a 3D boxels reconstruction. The rotation of the 3D projection was used to confirm BrdU and Arc co-localization. The scale bar in $\mathrm{G}$ is 100 $\mu \mathrm{m}$. 
Specific Arc expression response to spatial exploration develops in new neurons over a 30-day period.

By using double staining, we observed that in animals sacrificed at early PBI times (1-15 days), BrdU is found mostly in DCX-positive cells and in late $\mathrm{PBI}$ time (30-45 days) primarily in NeuN positive neurons (Fig. 3D-H). We also observed that Arc can be expressed in DCX positive cells at early times (Fig. 4). For these reasons we included all BrdU-positive cells found in the different DG layers in further analysis.

Arc expression in BrdU-positive population differed across the different treatment groups (Fig. 3B). A 2-way-ANOVA showed significant differences between days $\mathrm{PBI}\left(F_{4,25}=3.79=, P<0.02\right)$; between exploration and cage control conditions $\left(F_{4,25}=13.603, P<\right.$ $0.01)$ and among days and the behavioural treatment $\left(F_{4,25}=5.437 p\right.$ $<0.0027)$. On day $1 \mathrm{PBI}$, Arc expression was observed in $1.3 \%$ of the BrdU-positive cells found in cage control animals (CC) and in 1.01\% of the BrdU-positive cells found in animals exposed to spatial exploration (SE); these values were not significantly different. Arc was expressed in $2.1 \%$ of the 7-day-old new neurons from CC animals and in a similar percentage (1.56\%) of the corresponding new neurons from SE animals. Moreover, the proportion of 7-dayold, BrdU-positive cells expressing Arc did not differ from the proportion of new cells expressing Arc on day $1 \mathrm{PBI}$ from either the SE or CC group. Fifteen days PBI, Arc was expressed in a similar proportion of new cells from CC animals ( $2.3 \%)$ and from the SE group (2.9\%). Although Arc expression in BrdU-positive cells tended to increase from day 1 to day $15 \mathrm{PBI}$, this increase was not statistically significant. Importantly, these results suggest that Arc expression at this early time after these new neurons were born may not be driven by spatial behavior stimulation. In contrast, when new neurons were 30 days old, the proportion of BrdU+/Arc+ cells was significantly greater $(p<0.01)$ in SE $(\sim 5 \%)$ than in CC animals $(\sim 1.5 \%)$. The proportion of BrdU+/Arc+ cells at 45 days $\mathrm{PBI}$ also differed significantly $(p<0.001)$ between SE $(4.8 \%)$ and CC animals $(0.7 \%)$.

$A$ repeated measures ANOVA was done on the percentage of cells expressing Arc at the different $\mathrm{PBI}$ times and revealed 
significant changes with time $\left(F_{1,5}=26.839, P<0.01\right)$, differences between SE and CC groups $\left(F_{4,4}=3.385, P<0.05\right)$, and also a significant interaction $\left(F_{4,6}=5.887, P<0.01\right)$, indicating that a specific Arc expression response to spatial exploration developed between 30 and 45 days after new neurons were born.

It is important to note that the proportion of BrdU+/Arc+ cells in response to exploration at 45 days PBI was significantly greater than the percentage of total granular cells expressing Arc in response to exploration $\left(T_{6}=7.995 p<0.001\right)$.
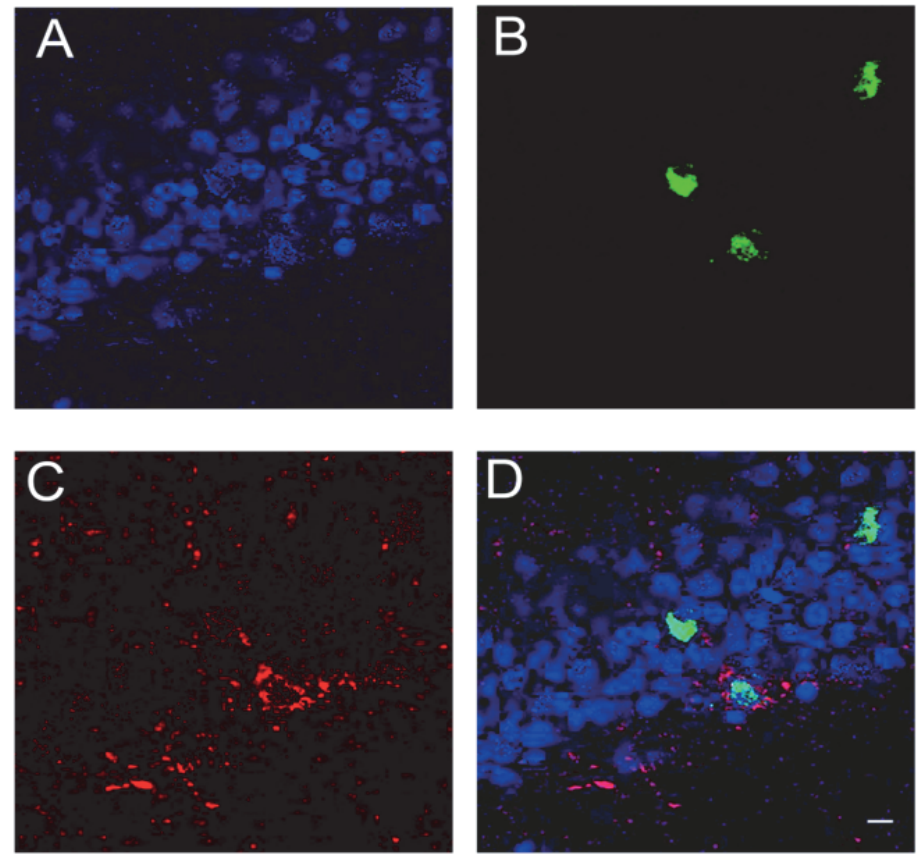

Figure 4. Arc Expression in DCX-positive cells. The images show double immunohistochemistry for Arc and DCX, and were taken with the Apotome microscope system (Zeiss) with a 40x/1.3 NA objective using $Z$ section resolution. A) DAPI is shown in blue, B) Arc protein is shown in green, C)DCX is shown in red, and D) the 3 channels were merged. Scale bar $=100 \mu \mathrm{m}$.

Exploration induced Arc expression in BrdU-positive cells is observed mainly in DG L1

The position of the BrdU-positive cells expressing Arc within the different dentate gyrus granular layers [8] was identified and for each layer we calculated the proportion of BrdU-positive cells expressing Arc relative to the total population of BrdU-positive cells 
that express Arc. These proportions were compared between CC and SE groups (Fig. $3 \mathrm{C}$ ) at all the 5 time points when the animals were sacrificed. Significant differences were found between CC and SE animals in $\mathrm{L} 1\left(F_{1,33}=8.754, P<0.01\right)$, where $89.3 \%$ of the BrdUpositive cells expressing Arc from the SE group but only $63.78 \%$ from the CC group were located. In L2, the proportion of Arc-expressing cells also differed significantly between CC and SE animals $\left(F_{1,33}=\right.$ 14.509, $P<0.001$ ): $29.56 \%$ of the BrdU-positive cells from the CC group expressing Arc were located in L2 as compared to $1.67 \%$ from the exploration animals. In L3, no significant differences were found between groups. The MANOVA analysis revealed significant differences between the various layers in the proportion of BrdUpositive cells expressing Arc (Wilks lambda $F_{2,31}=7.183, P<0.01$ ), and it is clear that $\mathrm{L} 1$ region had the highest Arc expression in BrdUpositive cells. Importantly BrdU-positive cells expressing Arc were not found in the SGZ. Using a Student's t-test we compared the proportion of $\mathrm{BrdU}+/ \mathrm{Arc}+$ cells with the proportion of BrdU-positive cells among the different DG layers. Since the specific Arc expression response to exploration develops after 30 days, in this analysis we included only the animals sacrificed 30 and 45 days after the BrdU injection. The proportion of BrdU+/Arc+ cells was significantly higher than the proportion of BrdU-positive cells in L1 only for SE animals but not CC animals $(p<0.01)$. In contrast, in layer 2 of SE but no CC animals, the proportion of BrdU+/Arc+ cells was significantly lower $(p<0.01)$ than the proportion of all BrdU-positive cells. No differences were found in layer 3.

\section{A hypothesis suggesting that adult-born neurons modify their contribution to spatial information processing throughout their life and the animal's life-span.}

Here, we found that the proportion of new granular cells that responded to exploration 30 days after these neurons were born was $5 \%$ and at day $45 \mathrm{PBI}$ it was $4.8 \%$. Previously, we reported that $2.8 \%$ of the 5 -month-old, newly incorporated neurons responded to exploration [2]. This suggests that the likelihood of a new neuron to respond to behavioral exploration decreases with time [27]. In this 
study we included $~ 80,000$ upper blade DG granular cells per animal, obtained from $450 \mu \mathrm{m}$ in the antero-posterior axis. The whole sample region measured $1300 \mu \mathrm{m}$ and we calculated that it contained 230,000 DG granular neurons. From this population of neurons, $1.5 \%$ (3465) responded to spatial exploration, a result similar to what has been reported previously $[24,26,27]$.

We hypothesize that the probability of the adult born granular neurons to respond to spatial exploration changes linearly with time:

$$
P(t)=P_{0}+r t
$$

where $P_{0}$ indicates the percentage of neurons that respond when they are 30 days old. We used a linear regression to estimate the parameters of our model $\left(P_{0}=0.054, r=-0.0002, R^{2}=0.9989\right.$, $p=0.0208$ ) and the result is shown in Figure $5 \mathrm{~A}$, were the red circles represent our current data, and the yellow circle represents our earlier result [2]. The line represents the model, with which we calculate the probability that granular cells will respond to spatial exploration after they are more than 150 days old. Obtaining the intercept of the line to reach a probability of 0 by the following formula:

$$
t=-\frac{P_{0}}{r}=-\frac{0.054}{0.0002}
$$

This suggests that 301 days after the new neurons where born, they no longer respond to spatial exploration. We also used the individual data from each animal to calculate this linear regression and obtained a significant regression $\left(\mathrm{P}_{0}=.0505, \mathrm{r}=-0.0002, R^{2}=0.5101, \mathrm{p}=0.0135\right)$, validating the conclusion obtained with the average proportions. We acknowledge that a linear model with only 3 data points presents clear limitations, and further research is needed to add more data points between 45 and 360 days. This will allow us to determine if a linear model is adequate and will test the prediction that cells no longer respond to exploration after they are $\sim 1$ year old. 

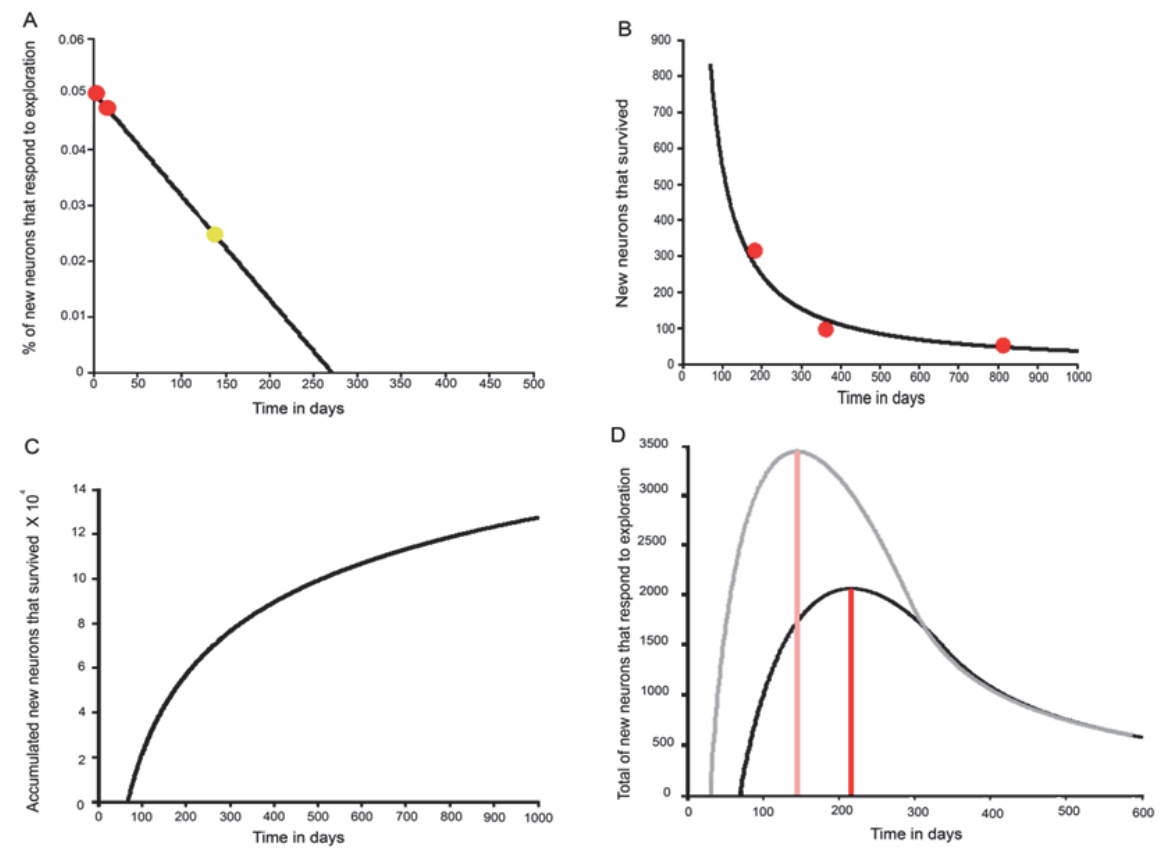

Figure 5. Contribution of adult-born neurons to spatial information processing: a hypothesis suggested by integrating our current data with that obtained previously. A) Linear regression plot calculated using the percentage of BrdU-positive cells that specifically respond to spatial exploration by expressing Arc from animals sacrificed on days 30 and $45 \mathrm{PBI}$ (red dots), and those sacrificed 150 days PBI (yellow dot) [2]. Using this model we calculated the maximum length of time throughout the life span of the animal during which adult-born neurons respond to spatial exploration (time in days means age of animals in $\mathrm{X}$ axis for all graphs). The result suggests that after $301(271+30)$ days, the neurons born in the adult brain may no longer respond to spatial exploration. B) The data obtained from Kuhn [29] was scaled to fit our BrdU-positive cell proportions, and a power model was used to calculate the number of neurons that survived at the different times through the animal's life. C) Cumulative number of new neurons that survived after 30 days including all the neurons born since 70 days post natal, when the animal is already mature. D) Total number of neurons born after DG development that contributes to the DG spatial exploration response over the course of the animal's life span. The red line shows the time (day 217) when the maximum number of newly incorporated neurons participates in the DG network response to spatial information processing. At this time, 2057 new neurons respond to spatial exploration, which represents $60 \%$ of the total DG granular cell population that responds to spatial exploration. The super-imposed graph (shown in light colors) represents the same calculation including the number of neurons born since postnatal day 1 that survive for 30 days. Notice in particular that the contribution to spatial information processing of neurons born after the DG development is complete increases through the early age of the animals, and after reaching its maximum, it rapidly decreases to a plateau reached in late adulthood.

The number of new granular neurons found 45 days after birth in the sampled regions was 345. Adult-born neurons that survived for 4 weeks remained stable for at least 11 months [8]; therefore we can assume that the number of newly incorporated 
neurons detected at days 30-45 PBI represents the number of cells born on 1 day that will survive for the rest of the animal's life. However, the rate of cell proliferation varies across the animal's lifespan [28], and this modifies the number of stable new neurons throughout the lifetime.

$\begin{array}{cccc}\text { Animal's age in days }=\mathrm{t} & 180 & 360 & 810 \\ \text { \# of Neurons in the sampled region } & 58 & 18 & 10\end{array}$

By using the data obtained previously [28] we proposed a power model.

$$
N(t)=N_{0}\left(\frac{t}{30}\right)^{s}
$$

Since the DG is fully assembled after the first post-natal weeks [29], sexual maturity is reach after 6 weeks [30], and the neurons that survive for 4 weeks remain, we performed further calculations using the number of granular cells that were born and survived since postnatal day $70 . \mathrm{N}_{0}$ is then the number of new granular neurons that survive for 30 days. In order to estimate the parameters of our model, we calculate a linear regression. We choose ' $s$ ' such as the equation predicts the number of BrdU-positive cells that we detect after 45 days in the current work (Figure 2C\&D). $(N(150)=345)$. The result $N_{0}=2218.2$, is shown in the Figure $5 \mathrm{~B}$, where the red dots are the data and the solid line is the model. From these data we calculate the cumulative number of neurons that were born after the animal was sexually mature and that survived throughout the animal's life span, assuming that there is no mortality after 30 days of maturation [8]).

$$
\int_{0}^{t} N(\tau) d \tau
$$

The cumulative number of adult-born granular neurons over the course of the animal's life-span is shown in Figure $5 \mathrm{C}$. In order to 
estimate the number of adult-born granular neurons that contribute to the DG response to spatial exploration throughout the animal's life span, we considered the number of neurons that are added through time $(\mathrm{N}(\mathrm{t}))$ and the probability that they will respond at different time intervals $(P(t))$ after they were added. In order to combine these measurements we used a convolution of the variables $N$ and $P$.

$$
R(t)=\int_{30}^{\infty} N(\tau) P(t-\tau) d \tau
$$

This is the overlap level of $\mathrm{N}$ and the function of $\mathrm{P}$ transferred and inverted, which implies the number of new neurons $N(\tau)$ at time $\mathrm{t}$ (throughout the animal's life span) under the proportion $P(t-\tau)$ that contribute to spatial information processing (see Fig. 6A and 6B for a graphic explanation). The resulting calculation showed that the time $t$, when the maximum number of neurons, that were born after the DG network was fully formed, contribute to spatial exploration processing, is at day 217, where 2057 of the adult-born neurons in the sample region are predicted to respond to spatial exploration (Fig. 5D). This represents $60 \%$ of the total granular cell population that responds to this behavior. If we include in our calculation all the neurons born after the animal's birth that survive for 30 days, the result suggest that at day 129 of the animal's life, $99 \%$ of the neurons that respond to exploration are neurons that were born post-natally (Figure 5D, shaded line).

We emphasize that this model is presented only as a new hypothesis suggesting that the neurons born in the adult mammal hippocampus change their contribution throughout both, their own and the animal's life span. These results, though inconclusive, should stimulate further studies that evaluate the relevance and contribution of newly incorporated granular neurons through time. 
A
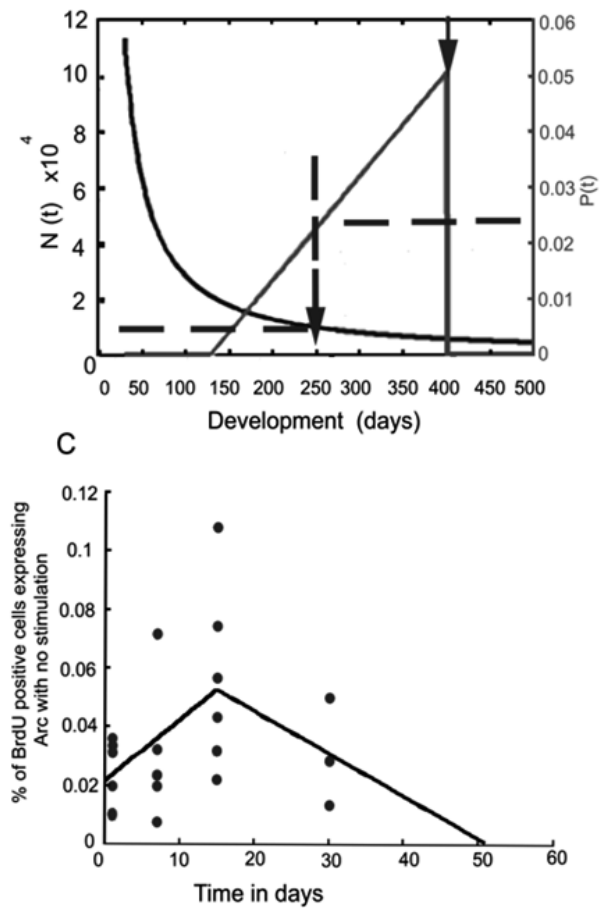

B

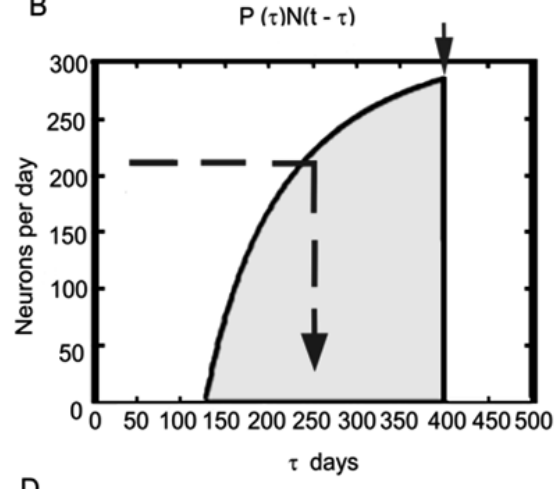

D

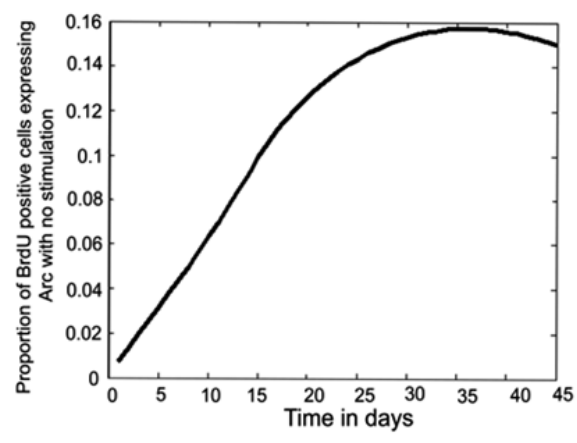

Figure 6. Illustration of the calculation procedure. A) As an example of our calculation that lead to the results found in Figure 6D, we can estimate the number of cells that contribute to the spatial exploration response at day 400 in the life of (small arrow), from cells born on day 250 . We found $, 11,000$ new neurons that were born on day 250 and survive for at least 30 days; when we multiplied this by the proportion of neurons that responds to exploration at day 400 (2\%), we calculated that ,220 cells respond to exploration (big arrow in B); B) When all the new neurons are considered (area under the line) we have a total number of neurons that respond at day 400 , from the cumulative number of new neurons at that time. C) To determine the background due to Arc expression during early development of new neurons, we calculated the probability of neurons to express Arc from 1 to 30 days, using 2 linear models. D) A similar convolution as the one used for our previous calculation was done to estimate the number of adult-born neurons found from 1 to 30 days PBI (Figure $5 \mathrm{C}$ ). Note that the maximum proportion of neurons that express Arc with no stimulation is, $0.16 \%$; for comparison, cage control animals present $0.31 \%$ of cells expressing Arc with no previous stimulation (Figure $5 \mathrm{~A}$ ), and this represents, $10 \%$ of the granular cells expressing Arc after spatial exploration.

\section{Discussion}

During the first 6 weeks, the average proportion of BrdU-positive cells found in the DG from all animals fell from $\sim 0.35 \%$ on day 7 to $\sim 0.15 \%$ on day 45 , suggesting that $\sim 60 \%$ of the neurons detected on day 7 died over the course of the next 5 weeks.

It has been reported that in mouse, new neurons that survive 
more than 4 weeks represent $20 \%$ to $45 \%$ of the proliferating cells $[2,32]$ and that in rats, they represent 42 to $60 \%$ of the newly born neurons $[11,32]$. In the present work, the number of BrdU-positive cells found on day 1 PBI was lower than the number of cells found on day 7 PBI. This may be explained by the fact that on day 1 , only 12 hrs had passed since the last BrdU administration, and more new cells may have incorporated BrdU in the following hours [33]. This is consistent with an earlier report that used a single exposure to $\left[{ }^{3} \mathrm{H}\right]$ methyl-thymidine and found more labeled cells on day 7 than on day 1 [34]. Here, we found that the proportion of granular cells born on one day that survive for 45 days is $0.15 \%$, and that these cells may survive for 3 to 11 months [8,32]; the result was similar using the absolute BrdU-positive cells counts. We calculated that the whole DG contains $\sim 1,200,000$ granular cells, which is consistent with previous reports $[35,36]$ and suggests that the number of cells born in the DG during one day that survive is $\sim 1,800$. A similar number can be calculated by using the estimated number of cells born each day in the adult rat DG [33] and subtracting the dying neurons [8,32].

The location of the BrdU-positive cells among the different DG layers throughout time indicated that new cells migrate from the SGZ through the rest of the layers, as previously reported $[8,14]$. The highest migration from the SGZ to DG L1 and L2 was reported to occur between day 7 and 14 [14]. We observed that from day 1 to 15 $\mathrm{PBI}$, when expression of DCX is highest [12], the location of new cells changed significantly, primarily from the SGZ to DG L1 and L2, indicating that this new neurons migrate through the DG layers. Our results also show that a small proportion of BrdU-positive cells $(, 10 \%)$ stay in the SGZ. Most (51\%) of the BrdU-positive cells that survive for 45 days stay in DG L1, consistent with previous observations that ,60\% of the newly incorporated neurons were located in this layer [8]; at day $45 \mathrm{PBI}$ the percentage of new cells that we found in L2 was $22.6 \%$, and in L3 it was $13.5 \%$, also consistent with the earlier report.

The proportion of DG neurons expressing Arc after exploration was $1.5 \%$, significantly higher than that observed in the cage control animals and in agreement with the notion of a sparse code for 
spatial information processing in the DG $[22,26,27]$.

The likelihood of observing Arc expression in BrdU-positive cells increases throughout new neuron maturation, as recently reported for other IEGs such as zif268 and cFos [32]. The highest IEG (zif268 and cFos) expression, after kainate-induced seizures, was observed at 4 weeks and remained stable at 10 weeks. The expression of zif268 induced by water maze training was maximal at 3 weeks; however, it is not clear if such expression was specifically induced by the behavioral treatment, since no behavioral controls were shown [32]. In our case, from day 1 until day $15 \mathrm{PBI}$ the proportion of BrdU-positive cells expressing Arc was similar in cage control and exploration animals. Likewise, in animals that received LTP-inducing stimulation, Arc expression was reported in both the stimulated and the non-stimulated hemispheres in 1-day-old new neurons [25]. These data suggest that Arc expression in new neurons at an early stage of their development occurs independently of sensory or behavioral stimulation. We cannot suggest that this seemingly spontaneous or constitutive Arc expression [25] is independent of neuronal activity, but it may occur without synaptic stimulation since immature granular neurons do not respond to synaptic input or are "silent" at this early stage [14]. It is possible then, that these new neurons may be activated in response to paracrine BDNF release or other signals [37], which is an interesting idea since this time is critical for the maturation and synaptic integration of adult- born neurons. Arc expression at this early stage may be indicative of an ongoing biological process involved in the synaptic integration of adult-born neurons [25]. This hypothesis is supported by recent evidence showing that Arc increases the density of immature spines and regulates spine morphology [38]. Studying the role of Arc expression in young, adult-born granular neurons may help to understand the cellular mechanisms underlying the synaptic integration of these neurons.

On the other hand, Arc expression at these early stages may represent background noise in the system. For this reason, we calculated the number of new neurons that contribute to Arc expression in the general population. The result indicated that in 
cage control animals $\sim 50 \%$ of all the granular neurons expressing Arc may be new granular neurons born between 1 and 30 days before sacrifice (See Fig. 6C \& D). However, this represents only $10 \%$ of the neurons expressing Arc in response to spatial exploration, suggesting that the background noise produced by this Arc expression in young new neurons contributes relatively little to the whole DG network response to exploration.

At days 30 and $45 \mathrm{PBI}$, Arc expression in the BrdU-positive cells was significantly higher in animals allowed to explore than in cage controls, indicating that a specific response to exploration develops with maturation. Previously, it was reported that the unspecific expression of Arc in response to LTP stimulation lasted for about 28 days, but the number of BrdU-positive cells expressing Arc under these conditions increased on day 28 in the granular cell layer, and from day 14 onwards in the SGZ [25]. In contrast, we found no Arc expression in the BrdU-positive neurons located in the SGZ (Fig. 3C), indicating that new granular cells found in this DG region are not responsive to behavioral exploration and may not be functionally integrated into the behaviorally relevant network. This agrees with our own analysis of Arc expression in the different DG layers (Fig. 7B), where we did not find Arc-expressing cells after spatial exploration in the SGZ. This may suggest that migration from the SGZ to the DG granular layer is mandatory for new neurons to be able to respond to behavioral exploration and express Arc. The discrepancies with Kuiper's work may also be explained by the different stimulation methods and the animals that were used. It is possible, even in the non-stimulated hemisphere and in the SGZ [24], that a strong electrophysiological stimulus can activate the CA3c commissural projections [39], thereby inducing Arc expression in new neurons due to their enhanced plasticity [40]. Another possibility is that the functional integration of adult-born neurons into the hippocampal network may take longer in Sprague Dawley than in Wistar rats.

The enhanced plasticity of newly incorporated neurons (4 to 6 weeks of age) was confirmed in the present study with the observation that ,5\% of the new neurons found at 30-45 days PBI 
responded to exploration by expressing Arc, whereas only $1.5 \%$ of the total DG neurons responded. This difference is similar to a previous report [19] and agrees with our earlier findings [2], where a significantly higher proportion of 5-month-old new neurons than of total DG neurons expressed Arc in response to spatial exploration.

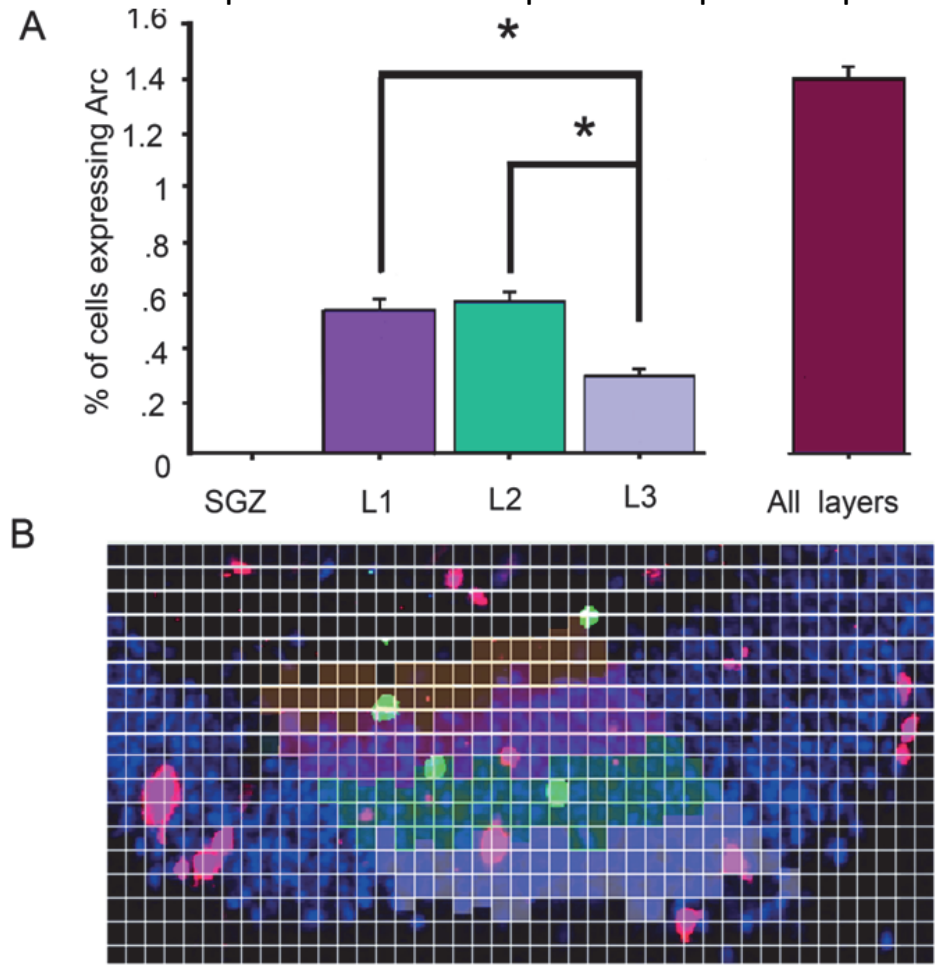

Figure 7. Dentate gyrus layer segmentation and Arc expression in the different layers. A) Percentage of granular cells (from the general population) expressing Arc in the different DG layers after spatial exploration. The red bar is the proportion of cells expressing Arc in all layers. B) Shows a representative DG layer image segmented into 4 equidistant layers. NeuN-positive granular cells are shown in blue, Arc-expressing cells in pink, and BrdU-positive cells in green. The grid was used as a guide for the segmentation procedure, and the cells that were mainly (.50\%) located in grids from a particular layer were considered to belong to that layer. The segmentation is represented by an overlay of translucent colors. In brown is the SGZ, in purple L1, in green L2, and in gray L3.

The timing for the development of this Arc expression in response to spatial exploration coincides with the dynamic cellular process that takes place in these cells $[9,10,14]$ and reflects the course of selective survival and integration into a network that processes spatial information. Around the time new neurons become 
responsive $[13,14]$ and their glutamatergic and GABAergic input matures $[13,14,15,16]$, the expression of Arc rises and becomes specific. This suggests that the enhanced survival effect of behavioral stimulation soon after new neurons are born [41,42] depends on a non-specific activation of DG neurons, probably related to BDNF expression $[43,44]$.

In animals exposed to spatial exploration, ,90\% of their BrdUpositive cells that express Arc were located in DG L1 compared to $60 \%$ in the cage control group. The distribution pattern of BrdUpositive neurons among the DG layers (Fig. 2D) is similar to that observed for BrdU-positive neurons expressing Arc in cage control animals but notably different from the distribution of new neurons that respond to spatial exploration by expressing Arc. The observations that mature (28-day-old), new neurons found in DG L1 exhibit a well-defined dendritic structure, a conspicuous axonal projection extending towards the hilus, and spiny dendrites reaching the outer molecular layer [14] suggest that neurons located in L1 mature earlier, developing a functional response to the input, while neurons located in L2 and L3 develop these features later. This may explain why most of the adult-born neurons that are functionally integrated into the behaviorally relevant network are located in this inner layer, and suggests that the time required for migration may delay the functional integration of new neurons; thus, it is expected that neurons located in L2 and L3 will acquire the ability to respond specifically to spatial exploration at a time point later than 45 days, since Arc- expressing cells are found in all 3 granular layers with a bias towards those located in the inner DG (see Fig. 4B).

When we estimated the proportion of BrdU-positive cells that respond to spatial exploration by expressing Arc over the course of the animal's life span, we found a highly significant linear regression; thus, our hypothesis is that neurons born in the adult DG after day 301 do not respond to exploration anymore; this does not suggest that new neurons lose their integration within the network but rather that they can no longer be recruited into circuits that process spatial information (Fig. 5A), which may be related to a network mechanism that ensures that the DG code for spatial information can 
change. It is important to acknowledge that a non-linear model may also fit the data, and that more data points are required to demonstrate that our hypothesis is correct; however, the hypothesis is supported by the highly significant linear regression analysis and by the fact that the number of new neural units under the curve throughout the animal's life (Fig. 6D) agrees with the total number of Arc-expressing cells after exploration.

The hypothesis that old granular cells no longer process spatial information after a certain time agrees with the granular cell retirement hypothesis [45], which suggests that granular neurons process spatial information for a limited period of time. This satisfies an important requirement of the associative memory model from Treves and Rolls [46], which proposes that: “...during retrieval..., the mossy fiber input should be absent or strongly reduced..., in order not to blur the signal relayed by the perforant path". Our data suggest that, instead of shutting down or reducing the DG input to the CA3 during retrieval, a few granular neurons retire every day, gradually changing the DG code of a particular experience. This hypothesis is of great interest, but its validity must be tested by further research with more time points, especially at late maturation times for adult-born neurons.

The model also suggests that in a 7-month-old animal, $60 \%$ ([5- month-old and 99\%] if we include all neurons added postnatally) of the total granular neurons that responded to exploration should be neurons born after the DG was fully formed. This suggests that adult-born neurons may contribute more to spatial information processing than pre-natally born granular neurons. This idea was recently tested in mice that received the administration of the thymidine analog CidU either on embryonic day 18 or postnatal day 7 and another thymidine analog IdU on postnatal day 60 [47]. The results showed no differences in the proportion of granular cells responding to spatial behavior by expressing cFos. However, if we compare the time of analysis (Postnatal day 60) with our model (Fig. 5D) and consider that rats and mice present slight differences in the speed of maturation and life span [31,48], it is possible that differences may be observed at later time points, congruently, other 
groups had recently found a higher proportion of adult born granular neurons responding to behavior compare to prenatally born granular neurons (Nora Abrous, Personal Communication). In any case, the model suggests that adult neurogenesis plays a pivotal role in spatial information processing, and that this contribution changes with time, which may explain cognitive changes related to hippocampal function over the course of the animal's life 


\section{References}

1. van Praag H, Schinder AF, Christie BR, Toni N, Palmer TD, et al. (2002) Functional neurogenesis in the adult hippocampus. Nature 415: 1030-1034.

2. Ramirez-Amaya V, Marrone DF, Gage FH, Worley PF, Barnes CA (2006) Integration of new neurons into functional neural networks. J Neurosci 26: 12237-12241.

3. Toni N, Laplagne DA, Zhao C, Lombardi G, Ribak CE, et al. (2008) Neurons born in the adult dentate gyrus form functional synapses with target cells. Nature Neurosci 11: 901-907.

4. Rihn LL, Claiborne BJ (1990) Dendritic growth and regression in rat dentate granule cells during late postnatal development. Brain Res Dev Brain Res 54: 115-124.

5. Jones SP, Rahimi O, O'Boyle MP, Diaz DL, Claiborne BJ (2003) Maturation of granule cell dendrites after mossy fiber arrival in hippocampal field CA3. Hippocampus 13: 413-427.

6. Rao MS, Hattiangady B, Abdel-Rahman A, Stanley DP, Shetty AK (2005) Newly born cells in the ageing dentate gyrus display normal migration, survival and neuronal fate choice but endure retarded early maturation. Eur J Neurosci 21: 464-476.

7. Overstreet-Wadiche LS, Bensen AL, Westbrook GL (2006) Delayed development of adult-generated granule cells in dentate gyrus. J Neurosci 26: 2326-34.

8. Kempermann G, Gast D, Kronenberg G, Yamaguchi M, Gage FH (2003) Early determination and long-term persistence of adult generated new neurons in the hippocapus mice. Development 130: 391-399.

9. Abrous DN, Koehl M, Le Moal M (2005) Adult neurogenesis: From precursors to network and physiology. Physiol Rev 85: 523-569.

10. Piatti VC, Espo' si to MS, Schinder AF (2006) The timing of neuronal development in adult hippocampal neurogenesis. Neuroscientist 12: 463468.

11. Dayer AG, Ford AA, Cleaver KM, Yassaee M, Cameron HA (2003) Short-term and long-term survival of new neurons in the rat dentate gyrus. J Comp Neurol 460: 563-572.

12. Brown JP, Couillard-Despres S, Cooper-Kuhn CM, Winkler J, Aigner L, et al. (2003) Transient expression of doublecortin during adult neurogenesis. J Comp Neurol 467: 1-10.

13. Ambrogini P, Lattanzi D, Ciuffoli S, Agostini D, Bertini L, et al. (2004) Morphofunctional characterization of neuronal cells at different stages of maturation in granule cell layer of adult rat dentate gyrus. Brain Res 1017: 21-31.

14. Esposito MS, Piatti VC, Laplagne DA, Morgenstern NA, Ferrari CC, et al. (2005) Neuronal differentiation in the adult hippocampus recapitulates 
embryonic development. J Neurosci 25: 10074-10086.

15. Ge S, Goh EL, Sailor KA, Kitabatake Y, Ming GL, et al. (2006) GABA regulates synaptic integration of newly generated neurons in the adult brain. Nature 439: 589-593.

16. Karten YJ, Jones MA, Jeurling SI, Cameron HA (2006) GABAergic signaling in young granule cells in the adult rat and mouse dentate gyrus. Hippocampus 16: 312-20.

17. Hastings NB, Gould E (1999) Rapid extension of axons into the CA3 region by adult generated granule cells. J Comp Neurol 413: 146-154.

18. Zhao C, Teng EM, Summers RG, Jr., Ming GL, Gage FH (2006) Distinct morphological stages of dentate granule neuron maturation in the adult mouse hippocampus. J Neurosci 26: 3-11.

19. Kee N, Teixeira CM, Wang AH, Frankland PW (2007) Preferential incorporation of adult-generated granule cells into spatial memory networks in the dentate gyrus. Nat Neurosci 10: 355-362 20. Jessberger S, Kempermann G (2003) Adult-born hippocampal neurons mature into activity-dependent responsiveness. Eur J Neurosci 18: 2707-2712.

21. Tashiro A, Makino H, Gage FH (2007) Experience-specific functional modification of the dentate gyrus through adult neurogenesis: a critical period during an immature stage. J Neurosci 27: 3252-9.

22. Ramírez-Amaya V, Vazdarjanova A, Mikhael D, Rosi S, Worley PF, et al. (2005) Spatial exploration induced Arc mRNA and protein expression: Evidence for selective, network-specific reactivation. J Neurosci 25(7): 1761-1768.

23. Guzowski JF, Lyford GL, Stevenson GD, Houston FP, McGaugh JL, et al. (2000) Inhibition of activity-dependent arc protein expression in the rat hippocampus impairs the maintenance of long-term potentiation and the consolidation of long-term memory. J Neurosci 20: 3993-4001.

24. Plath N, Ohana O, Dammermann B, Errington ML, Schmitz D, et al. (2006) Arc/Arg3.1 is essential for the consolidation of synaptic plasticity and memories. Neuron 52: 437-444.

25. Kuipers SD, Tiron A, Soule J, Messaoudi E, Trentani A, et al. (2009) Selective survival and maturation of adult-born dentate granule cells expressing the immediate early gene Arc/Arg3.1. PLoS One 4: e4885.

26. Rosi S, Ramirez-Amaya V, Vazdarjanova A, Worley PF, Barnes CA, et al. (2005) Neuroinflammation alters the hippocampal pattern of behaviorally induced Arc expression. J Neurosci 25: 723-731.

27. Chawla MK, Guzowski JF, Ramirez-Amaya V, Lipa P, Hoffman KL, et al. (2005) Sparse, environmentally selective expression of Arc RNA in the upper blade of the rodent fascia dentata by brief spatial experience. Hippocampus 15: 579-86.

28. Bischofberger J (2007) Young and excitable: new neurons in memory networks. Nat Neurosci; (3): 273-275.

29. Kuhn HG, Dickinson-Anson H, Gage FH (1996) Neurogenesis in the dentate 
gyrus of the adult rat: age-related decrease of neuronal progenitor proliferation. J Neurosci 16: 2027-33.

30. Schlessinger AR, Cowan WM, Gottlieb DI (1975) An autoradiographic study of the time of origin and the pattern of granule cell migration in the dentate gyrus of the rat. J Comp Neurol 159: 149-175.

31. Adams W, Boice R (1983) A longitudinal study of dominance in an outdoor colony of domestic rats. J Comp Psychol 97: 24-33.

32. Snyder JS, Choe SC, Clifford MA, Jeurling SI, Hurley P, et al. (2009) Adult- Born hippocampal Neurons are more numerous, faster maturing, and more involved in behavior in rats than in mice.

33. Cameron HA, McKay RD (2001) Adult neurogenesis produces a large pool of new granule cells in the dentate gyrus. J Comp Neurol 435: 406-417.

34. Cameron HA, Woolley CS, McEwen BS, Gould E (1993) Differentiation of newly born neurons and glia in the dentate gyrus of the adult rat. Neuroscience 56: 337-344.

35. West MJ, Slomianka L, Gundersen HJ (1991) Unbiased stereological estimation of the total number of neurons in the subdivisions of the rat hippocampus using the optical fractionator. Anat Rec 231: 482-497.

36. Rapp PR, Gallagher M (1996) Preserved neuron number in the hippocampus of aged rats with spatial learning deficits. Proc Natl Acad Sci U S A 93: 99269930.

37. Babu H, Ramirez-Rodriguez G, Fabel K, Bischofberger J, Kempermann G (2009) Synaptic network activity induces neuronal differentiation of adult hippocampal precursor cells through BDNF signaling. Frontiers in Neuroscience 3: 49.

38. Peebles CL, Yoo J, Thwin MT, Palop JJ, Noebels JL, et al. (2010) Arc regulates spine morphology and maintains network stability in vivo. Proc Natl Acad Sci U S A 107: 18173-8.

39. Scharfman HE (2007) The CA3 "backprojection" to the dentate gyrus. Prog Brain Res 163: 627-637.

40. Ge S, Yang CH, Hsu KS, Ming GL, Song H (2007) A critical period for enhanced synaptic plasticity in newly generated neurons of the adult brain. Neuron 54: 559-566.

41. Kempermann G, Kuhn HG, Gage FH (1997) More hippocampal neurons in adult mice living in an enriched environment. Nature 386(6624): 493-495.

42. Ambrogini P, Cuppini R, Cuppini C, Ciaroni S, Cecchini T, et al. (2000) Spatial learning affects immature granule cell survival in adult rat dentate gyrus. Neurosci Lett 286: 21-24.

43. Rossi C, Angelucci A, Costantin L, Braschi C, Mazzantini M, et al. (2006) Brainderived neurotrophic factor (BDNF) is required for the enhancement of hippocampal neurogenesis following environmental enrichment. Eur J Neurosci 24: 1850-1856.

44. Lee $\mathrm{E}$, Son $\mathrm{H}$ (2009) Adult hippocampal neurogenesis and related neurotrophic 
factors. BMB Rep 42:239-44.

45. Alme CB, Buzzetti RA, Marrone DF, Leutgeb JK, Tashiro A, et al. (2010) Hippocampal Granule Cells Opt for Early Retirement. Hippocampus 10: 1109-1123.

46. Treves A, Rolls ET (1992) Computational constraints suggest the need for two distinct input systems to the hippocampal CA3 network. Hippocampus 2: 189-199.

47. Stone SSD, Teixeira CM, Zaslavsky K, Wheeler AL, Martinez-Canabal A, et al. (2010) Functional convergence of developmentally and adult-generated granule cells in dentate gyrus circuits supporting hippocampus-dependent memory. Hippocampus Sep 7, Online.

48. Drickamer LC (1977) Seasonal variation in litter size, bodyweight and sexual maturation in juvenile female house mice (Mus musculus). Laboratory Animals 11: 159-162.

49. Paxinos G, Watson C (1998) The rat brain in stereotaxic coordinates Academic Press An imprint of Elsevier. Fourth edition. 


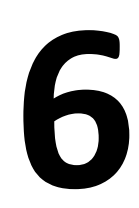

Summary and

General Conclusions

Martínez-Claros M 
The present thesis aimed to shed light on the complex relationship between corticosterone levels, hippocampal plasticity and learning. Thus, the experiments performed investigated changes in hippocampal morphology and neurogenesis in relation to different corticosterone levels and spatial learning.

Chapter $\mathbf{1}$ is an introduction to my hypothesis. Here I highlighted the importance of the plastic changes occurring in the hippocampus, their relation with cognition, and the possible participation of corticosterone as a modulator of those changes.

In chapter $\mathbf{2}$ of this thesis I investigated the role of corticosterone, swimming stress and habituation in the Morris water maze on hippocampal plasticity in both the dentate gyrus and CA3 regions. Here, I report that habituation to exposure to this water maze habituation appeared to have a significant effect on hippocampal plasticity as it reduced the NeuN/BrdU-labeled cell number. This may be due to the effect of increased chronic elevated circulating corticosterone, leading to a reduction in the generation and survival of new neurons. In addition, together with a reduced number of new-born cells, we observed an increased amount of synaptophysin in the stratum lucidum of the CA3 of habituated animals, suggesting an increased pre-synaptic activity in these animals, possibly to compensate for the reduced levels of new granule neurons in the dentate gyrus (DG). This works shows the complex relationship between many variables in the water maze task, stress, learning and hippocampal plasticity.

In chapter $\mathbf{3}$ it is shown that low and moderately elevated corticosterone levels differentially affect plasticity in both the CA3 and DG. In this study, adrenalectomized animals had decreased dendritic complexity in the apical region of CA3, but an increased number of surviving new cells in the DG, regardless of corticosterone replacement. To determine if the function of CA3 pyramidal cells and the new cells in the hippocampal circuitry had a physiological role, I investigated how adrenalectomy and corticosterone replacement could affect learning in a modified version of the Barnes maze, i.e., the Koopmaze, as described in Chapter 4. 
In Chapter 4 I observed that adrenalectomy, regardless of corticosterone replacement, resulted in poorer learning and memory as well as dendritic atrophy of CA3 pyramidal neurons. Interestingly, I did not find any marked effects of training or corticosterone on new cell survival in the DG. A possible explanation of these findings may be due to changes in Long Term Potentiation (LTP). LTP is a proposed correlate between synaptic plasticity and learning and memory in the hippocampus [1,2] and there is an inverted U-shaped doseresponse relationship between corticosterone and hippocampal LTP $[2,3]$. This suggests that morphological changes that were found in the CA3 dendrites of the adrenalectomized animals have a functional consequence, i.e.,reflecting impaired plasticity and, consequently, impaired learning and memory.

Finally, in chapter 5 we analyzed the incorporation of newborn hippocampal neurons in response to spatial exploration in the Open Field task. This was shown by the increased expression of Activity-Regulated Cytoskeleton-associated protein (Arc) associated with enhanced plasticity. The estimated proportion of BrdU-positive cells that responds to spatial exploration by expressing Arc throughout the animal's life-span showed a linear relationship, suggesting that after at least postnatal day 337, neurons born in the adult DG may not respond to exploration any more. Thus, these cells may no longer be recruited into circuits that process spatial information.

Proposing a mechanism of action of glucocorticoids on hippocampal plasticity and memory performance, I can say that they are likely mediated via a number of factors, but most notably through differential activation of the mineralocorticoid (MR) and glucocorticoid (GR) receptors. Previous work has shown that stimulation of the MR is sufficient to mediate the effects of corticosterone on neurogenesis by protecting mature cells from death [4]. The activation of the MR has also a long term trophic effect on DG [5]. The effects of the differential activation of these receptors are not only involved with the proliferation and survival of the new-born cells in the DG, the activation of the GR modulates specific molecules such as the adhesion molecule PSA-NCAM that is 
associated with the maintenance of cellular plasticity and cognitive functions [4]. MR and GR as nuclear receptors can also affect the transcription of genes [2] and it would be interesting see if one of those is Arc.

Obviously, corticosterone has an important role in the morphology of the hippocampus and in the interplay between neurogenesis in the DG, the plasticity of the CA3, and cognitive function (Chapters 2-4) [6,7,8,9,10,11,12,13,14]. However, changes in hippocampal plasticity, including new neuronal survival, do not necessarily correlate directly with memory performance; as newborn cells are not always functionally incorporated into the preexisting circuitry. This may be due to a number of factors and in particular increased death in a different cell population of the DG after adrenalectomy may play a pivotal role in this respect $[15,16]$.

Taken together, the findings of the present thesis show that hippocampal plasticity plays a crucial role in spatial information processing and that this process is highly dependent on stressassociated corticosterone levels (Chapters 2-4) as well as aging (Chapter 5). These findings may aid in understanding changes in hippocampus-dependent cognitive functions throughout the animal's life span. 


\section{References}

1. Bliss TV, Collingridge GL (1993) A synaptic model of memory: long-term potentiation in the hippocampus. Nature 361: 31-39.

2. Prickaerts J, Streckler T (2005) Effects of glucocorticoids on emotion and cognitive processes in animals. In: Steckler T, Kalin NH, Reul JMHM, editors. Handbook of Stress and the Brain part 1: the Neurobiology of stress. Amsterdam: Elsevier Science.

3. Diamond DM, Bennett MC, Fleshner M, Rose GM (1992) Inverted-U relationship between the level of peripheral corticosterone and the magnitude of hippocampal primed burst potentiation. Hippocampus 2: 421-430.

4. Montaron MF, Piazza PV, Aurousseau C, Urani A, Le Moal M, et al. (2003) Implication of corticosteroid receptors in the regulation of hippocampal structural plasticity. Eur J Neurosci 18: 3105-3111.

5. Gass P, Kretz O, Wolfer DP, Berger S, Tronche F, et al. (2000) Genetic disruption of mineralocorticoid receptor leads to impaired neurogenesis and granule cell degeneration in the hippocampus of adult mice. EMBO Rep 1: 447451.

6. Farioli-Vecchioli S, Saraulli D, Costanzi M, Pacioni S, Cina I, et al. (2008) The timing of differentiation of adult hippocampal neurons is crucial for spatial memory. PLoS Biol 6: e246.

7. Bruel-Jungerman E, Laroche S, Rampon C (2005) New neurons in the dentate gyrus are involved in the expression of enhanced long-term memory following environmental enrichment. Eur J Neurosci 21: 513-521.

8. Abrous DN, Koehl M, Le Moal M (2005) Adult neurogenesis: from precursors to network and physiology. Physiol Rev 85: 523-569.

9. Aimone JB, Wiles J, Gage FH (2009) Computational influence of adult neurogenesis on memory encoding. Neuron 61: 187-202.

10. Becker S (2005) A computational principle for hippocampal learning and neurogenesis. Hippocampus 15: 722-738.

11. Clelland CD, Choi M, Romberg C, Clemenson GD, Jr., Fragniere A, et al. (2009) A functional role for adult hippocampal neurogenesis in spatial pattern separation. Science 325: 210-213.

12. Drapeau E, Mayo W, Aurousseau C, Le Moal M, Piazza PV, et al. (2003) Spatial memory performances of aged rats in the water maze predict levels of hippocampal neurogenesis. Proc Natl Acad Sci U S A 100: 14385-14390.

13. Galimberti I, Gogolla N, Alberi S, Santos AF, Muller D, et al. (2006) Long-term rearrangements of hippocampal mossy fiber terminal connectivity in the adult regulated by experience. Neuron 50: 749-763.

14. Ge S, Sailor KA, Ming GL, Song H (2008) Synaptic integration and plasticity of new neurons in the adult hippocampus. J Physiol 586: 3759-3765. 
15. Krugers HJ, van der Linden S, van Olst E, Alfarez DN, Maslam S, et al. (2007) Dissociation between apoptosis, neurogenesis, and synaptic potentiation in the dentate gyrus of adrenalectomized rats. Synapse 61: 221-230.

16. Sloviter RS, Valiquette G, Abrams GM, Ronk EC, Sollas AL, et al. (1989) Selective loss of hippocampal granule cells in the mature rat brain after adrenalectomy. Science 243: 535-538. 


\section{Co-authors and affiliations}

Bello-Medina P.C. Laboratorio de redes neuronales plásticas, Departamento de Neurobiología Conductual y Cognitiva, Instituto de Neurobiología, Universidad Nacional Autónoma de México, Campus Juriquilla, Querétaro Qro. México.

Pawluski J.L.

School for Mental Health and Neuroscience, Department of Neuroscience, Faculty of Health, Medicine and Life Sciences, Maastricht University, The Netherlands

GIGA-Neurosciences, University of Liège, Belgium

Pérez, 0.

Laboratorio de redes neuronales plásticas, Departamento de Neurobiología Conductual y Cognitiva, Instituto de Neurobiología, Universidad Nacional Autónoma de México, Campus Juriquilla, Querétaro Qro. México.

Prickaerts J.

School for Mental Health and Neuroscience, Department of Neuroscience, Faculty of Health, Medicine and Life Sciences, Maastricht University, The Netherlands

Ramírez-Amaya V. Laboratorio de redes neuronales plásticas, Departamento de Neurobiología Conductual y Cognitiva, Instituto de Neurobiología, Universidad Nacional Autónoma de México, Campus Juriquilla, Querétaro Qro. México.

Sandoval C.J. Laboratorio de redes neuronales plásticas, Departamento de Neurobiología Conductual y Cognitiva, Instituto de Neurobiología, Universidad Nacional Autónoma de México, 
Campus Juriquilla, Querétaro Qro. México.

Steinbusch H.W.M. School for Mental Health and Neuroscience, Department of Neuroscience, Faculty of Health, Medicine and Life Sciences, Maastricht University, The Netherlands

van den Hove

D.L.A. van Selm A.
School for Mental Health and Neuroscience, Department of Neuroscience, Faculty of Health, Medicine and Life Sciences, Maastricht University, The Netherlands

Laboratory of Translational Neuroscience, Department of Psychiatry, Psychosomatics and Psychotherapy, University of Wuerzburg, Wuerzburg, Germany

School for Mental Health and Neuroscience, Department of Neuroscience, Faculty of Health, Medicine and Life Sciences, Maastricht University, The Netherlands 


\section{Curriculum Vitae}

Marisela Martínez-Claros was born on March 6 ${ }^{\text {th }}, 1978$ in Mexico City, Mexico. She graduated from high school at "Colegio Williams" in 1997. She started her medical studies on September of the same year at the Faculty of Medicine in the National Autonomous University of Mexico, (U.N.A.M.). During her medical studies (19972003) she was part of the academic excellence group (Núcleos de Calidad Educativa) where she had the opportunity to make her research internship at the Institute of Cellular Physiology, at the laboratory of Neurobiology of Learning and Memory. After receiving her medical doctor degree she worked in the same laboratory focusing on hippocampal plasticity in relation to estradiol. In 2005 she obtained the candidate to doctor degree and she went to the laboratory of Plastic Neuronal networks at the Institute of Neurobiology in Queretaro, Mexico, where she started with the topic of this thesis. In August 2008, she was awarded with a Marie-Curie fellowship grant and she continued her PhD at the Department of Neuroscience, Maastricht University under the supervision of Prof.Dr. Harry Steinbusch, Dr. Jodi Pawluski and Dr. Jos Prickaerts. She investigated the effect of corticosterone and spatial learning on hippocampal plasticity. The results of her PhD project are described in this thesis. 


\section{List of Publications}

\section{Journal articles}

1. Sandoval C.J., Martınez-Claros M, Bello-Medina P.C., Perez O, Ramırez-Amaya $\mathrm{V}$. When Are New Hippocampal Neurons, Born in the Adult Brain, Integrated into the Network That Processes Spatial Information? PLoS ONE, (2011) 6(3): e17689. doi:10.1371/journal.pone.0017689

2. Martinez-Claros $\mathbf{M}$, Steinbusch $\mathrm{HW}$, van Selm A, van den Hove DLA, Prickaerts J, Pawluski JL. Adrenalectomy and corticosterone replacement differentially alter CA3 dendritic morphology and new cell survival in the adult rat hippocampus. Journal of Chemical Neuroanatomy, 2013, Epub ahead of print

\section{Publications in progress}

1. Martinez-Claros M., Sandoval C.J., Bello-Medina P., Steinbusch H.W.M., Ramirez-Amaya V. Effect of water maze training and swimming on neurogenesis and synaptogenesis in the hippocampus.

2. Martinez-Claros M., Pawluski J.L., Van Den Hove D., Prickaerts J., Steinbusch H.W.M. Adrenalectomy, regardless of corticosterone replacement, affects memory and hippocampal morphology.

3. Van den Hove D.L.A., Leibold N.K., Strackx E, Martinez-Claros M, Lesch K.P., Steinbusch H.W.M., Schruers K.R., Prickaerts J. Prenatal stress and the effects of a subsequent exposure to chronic mild stress; interdependent effects on affective behavior and $5-\mathrm{HT}$ and TPH2 immunoreactivity in the rat dorsal raphe, hippocampus and prefrontal cortex. Submitted. 


\section{Abstracts}

1. Martinez-Claros M., Benavidez-Castagnola E.N., Carrillo-Alvarez J.D., Bermudez-Rattoni F. Spatial overtraining induces expression of synaptophysin in both stratum lucidum and oriens of CA3 hippocampal region. $34^{\text {th }}$ Society for Neuroscience meeting, October, $23-27^{\text {th }} 2004$, San Diego, USA

2. Martinez-Claros M., Ramirez-Amaya V. Mossy fiber synaptogenesis after spatial learning: are the new synapses arising from new neurons? $37^{\text {th }}$ Society for Neuroscience meeting, November, $3-7^{\text {th }} 2007$, San Diego, USA

4. Martinez-Claros M., Ramirez-Amaya V. Neurogenesis and synaptogenesis in the adult rat hippocampus: their interaction and relation with memory $12^{\text {th }}$ EURON PhD student days, $18^{\text {th }}-19^{\text {th }}$ September 2008. RWTH Aachen University, Aachen, Germany

5. Martinez-Claros M., Ramirez-Amaya V. Neurogenesis and synaptogenesis in the adult rat hippocampus: their interaction and relation with memory Research day, March $17^{\text {th }} 2009$. Maastricht University, The Netherlands

6. Martinez-Claros M., Pawluski J.L., Van den Hove D., van Selm A., Prickaerts J., Steinbusch H.W.M. The effect of stress and spatial memory on hippocampus morphology $7^{\text {th }}$ Dutch Endo-Neuro-Psycho meeting, June $4^{\text {th }}-5^{\text {th }}$ 2009, Doorwerth, The Netherlands

7. Martinez-Claros M., Pawluski J.L., Van den Hove D., van Selm A., Prickaerts J., Steinbusch H.W.M. The effect of stress and spatial memory on hippocampus morphology $41^{\text {st }}$ European Brain and Behavior Society Meeting. September $14^{\text {th }}-18^{\text {th }} 2009$. Rhodes, Greece

8. Martinez-Claros M., Pawluski J.L., Van den Hove D., van Selm A., Prickaerts J., Steinbusch H.W.M. The effect of stress and spatial memory on hippocampus morphology13th EURON PhD student days, October 1st -2nd, 2009. Radboud University Nijmegen, The Netherlands

9. Martinez-Claros M, Pawluski J.L., Van den Hove D., Prickaerts J., Ramirez-Amaya V., Steinbusch H.W.M. Analyzing the effect of stress and spatial memory on hippocampus morphology using a new non stressful maze. $39^{\text {th }}$ Society for Neuroscience meeting, October, $17^{\text {th }}$ $21^{\text {st }}$ 2009, Chicago, USA

10. Martinez-Claros M, Pawluski J.L., Van den Hove D., Prickaerts J., Ramirez-Amaya V., Steinbusch H.W.M. The effect of corticosterone 
levels in spatial learning performance and hippocampal morphology Research day March $17^{\text {th }}$ 2010. Maastricht University, The Netherlands

11. Martinez-Claros M, Pawluski J.L, Van den Hove D., van Selm A., Prickaerts J., Steinbusch H.W.M. The effect of stress and spatial memory on hippocampus morphology Marie Curie fellows meeting. March $25^{\text {th }}$, 2009. Maastricht University, The Netherlands

12. Martinez-Claros M, Ramirez-Amaya V. Neurogenesis and synaptogenesis in the adult rat hippocampus: their interaction and relation with memory GROW Master Class. "Stem cells in health and disease". Maastricht University, The Netherlands

13. Martinez-Claros M, Pawluski J.L., Van den Hove D., Prickaerts J., Ramirez-Amaya V., Steinbusch H.W.M. The effect of corticosterone levels in spatial learning performance and hippocampal morphology Marie Curie fellows' final meeting. March $16^{\text {th }}, 2010$. Maastricht University, the Netherlands. 


\section{Acknowledgments}

I would like to say "thank you" in as many languages as possible. I had the fortune and pleasure to meet many different people, from many different countries but with a same goal: to understand a little bit more about the brain.

My immense gratitude to my promotor and co-promotores, I deeply appreciate your support. Thank you for believing in me more than I do. Sometimes my goal was lost, but with your firm and strict supervision I found it and I concluded safe and happy my long trip.

First of all, thanks to my promotor, Prof.Steinbusch. I would never thought what wonderful surprises your invitation to come to the Netherlands would bring to my personal and professional life. I am grateful for your unconditional support, your invaluable help and your considerations since I arrived. Thank you also for helping me on my future career in science. Heel erg bedankt!

Dr. Pawluski, dear Jodi, there are not enough words to say how grateful I am with you. I always told you that you are my "sensei". You are not only a supervisor; you are my guide and my inspiration to be a great scientist (just like you). Thank you for your time (precious with a baby of less than 2 years and one to come), thank you for your patience: reading back and forth, correcting the graphs and overall for keeping me focused.

Dr. Prickaerts, dear Jos, thank you very much for accepting me in the "mood and cognition" group. I know that my arrival to Maastricht University was a big surprise; I hope at the end it was a pleasant one too. Dank je wel!

I would also like to express my sincerest gratitude to the members of the assessment committee and corona, for your time and your invaluable suggestions and comments. 
I want to thank all the supporting people from the Neuroscience department who helped me so much and in so many different ways. Dr. van den Hove, dear Daniel, thank you for accepting me as a "refugee" when I arrived to the Netherlands. I was "lost in translation". With out your support and guidance I wouldn't be able to start working. Thanks to the technical team: Helen, Denise, Marjan for the patience and help always. To Marijke for the huge help using the DSU microscope and MBF programs. My deepest gratitude to the "administrative" team: Marie-Therese, Lisa, Nicole and Anja. Since the very beginning, even before stepping on dutch ground you have been always my guardian angels.

Thanks to my colleagues and friends (I will make the list in alphabetical order): En Mexico (desde la epoca antigua de mi doctorado en tiempos de FB y VRA): Adrian, Adriana, Ale, Almita, Alondra, Anaid, Arafat, Bertha, Carlos, Claudio, Cudberto, Edgar, Edu, Emmanuel, Enrique, Erminda, Fer, Gustavo, Ismael, Israela, Itzel, JC, Jeans, Jimena, Leticia, los Luises, Mac, Maribel, Martha, Miriam Hernandez, Miriam Zamorano, Natalia, Nissyen, Paola, Pascal, Paty, Ranier, Sandra, Tomás, Vanesa y Gerardo (un beso hasta donde esten), Vero y Vico. In the Netherlands: Ali, Annerieke, Anthony, Bart, Caroline, Chiara, Eva, Eveline, Evi, Fabien, Frank, Gerard, Ivona, Jochen, Kathleen, Leonidas, Lucas, Maria, Mark, Marko, Marlien, Natalia, Olga, Pablo, Rinske, Sofie, Sven and Thibaut.

To my "students", who have overtaken their humble teacher: Annemarie, David, Grisel, Israel, Luciana, Marisoco, Memo, Oscar, Paty y Rodrigo. Gracias por su ayuda y apoyo, thank you for your help and support.

A mis paranymph: Alejandro te toco literal "el principio y el fin" de mi aventura cientifica holandesa. A Eva, por estar conmigo en los momentos mas importantes de mi vida. 
A Borja "por lo que tu y yo sabemos". Los quiero familia Roses-van Donkelaar.

Gracias a mis querid@s amig@s y familia que me han acompañado en todo momento compartiendo: penas, preocupaciones y alegrias.

Bedankt ook aan mijn lieve schoonfamilie: Sandra, Ed, tante Nel, ome Tom, Tom, Yvonne, Ron, Chantal, Fabiene, Duncan, Marco, Renate en Lindsey.

Gracias sobretodo a mis padres a quienes quiero con toda mi alma y a quienes debo todo lo que tengo y todo lo que soy. Paso mucho tiempo, pero aqui esta la tan "mentada" tesis. Papito en palabras simples: "resulto que el carrizo no es medicinal".

En naar mijn man, mijn "amorcito", mijn alles: Lion. Ik hou van je! Zo fijn mijn leven met jou te mogen delen. 